Cahiers du MONDE RUSSE

\section{Cahiers du monde russe}

Russie - Empire russe - Union soviétique et États indépendants

$53 / 1 \mid 2012$

Pratiques du droit et de la justice en Russie (XVIIIe-XXe siècles)

\title{
ВЛАСТЬ И СОБСТВЕННОСТЬ
}

\section{ОСОБЕННОСТИ МОБИЛИЗАЦИИ ЗЕМЕЛЬНЫХ ВЛАДЕНИЙ В МОСКОВСКОМ} УЕЗДЕ В ПЕРВОЙ ПОЛОВИНЕ XVIII ВЕКА

Power and property. Features of landed property transfer in the Moscow district during the first half of the eighteenth centuryLes particularités de la cession des propriétés terriennes dans le district de Moscou dans la première moitié du XVIII siècle

Le pouvoir et la propriété. Les particularités de la cession des propriétés terriennes dans le district de Moscou dans la première moitié du XVIII siècle

\section{Сергей В. Черников}

\section{OpenEdition} Journals

\section{Édition électronique}

URL : http://journals.openedition.org/monderusse/9372

DOI : $10.4000 /$ monderusse. 9372

ISSN : $1777-5388$

\section{Éditeur}

Éditions de l'EHESS

\section{Édition imprimée}

Date de publication : 15 mars 2012

Pagination : $141-245$

ISBN : 978-2-7132-2390-7

ISSN : $1252-6576$

\section{Référence électronique}

Сергей В. Черников, «Власть и собственность », Cahiers du monde russe [Онлайн], 53/1 | 2012, Выложить онлайн 02 avril 2015, Наводить справки в 19 avril 2019. URL : http:// journals.openedition.org/monderusse/9372 ; DOI : 10.4000/monderusse.9372

Ce document a été généré automatiquement le 19 avril 2019

(c) École des hautes études en sciences sociales 


\title{
ВЛАСТЬ И СОБСТВЕННОСТЬ
}

\author{
ОСОБЕННОСТИ МОБИЛИЗАЦИИ ЗЕМЕЛЬНЫХ ВЛАДЕНИЙ В МОСКОВСКОМ \\ УЕЗДЕ В ПЕРВОЙ ПОЛОВИНЕ XVIII ВЕКА
}

Power and property. Features of landed property transfer in the Moscow district during the first half of the eighteenth centuryLes particularités de la cession des propriétés terriennes dans le district de Moscou dans la première moitié du XVIII siècle

Le pouvoir et la propriété. Les particularités de la cession des propriétés terriennes dans le district de Moscou dans la première moitié du XVIII siècle

\section{Сергей В. Черников}

1 В ИСТОРИЧЕСКОЙ ЛИТЕРАТУРЕ БЫТУЕТ ПРОЧНОЕ И АРГУМЕНТИРОВАННОЕ МНЕНИЕ О ВЫСОКОЙ МОБИЛЬНОСТИ ЗЕМЕЛЬНЫХ ВЛАДЕНИЙ РОССИЙСКОГО ДВОРЯНСТВА ${ }^{1}$ ЧАСТЫЕ ДРОБЛЕНИЕ, КУПЛЯ-ПРОДАЖА И ЗАКЛАД ИМЕНИЙ НЕРЕДКО РАССМАТРИВАЮТСЯ КАК НЕОТЪЕМЛЕМЫЕ ХАРАКТЕРИСТИКИ СОБСТВЕННОСТИ СЛУЖИЛОГО КЛАССА КАК В СРЕДНЕВЕКОВОЙ РУСИ, ТАК И В РАННЕЕ НОВОЕ ВРЕМЯ. ЭТО ПРЕДСТАВЛЕНИЕ СПРАВЕДЛИВО И ХОРОШО ОПИСЫВАЕТ САМЫЕ ОБЩИЕ ТЕНДЕНЦИИ В РАЗВИТИИ ЗЕМЛЕВЛАДЕНИЯ. НО НЕ МЕНЕЕ ПОЗНАВАТЕЛЬНЫ РАБОТЫ, ПОСТРОЕННЫЕ НА МАТЕРИАЛАХ ОТДЕЛЬНЫХ РЕГИОНОВ. ИМЕННО ОНИ ПОЗВОЛЯЮТ ВЫЯВИТЬ ОСОБЕННОСТИ ПРОЦЕССА МОБИЛИЗАЦИИ. СРЕДИ ТАКИХ ИССЛЕДОВАНИЙ, В ПЕРВУЮ ОЧЕРЕДЬ, СЛЕДУЕТ ОТМЕТИТЬ ТРУДЫ В. КИВЕЛЬСОН И М. МАРРЕЗЕ².

НАСТОЯЩАЯ СТАТЬЯ ПОСВЯЩЕНА МОБИЛИЗАЦИИ ДВОРЯНСКИХ ВЛАДЕНИЙ В МОСКОВСКОМ УЕЗДЕ МЕЖДУ І И ІІ РЕВИЗИЯМИЗ. ИЗУЧЕНИЕ СТОЛИЧНОГО РЕГИОНА ДАЕТ ВОЗМОЖНОСТЬ ПРОСЛЕДИТЬ НЕПОСРЕДСТВЕННУЮ ВЗАИМОСВЯЗЬ ВЛАСТИ И СОБСТВЕННОСТИ - ВЛИЯНИЕ ИЗМЕНЕНИЙ В СТРАТИФИКАЦИИ ПРАВЯЩЕГО СЛОЯ НА СТРУКТУРУ ЗЕМЛЕВЛАДЕНИЯ. ДЛЯ СРАВНЕНИЯ БЫЛИ ПРИВЛЕЧЕНЫ ДАННЫЕ ПО САНКТПЕТЕРБУРГСКОМУ И РЯДУ ДРУГИХ РЕГИОНОВ СТРАНЫ. КОРОТКИЙ ХРОНОЛОГИЧЕСКИЙ ОТРЕЗОК (ЧЕТВЕРТЬ ВЕКА ${ }^{4}$, Т.Е. ПРИБЛИЗИТЕЛЬНОЕ ВРЕМЯ СМЕНЫ ОДНОГО ПОКОЛЕНИЯ) БЫЛ ВЫБРАН НАМЕРЕННО. НАПРОТИВ, БОЛЕЕ ДЛИТЕЛЬНЫЙ ПЕРИОД С ВЫСОКОЙ ДОЛЕЙ ВЕРОЯТНОСТИ МОГ БЫ «СГЛАДИТЬ» СПЕЦИФИКУ ИЗУЧАЕМОЙ ТЕРРИТОРИИ. СРЕДИ 
ОСНОВНЫХ ВОПРОСОВ, КОТОРЫЕ ПРЕДПОЛАГАЕТСЯ РАССМОТРЕТЬ В ЭТОЙ СТАТЬЕ, СЛЕДУЮЩИЕ. НАСКОЛЬКО УСТОЙЧИВОЙ БЫЛА РОДОВАЯ СТРУКТУРА СОБСТВЕННОСТИ В МОСКОВСКОМ УЕЗДЕ? КАКОВА СТЕПЕНЬ ВЛИЯНИЯ РАЗЛИЧНЫХ ФАКТОРОВ НА МОБИЛИЗАЦИЮ ВОТЧИН? ТАКЖЕ ВАЖНО ВЫЯВИТЬ ТИПИЧНУЮ МОДЕЛЬ НАСЛЕДОВАНИЯ ПО КАКИМ КАНАЛАМ РОДСТВЕННЫХ СВЯЗЕЙ ЧАЩЕ ВСЕГО ПЕРЕДАВАЛАСЬ НЕДВИЖИМОСТЬ. СТАТЬЯ СОПРОВОЖДАЕТСЯ ПРИЛОЖЕНИЯМИ, В КОТОРЫХ ПРИВЕДЕНЫ АЛФАВИТНЫЕ СПИСКИ ПОМЕЩИКОВ МОСКОВСКОГО УЕЗДА И САНКТ-ПЕТЕРБУРГСКОГО РЕГИОНА (ИНГЕРМАНЛАНДИИ).

ВНАЧАЛЕ ИЗУЧИМ ОСОБЕННОСТИ РАЗВИТИЯ ЗЕМЕЛЬНОГО ФОНДА ПОДМОСКОВЬЯ И СРАВНИМ ЭТУ ТЕРРИТОРИЮ С БЛИЖАЙШИМ ОКОЛОГОРОДЬЕМ «НОВОЙ СТОЛИЦЫ». КАК ИЗВЕСТНО, ЗЕМЛЕВЛАДЕНИЕ МОСКОВСКОГО УЕЗДА (КАКИМ МЫ ЕГО ВИДИМ В ПЕРВОЙ ПОЛОВИНЕ XVIII В.) СЛОЖИЛОСЬ ПОД ВЛИЯНИЕМ ПРАКТИКИ ИСПОМЕЩЕНИЯ В СТОЛИЧНОМ РЕГИОНЕ ПРЕДСТАВИТЕЛЕЙ ВЕРХУШКИ СЛУЖИЛОГО КЛАССА - ГОСУДАРЕВА ДВОРА. ЭТА ПОЛИТИКА ПЛАНОМЕРНО ОСУЩЕСТВЛЯЛАСЬ С СЕРЕДИНЫ XVI В. НА ПРОТЯЖЕНИИ ПОЛУТОРА СТОЛЕТИЙ. ЯВНОЕ ПРЕДПОЧТЕНИЕ ПРИ НАДЕЛЕНИИ ЗЕМЛЕЙ ЗДЕСЬ ОТДАВАЛОСЬ ДУМНЫМ ЛЮДЯМ ${ }^{5}$, СОСТАВЛЯВШИМ ПРАВЯЩУЮ ЭЛИТУ МОСКОВСКОГО ГОСУДАРСТВА. ВСЛЕДСТВИЕ ЭТОГО, ДАЖЕ В ПЕРВОЙ ПОЛОВИНЕ ХVIII В., РОДОВАЯ СТРУКТУРА СОБСТВЕННОСТИ В ОКРЕСТНОСТЯХ СТАРОЙ СТОЛИЦЫ ОБЛАДАЛА ВЫСОКОЙ УСТОЙЧИВОСТЬЮ, А РАЗВИТИЕ ЗЕМЕЛЬНОГО ФОНДА И СОСТАВ ВЛАДЕЛЬЦЕВ ОТЛИЧАЛИСЬ ИНЕРЦИОННОСТЬЮ И ПРЕЕМСТВЕННОСТЬЮ ПО ОТНОШЕНИЮ К ПРЕДШЕСТВУЮЩЕМУ ПЕРИОДУ.

СВОЕОБРАЗИЕ ЭТИХ ЧЕРТ ОСОБЕННО ПРОЯВЛЯЕТСЯ ПО КОНТРАСТУ С СЕВЕРО-ЗАПАДНЫМ РЕГИОНОМ, КОТОРЫЙ НАЧАЛ АКТИВНО ОСВАИВАТЬСЯ РУССКИМИ ПОМЕЩИКАМИ ТОЛЬКО ПОСЛЕ ПЕРЕНОСА СТОЛИЦЫ В САНКТ-ПЕТЕРБУРГ (1712 Г.). ЗЕМЕЛЬНЫЕ РАЗДАЧИ В ИНГЕРМАНЛАНДИИ В ПЕРВОЙ ЧЕТВЕРТИ XVIII В. ДОЛЖНЫ БЫЛИ ВЫПОЛНЯТЬ ТЕ ЖЕ ФУНКЦИИ, ЧТО И РАЗДАЧИ В ПОДМОСКОВЬЕ ВО ВТОРОЙ ПОЛОВИНЕ XVI-XVII ВВ.: ОНИ СОЗДАВАЛИ ПРЕДСТАВИТЕЛЯМ ЦЕНТРАЛЬНОГО И МЕСТНОГО АППАРАТА УПРАВЛЕНИЯ БЛАГОПРИЯТНЫЕ УСЛОВИЯ ДЛЯ ПРОХОЖДЕНИЯ СЛУЖБЫ В СТОЛИЦЕ. РАЗВИТИЕ ЗЕМЛЕВЛАДЕНИЯ ИНГЕРМАНЛАНДИИ (КАК «НОВОЗАСЕЛЯЕМОЙ ТЕРРИТОРИИ») БЫЛО БОЛЕЕ ДИНАМИЧНЫМ, А РОДОВАЯ СТРУКТУРА СОБСТВЕННОСТИ ОБЛАДАЛА ЗНАЧИТЕЛЬНОЙ ПОДВИЖНОСТЬЮ И ОТРАЖАЛА ТЕ ПЕРЕМЕНЫ, КОТОРЫЕ ПРОИСХОДИЛИ В СОСТАВЕ ПРАВЯЩЕГО СЛОЯ ПЕТЕРБУРГСКОГО ПЕРИОДА ${ }^{6}$.

ОТЛИЧИЯ МЕЖДУ ДВУМЯ СТОЛИЧНЫМИ РЕГИОНАМИ ИЛЛЮСТРИРУЮТ ДАННЫЕ В ТАБЛИЦЕ 1. ОНИ ПОКАЗЫВАЮТ ЭВОЛЮЦИЮ ДУШЕВЛАДЕНИЯ ТЕХ РОДОВ, ПРЕДСТАВИТЕЛИ КОТОРЫХ СИДЕЛИ В ДУМЕ ДО НАЧАЛА ПРАВЛЕНИЯ ПЕТРА І (ДЛЯ ИХ ОБОЗНАЧЕНИЯ В СТАТЬЕ ИСПОЛЬЗУЕТСЯ ТЕРМИН «ДУМНЫЕ ФАМИЛИИ»). 
1. Доля душевладения «думных фамилий» в столичных регионах, \%*,*夫

\begin{tabular}{|c|c|c|c|c|c|c|}
\hline \multirow{2}{*}{$\begin{array}{l}\text { Пернод попучения } \\
\text { первого думного чнна }\end{array}$} & \multicolumn{3}{|c|}{ Московскй̆ уезд } & \multicolumn{3}{|c|}{ Ингерманттандеия } \\
\hline & I рев. & II peв. & III pes. & $\begin{array}{l}\text { шаqано } \\
\text { 1730-x rr: }\end{array}$ & II pes. & III pes. \\
\hline Bсе ждумные фампнин) * & 66 & 61 & 57 & 43 & 39 & 24 \\
\hline \multicolumn{7}{|c|}{6 mou tucre, no spymau: ${ }^{* 0}$} \\
\hline до $1613 \mathrm{r}$ & 65 & 59 & 54 & 44 & 56 & 41 \\
\hline $1613-16.45 \mathrm{rr}$. & 3 & 4 & 5 & 1 & 1 & 0 \\
\hline $1645-1676 \mathrm{mr}$. & 19 & 22 & 26 & 8 & 12 & 23 \\
\hline $1676-1682 \mathrm{~m}$. & 4 & 6 & 3 & 3 & 3 & 0 \\
\hline $1682-1689 \mathrm{rr}$. & 9 & 9 & 12 & 44 & 27 & 36 \\
\hline
\end{tabular}

КАК ВИДИМ, ДОЛЯ СОБСТВЕННОСТИ, ПРИНАДЛЕЖАВШЕЙ ДУМНЫМ ФАМИЛИЯМ В МОСКОВСКОМ УЕЗДЕ, БЫЛА ВЫШЕ, ЧЕМ В ИНГЕРМАНЛАНДИИ, И ЗА 40 С ЛИШНИМ ЛЕТ (МЕЖДУ І И ІІІ РЕВИЗИЯМИ) ИЗМЕНИЛАСЬ НЕЗНАЧИТЕЛЬНО - С 66 ДО $57 \%$. ХРОНОЛОГИЧЕСКИЙ ПРОМЕЖУТОК МЕЖДУ ПЕРЕПИСЬЮ И.А. ШИПОВА 1732-1733 ГГ. ${ }^{7}$ И III РЕВИЗИЕЙ БЫЛ СУЩЕСТВЕННО КОРОЧЕ. НО ЗА ЭТО ВРЕМЯ АНАЛОГИЧНЫЙ ПОКАЗАТЕЛЬ ПО САНКТ-ПЕТЕРБУРГСКОМУ РЕГИОНУ УПАЛ С 43 ДО $24 \%$. ДЛЯ СРАВНЕНИЯ ОТМЕТИМ, ЧТО РУССКАЯ ЧАСТЬ ПРАВЯЩЕГО СЛОЯ ПЕРВОЙ ЧЕТВЕРТИ ХVIII В. СОСТОЯЛА ИЗ ПРЕДСТАВИТЕЛЕЙ ДУМНЫХ ФАМИЛИЙ НА 57 \%, В 1730 Г. - НА 59 \%, А В 1758 Г. - УЖЕ НА $44 \%^{8}$. СЛЕДОВАТЕЛЬНО, ЗЕМЛЕВЛАДЕНИЕ ИНГЕРМАНЛАНДИИ, В ОТЛИЧИЕ ОТ МОСКОВСКОГО УЕЗДА, БОЛЕЕ АКТИВНО РЕАГИРОВАЛО НА ИЗМЕНЕНИЯ В СТРАТИФИКАЦИИ ПРАВЯЩЕЙ ЭЛИТЫ СТРАНЫ.

ТЕПЕРЬ ОБРАТИМСЯ К ТОЙ ЧАСТИ ТАБЛИЦЫ, КОТОРАЯ ХАРАКТЕРИЗУЕТ СТРУКТУРУ ДУШЕВЛАДЕНИЯ ПО ГРУППАМ (В ЗАВИСИМОСТИ ОТ ВРЕМЕНИ ПОЛУЧЕНИЯ ПЕРВОГО ДУМНОГО ЧИНА). НА ОСНОВЕ ЭТИХ ДАННЫХ МОЖНО ГОВОРИТЬ КАК О ПРЕЕМСТВЕННОСТИ ЗЕМЕЛЬНОЙ ПОЛИТИКИ МОСКОВСКОГО ГОСУДАРСТВА И ИМПЕРАТОРСКОЙ РОССИИ, ТАК И О СОХРАНЕНИИ ТРАДИЦИЙ ФОРМИРОВАНИЯ ПРАВЯЩЕГО СЛОЯ. ДОЛЯ СОБСТВЕННОСТИ, ПРИНАДЛЕЖАВШЕЙ НАИБОЛЕЕ РОДОВИТОЙ ЧАСТИ ДВОРЯНСТВА (ЧЬИ ПРЕДКИ ПОПАЛИ В ДУМУ ДО 1613 Г.), СОСТАВЛЯЛА В ПОДМОСКОВЬЕ ОТ 65 ДО $54 \%$, А В ИНГЕРМАНЛАНДИИ КОЛЕБАЛАСЬ ОТ 56 ДО $41 \%$ (СРЕДИ ДУМНЫХ ФАМИЛИЙ). ПРОЧНЫЕ ПОЗИЦИИ ЗНАТИ В СТОЛИЧНЫХ РЕГИОНАХ В ПОЛНОЙ МЕРЕ ОТРАЖАЮТ ТО ВЫСОКОЕ ПОЛОЖЕНИЕ, КОТОРОЕ АРИСТОКРАТИЯ ЗАНИМАЛА В СОСТАВЕ РОССИЙСКОЙ ЭЛИТЫ XVII-ПЕРВОЙ ПОЛОВИНЫ XVIII BB. ${ }^{9}$

НАРЯДУ СО СХОДСТВОМ, СТРУКТУРА ЗЕМЕЛЬНОГО ФОНДА ИНГЕРМАНЛАНДИИ И МОСКОВСКОГО УЕЗДА ИМЕЛА ВАЖНЫЕ ОТЛИЧИЯ. ТАК, НА ВТОРОМ МЕСТЕ ПО МАСШТАБАМ СОБСТВЕННОСТИ В ПОДМОСКОВЬЕ НАХОДИЛИСЬ ПРЕДСТАВИТЕЛИ РОДОВ, ВОШЕДШИХ В ДУМУ ПРИ АЛЕКСЕЕ МИХАЙЛОВИЧЕ - 19-26\%. В ОКРЕСТНОСТЯХ САНКТ-ПЕТЕРБУРГА, НАПРОТИВ, ОФОРМЛЕНИЕ ЗЕМЛЕВЛАДЕНИЯ ЭТОЙ ГРУППЫ БЫЛО ЗАМЕДЛЕННЫМ, А ОЧЕНЬ ВИДНОЕ ПОЛОЖЕНИЕ ЗАНИМАЛИ ФАМИЛИИ, ПОПАВШИЕ В ДУМУ В КОРОТКОЕ РЕГЕНТСТВО СОФЬИ - 27-44 \%. ИМЕННО ЭТОТ СЛОЙ ПОЛЬЗОВАЛСЯ ПРЕИМУЩЕСТВОМ ПРИ РАЗДАЧЕ ЗЕМЕЛЬ В СЕВЕРО-ЗАПАДНОМ РЕГИОНЕ В ПЕРИОД ПРАВЛЕНИЯ ПЕТРА ВЕЛИКОГО, А АПРАКСИНЫ, ГОЛОВКИНЫ, ЗОТОВЫ, МУСИНЫ-ПУШКИНЫ, ШЕПЕЛЕВЫ И РЯД ДРУГИХ ФАМИЛИЙ ИГРАЛИ ОЧЕНЬ ЗАМЕТНУЮ РОЛЬ В СОСТАВЕ ПРАВЯЩЕЙ ЭЛИТЫ РОССИИ ПЕРВОЙ ПОЛОВИНЫ XVIII СТОЛЕТИЯ ${ }^{10}$. 
НАСКОЛЬКО УСТОЙЧИВЫМ И ПРЕДСКАЗУЕМЫМ БЫЛО РАЗВИТИЕ СОБСТВЕННОСТИ В МОСКОВСКОМ УЕЗДЕ МЕЖДУ І И ІІ РЕВИЗИЯМИ? ЧТОБЫ ОТВЕТИТЬ НА ЭТОТ ВОПРОС, МЫ СРАВНИЛИ РАЗМЕРЫ ДУШЕВЛАДЕНИЯ КАЖДОЙ ФАМИЛИИ ПО ДВУМ ПЕРЕПИСЯМ И ПОДСЧИТАЛИ КОЭФФИЦИЕНТЫ ЛИНЕЙНОЙ КОРРЕЛЯЦИИ $(r)$ МЕЖДУ РЯДАМИ ДАННЫХ (ТАБЛИЦА 2). В ТОЙ ЖЕ ТАБЛИЦЕ ПРИВЕДЕНЫ ПОКАЗАТЕЛИ ПО ИНГЕРМАНЛАНДИИ ${ }^{11}$.

\section{2. Число душ м.п. у каждой фамилии (матрица корреляций)}

\begin{tabular}{|c|c|c|c|}
\hline \multirow{2}{*}{\multicolumn{2}{|c|}{ Груптв фамилий }} & Московский уезд & Ингерманиандия \\
\hline & & I-II pes. & вачало $1730-\mathrm{x}$.r. - II pes. \\
\hline \multicolumn{2}{|c|}{ Bce фамнтии } & 0,83 & 0,70 \\
\hline \multirow{6}{*}{ 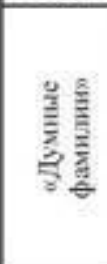 } & Bce & 0,90 & 0.87 \\
\hline & to $1613 \mathrm{t}^{*}$ & 0,94 & 0,78 \\
\hline & $1613-1645 \mathrm{mr}^{*}$ & 0,98 & - \\
\hline & $1645-1676 \mathrm{rr}^{*}$ & 0,76 & 0,85 \\
\hline & $1676-1682 \mathrm{~m} \cdot$ & 0,52 & 0,98 \\
\hline & $1682-1689 \mathrm{~m}^{*}$ & 0.55 & 0.94 \\
\hline \multicolumn{2}{|c|}{ жНедумные фамплиш } & 0,23 & 0.49 \\
\hline
\end{tabular}

ДЛЯ НАЧАЛА, ОСТАНОВИМСЯ НА МЕТОДИКЕ ПОДСЧЕТА. СВЕДЕНИЯ, СОДЕРЖАЩИЕСЯ В ПЕРЕПИСНЫХ КНИГАХ ІІ РЕВИЗИИ ПО МОСКОВСКОМУ УЕЗДУ, НЕПОЛНЫ (КНИГИ ПО РЯДУ СТАНОВ НЕ СОХРАНИЛИСЬ, А В ОБЩЕЙ СЛОЖНОСТИ УЧТЕНО 45663 ИЗ 78128 ДУШ М.П. ${ }^{12}$, Т.Е. 58\% ПОМЕЩИЧЬИХ КРЕСТЬЯН). ПОЭТОМУ РАСЧЕТЫ ПРОИЗВОДИЛИСЬ НА ОСНОВЕ СОПОСТАВИМЫХ ДАННЫХ ${ }^{13}$. КРОМЕ ТОГО, ИЗ МАССИВА БЫЛИ ИСКЛЮЧЕНЫ КОНФИСКОВАННЫЕ МЕЖДУ РЕВИЗИЯМИ ВОТЧИНЫ КН. А.Д. МЕНШИКОВА (ПО І РЕВИЗИИ 9400 ДУШ М.П.) И КН. А.Г. ДОЛГОРУКОВА (6547 ДУШ М.П.), КОТОРЫЕ ИСКУССТВЕННО ЗАНИЖАЛИ КОЭФФИЦИЕНТ КОРРЕЛЯЦИИ С 0,83 ДО 0,49 ${ }^{14}$. СТОЛЬ РЕЗКОЕ ИЗМЕНЕНИЕ КОЭФФИЦИЕНТА ПОЗВОЛЯЕТ СРАЗУ СДЕЛАТЬ ДВА ВАЖНЫХ ВЫВОДА. ВО-ПЕРВЫХ, КОНФИСКАЦИЯ ОСОБО КРУПНЫХ ИМЕНИЙ БЫЛА НЕХАРАКТЕРНА ДЛЯ МОСКОВСКОГО УЕЗДА ЭТОГО ВРЕМЕНИ И СУДЬБА ВОТЧИН А.Д. МЕНШИКОВА И А.Г. ДОЛГОРУКОВА ЯВЛЯЕТСЯ АНОМАЛИЕЙ. ВО-ВТОРЫХ, ВЕРХОВНАЯ ВЛАСТЬ, В СЛУЧАЕ ЕЕ ВМЕШАТЕЛЬСТВА, СТАНОВИЛАСЬ ГЛАВНЫМ ДЕСТАБИЛИЗИРУЮЩИМ ФАКТОРОМ, ВЛИЯВШИМ НА РОДОВУЮ СТРУКТУРУ ЗЕМЛЕВЛАДЕНИЯ. НАПРОТИВ, КУПЛЯ-ПРОДАЖА И ЗАКЛАД ИМЕНИЙ НЕ ОКАЗЫВАЛИ ПОДОБНОГО ВОЗДЕЙСТВИЯ.

11 ПРОАНАЛИЗИРУЕМ ДАННЫЕ ИЗ ТАБЛИЦЫ 2. ОНИ НЕ ЯВЛЯЮТСЯ ПОЛНОСТЬЮ СОПОСТАВИМЫМИ, ПОСКОЛЬКУ ПО МОСКОВСКОМУ УЕЗДУ ВРЕМЕННОЙ ИНТЕРВАЛ МЕЖДУ РЕВИЗИЯМИ СОСТАВЛЯЛ ОКОЛО 25 ЛЕТ, А ПО ИНГЕРМАНЛАНДИИ - ОКОЛО 12 ЛЕТ. ТЕМ НЕ МЕНЕЕ, ЭТИ ПОДСЧЕТЫ ПОЗВОЛЯЮТ СДЕЛАТЬ ЦЕЛЫЙ РЯД ВАЖНЫХ ВЫВОДОВ. ОЧЕВИДНО, ЧТО СТРУКТУРА СОБСТВЕННОСТИ В МОСКОВСКОМ УЕЗДЕ ОТЛИЧАЛАСЬ СРАВНИТЕЛЬНОЙ ПРОЧНОСТЬЮ ( $r=0,83)$. АНАЛОГИЧНЫЙ ПОКАЗАТЕЛЬ ПО ПЕТЕРБУРГСКОМУ РЕГИОНУ НИЖЕ $(r=0,7)$, ХОТЯ И ЗДЕСЬ (В РАМКАХ КОРОТКОГО ХРОНОЛОГИЧЕСКОГО ПРОМЕЖУТКА) МОЖНО ГОВОРИТЬ О ПРЕДСКАЗУЕМОСТИ РАЗВИТИЯ. ЭТИ ПОДСЧЕТЫ ПОДТВЕРЖДАЮТ НАШ ТЕЗИС О ВЫСОКОЙ УСТОЙЧИВОСТИ И ИНЕРЦИОННОСТИ РАЗВИТИЯ ПОДМОСКОВЬЯ И БОЛЕЕ ПОДВИЖНОЙ СТРУКТУРЕ СОБСТВЕННОСТИ В ОКРЕСТНОСТЯХ НОВОЙ СТОЛИЦЫ. ЗЕМЛЕВЛАДЕНИЕ ДУМНЫХ ФАМИЛИЙ В ОБОИХ РЕГИОНАХ ВЫДЕЛЯЛОСЬ ОЧЕНЬ ВЫСОКИМ УРОВНЕМ УСТОЙЧИВОСТИ ( $\mathrm{r}=0,90$ И 0,87$)$. ДЛЯ СРАВНЕНИЯ, ПОКАЗАТЕЛИ ПО ФАМИЛИЯМ, ЧЬИ ПРЕДСТАВИТЕЛИ НЕ ПОЛУЧАЛИ ДУМНЫХ ЧИНОВ, ГОРАЗДО НИЖЕ $(r=0,23$ И 0,49). 
СЛЕДОВАТЕЛЬНО, ПРИНАДЛЕЖНОСТЬ К ПРАВЯЩЕЙ ЭЛИТЕ XVI-XVII ВВ. ЗНАЧИТЕЛЬНО УСИЛИВАЛА СТАБИЛЬНОСТЬ РОДОВОЙ СОБСТВЕННОСТИ ДАЖЕ В ДОЛГОСРОЧНОЙ ПЕРСПЕКТИВЕ. ТАКЖЕ МОЖНО ЗАМЕТИТЬ, ЧТО ВЫСОКИЙ ОБЩИЙ ПОКАЗАТЕЛЬ КОРРЕЛЯЦИИ ПО ПОДМОСКОВЬЮ $(r=0,83)$ В ОСНОВНОМ ОБЪЯСНЯЛСЯ ЗНАЧИТЕЛЬНЫМ УДЕЛЬНЫМ ВЕСОМ ЗЕМЛЕВЛАДЕНИЯ ПОТОМКОВ ДУМНЫХ ЛЮДЕЙ В ЭТОМ УЕЗДЕ (61-66 \%, СМ. ТАБЛ. 1).

ТЕПЕРЬ ОБРАТИМ ВНИМАНИЕ НА КОЭФФИЦИЕНТЫ ПО ОТДЕЛЬНЫМ ГРУППАМ ДУМНЫХ ФАМИЛИЙ. ТАК, В МОСКОВСКОМ УЕЗДЕ СТАБИЛЬНОСТЬ ЗЕМЕЛЬНОГО ФОНДА НАПРЯМУЮ ЗАВИСЕЛА ОТ ВРЕМЕНИ ВХОЖДЕНИЯ ПРЕДСТАВИТЕЛЕЙ РОДА В СОСТАВ ПРАВЯЩЕГО СЛОЯ, А НАИБОЛЬШУЮ УСТОЙЧИВОСТЬ ДЕМОНСТРИРОВАЛИ ТЕ ФАМИЛИИ, ЧЛЕНЫ КОТОРЫХ ПОПАЛИ В ДУМУ ДО 1613 Г. И ПРИ ПЕРВОМ РОМАНОВЕ. ФАКТИЧЕСКИ МЫ СТАЛКИВАЕМСЯ С СИТУАЦИЕЙ, КОГДА ЗЕМЛЕВЛАДЕНИЕ ИСТОРИЧЕСКОГО ЦЕНТРА СТРАНЫ ЯВЛЯЛОСЬ НОСИТЕЛЕМ СОЦИАЛЬНОЙ ПАМЯТИ И ОТРАЖАЛО В СВОЕЙ СТРУКТУРЕ ОБЩИЕ ЧЕРТЫ ВЛАСТНОЙ ИЕРАРХИИ ХVII СТОЛЕТИЯ. ПОД САНКТ-ПЕТЕРБУРГОМ НАБЛЮДАЛАСЬ ПРОТИВОПОЛОЖНАЯ КАРТИНА: САМЫЕ ВЫСОКИЕ КОЭФФИЦИЕНТЫ ХАРАКТЕРНЫ ДЛЯ НЕРОДОВИТОГО ДВОРЯНСТВА, КОТОРОЕ ПРОБИЛОСЬ В ДУМУ ЛИШЬ В ПОСЛЕДНЕЙ ЧЕТВЕРТИ XVII В. (ПРИ ФЕДОРЕ И СОФЬЕ). КАК УЖЕ ОТМЕЧАЛОСЬ РАНЕЕ, ЗДЕСЬ СКАЗЫВАЛИСЬ ПРЕДПОЧТЕНИЯ ГОСУДАРЕЙ ИМПЕРСКОГО ПЕРИОДА ОТНОСИТЕЛЬНО ФОРМИРОВАНИЯ СОСТАВА ПРАВЯЩЕЙ ЭЛИТЫ РОССИИ ${ }^{15}$.

НА ОСНОВЕ ПРЕДСТАВЛЕННЫХ ДАННЫХ МОЖНО СДЕЛАТЬ ЕЩЕ ОДНО ИНТЕРЕСНОЕ НАБЛЮДЕНИЕ. В ИНГЕРМАНЛАНДИИ РАЗБРОС КОЭФФИЦИЕНТОВ ПО ГРУППАМ ДУМНЫХ ФАМИЛИЙ БЫЛ ГОРАЗДО НИЖЕ (ОТ 0,78 ДО 0,98), НЕЖЕЛИ В ПОДМОСКОВЬЕ (ОТ 0,52 ДО 0,98). ПРИЧИНЫ ЭТОГО КРЫЛИСЬ В РАЗЛИЧНОМ СОСТАВЕ ЗЕМЛЕВЛАДЕЛЬЦЕВ. ОЧЕВИДНО, ЧТО ВОТЧИНЫ ПОД САНКТ-ПЕТЕРБУРГОМ ПОЛУЧАЛИ ТЕ, КТО БЫЛ БЛИЗОК К ВЛАСТИ ${ }^{16}$. ПОЭТОМУ РОДОВИТОСТЬ И ДЛИТЕЛЬНОСТЬ СЛУЖБЫ ПРЕДКОВ В ДУМНЫХ ЧИНАХ НЕ ОКАЗЫВАЛИ РЕШАЮЩЕГО ВЛИЯНИЯ НА СТАБИЛЬНОСТЬ СОБСТВЕННОСТИ. ГЛАВНУЮ РОЛЬ ЗДЕСЬ ИГРАЛА БЛАГОСКЛОННОСТЬ НЫНЕ ЗДРАВСТВУЮЩЕГО МОНАРХА И ЕГО БЛИЖАЙШИХ НАСЛЕДНИКОВ. КРУГ ФАМИЛИЙ, ВЛАДЕВШИХ ВОТЧИНАМИ В ПОДМОСКОВЬЕ, БЫЛ ГОРАЗДО ШИРЕ. ТУТ ВСТРЕЧАЛИСЬ КАК ПРЕДСТАВИТЕЛИ ПРАВЯЩЕЙ ЭЛИТЫ ПЕРВОЙ ПОЛОВИНЫ XVIII В., ТАК И ЧЛЕНЫ РОДОВ УЖЕ УТРАТИВШИХ СВОЕ БЫЛОЕ ВЛИЯНИЕ. ДЛЯ ОЧЕНЬ МНОГИХ ДВОРЯН ПРИЧАСТНОСТЬ К ВЛАСТИ ПЕРЕСТАЛА БЫТЬ ФАКТОРОМ ПОДДЕРЖКИ. КАК ВИДИМ, ЭТО СИЛЬНЕЕ ВСЕГО ОТРАЗИЛОСЬ НА БЛАГОСОСТОЯНИИ САМОГО НЕЗНАТНОГО СЛОЯ ДУМНЫХ ФАМИЛИЙ $(\mathrm{r}=0,52$ И 0,55). В САМОМ ОБЩЕМ ВИДЕ ЭТУ ЗАКОНОМЕРНОСТЬ МОЖНО ВЫРАЗИТЬ СЛЕДУЮЩИМ ОБРАЗОМ. БЛИЗОСТЬ К ВЛАСТИ (КАК НАИБОЛЕЕ СИЛЬНЫЙ ФАКТОР) НИВЕЛИРОВАЛА РАЗЛИЧИЯ В СОЦИАЛЬНОМ СТАТУСЕ И РОДОВИТОСТИ, НО ПО МЕРЕ УДАЛЕНИЯ ОТ ТРОНА ПРОИСХОЖДЕНИЕ И ПРОШЛЫЕ ЗАСЛУГИ ПРЕДСТАВИТЕЛЕЙ ФАМИЛИИ ОКАЗЫВАЛИ ВСЕ БОЛЬШЕЕ ВОЗДЕЙСТВИЕ НА РАЗВИТИЕ СОБСТВЕННОСТИ.

СРАВНИМ ИЗМЕНЕНИЯ В РОДОВОЙ СТРУКТУРЕ ЗЕМЛЕВЛАДЕНИЯ ВБЛИЗИ ДВУХ СТОЛИЦ С ДРУГИМИ ТЕРРИТОРИЯМИ ЕВРОПЕЙСКОЙ РОССИИ. МЫ РАСПОЛАГАЕМ ДАННЫМИ І И ІІІ РЕВИЗИЙ ПО РЯЗАНСКОМУ УЕЗДУ И РЯДУ РАЙОНОВ ЦЕНТРАЛЬНОГО ЧЕРНОЗЕМЬЯ (КУРСКОМУ, ЕЛЕЦКОМУ УЕЗДАМ И ВОРОНЕЖСКОЙ ПРОВИНЦИИ) ${ }^{17}$. В ТАБЛИЦЕ 3 ПОКАЗАНО, КАКАЯ ЧАСТЬ ДВОРЯНСКИХ ФАМИЛИЙ СМОГЛА СОХРАНИТЬ СВОИ ВОТЧИНЫ В ТОМ ИЛИ ИНОМ РЕГИОНЕ МЕЖДУ І И ІІІ РЕВИЗИЯМИ. ТАКЖЕ ПРИВЕДЕНЫ ДАННЫЕ О 
КРЕПОСТНЫХ, ПРОЖИВАВШИХ В ЭТИХ ИМЕНИЯХ (В ПРОЦЕНТАХ ОТ ОБЩЕЙ ЧИСЛЕННОСТИ ПОМЕЩИЧЬИХ КРЕСТЬЯН ПО III РЕВИЗИИ).

3. Интенсивность изменений структуры родовой собственности между I и III ревизиями*

\begin{tabular}{|c|c|c|}
\hline \multirow[b]{2}{*}{ Регион } & \multicolumn{2}{|c|}{ к0 времени III ревнзин } \\
\hline & 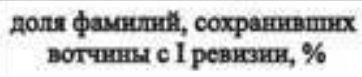 & у них душ м.п., \% \\
\hline Московский уезд & 65 & 85 \\
\hline Ингерманландня * & 43 & 54 \\
\hline Pязанскнй уезд & 62 & 74 \\
\hline Курскнй уез. & 58 & 69 \\
\hline Eлемкнй уезд & 39 & 66 \\
\hline Воронежская провнншня & 27 & 53 \\
\hline
\end{tabular}

РЯЗАНСКИЙ КРАЙ ЯВЛЯЛСЯ КРУПНЫМ ВОТЧИННЫМ ЦЕНТРОМ УЖЕ В ЭПОХУ СУЩЕСТВОВАНИЯ НЕЗАВИСИМОГО ОТ МОСКВЫ КНЯЖЕСТВА. ПОСЛЕ ПРИСОЕДИНЕНИЯ РЯЗАНСКИХ ЗЕМЕЛЬ К МОСКВЕ, УСЛОВИЯ МОБИЛИЗАЦИИ СОБСТВЕННОСТИ ЗДЕСЬ БЫЛИ ВО МНОГОМ СХОЖИ С ЗАМОСКОВНЫМ КРАЕМ. К КОНЦУ XVII СТОЛЕТИЯ В РЯЗАНСКОМ УЕЗДЕ СЛОЖИЛОСЬ ОБШИРНОЕ ДВОРЯНСКОЕ ПОМЕСТНО-ВОТЧИННОЕ ЗЕМЛЕВЛАДЕНИЕ, А ЗНАЧИТЕЛЬНАЯ ЧАСТЬ РЯЗАНСКИХ ИМЕНИЙ ПРИНАДЛЕЖАЛА СЛУЖИЛЫМ ЛЮДЯМ МОСКОВСКИХ ЧИНОВ ${ }^{18}$. НАПРОТИВ, ЦЕНТРАЛЬНОЕ ЧЕРНОЗЕМЬЕ СТАЛО ОСВАИВАТЬСЯ ТОЛЬКО НА РУБЕЖЕ XVI-XVII СТОЛЕТИЙ. В 1630-1680-Х ГГ. ПРАВИТЕЛЬСТВО ПРОВОДИЛО ЗДЕСЬ ПОЛИТИКУ «ЗАКАЗНЫХ ГОРОДОВ» ${ }^{19}$ И В РЯДЕ СЛУЧАЕВ ДАЖЕ ШЛО НА КОНФИСКАЦИЮ УЖЕ СЛОЖИВШИХСЯ ВЛАДЕНИЙ ${ }^{20}$. ТАКИМ ОБРАЗОМ, ЮГ РОССИИ ДОЛГОЕ ВРЕМЯ БЫЛ ЗАКРЫТ ДЛЯ МАССОВОГО ПРОНИКНОВЕНИЯ СТОЛИЧНОГО ДВОРЯНСТВА. К КОНЦУ XVII СТОЛЕТИЯ ЭТОТ РЕГИОН ОТЛИЧАЛСЯ СРАВНИТЕЛЬНОЙ МАЛОЧИСЛЕННОСТЬЮ ДВОРЯНСКИХ ВОТЧИН, НЕРАЗВИТОСТЬЮ КРУПНОГО ПОМЕЩИЧЬЕГО ЗЕМЛЕВЛАДЕНИЯ И НАЛИЧИЕМ ЗНАЧИТЕЛЬНОГО КОНТИНГЕНТА МЕЛКИХ СОБСТВЕННИКОВ (ОДНОДВОРЦЕВ), КОТОРЫЕ ПРИ ПЕТРЕ I, ПОТЕРЯВ СВОЙ ПРИВИЛЕГИРОВАННЫЙ СТАТУС, БЫЛИ ВКЛЮЧЕНЫ В СОСТАВ ГОСУДАРСТВЕННЫХ КРЕСТЬЯН ${ }^{21}$.

16 АНАЛИЗ ДАННЫХ, ПРЕДСТАВЛЕННЫХ В ТАБЛИЦЕ, ПОЗВОЛЯЕТ СДЕЛАТЬ ВЫВОД, ЧТО УСТОЙЧИВОСТЬ РОДОВОГО СОСТАВА ДВОРЯН-ЗЕМЛЕВЛАДЕЛЬЦЕВ НА ТОЙ ИЛИ ИНОЙ ТЕРРИТОРИИ НАПРЯМУЮ ЗАВИСЕЛА ОТ ЕЕ ГЕОГРАФИЧЕСКОГО РАСПОЛОЖЕНИЯ, ВРЕМЕНИ ВКЛЮЧЕНИЯ В СОСТАВ МОСКОВСКОГО ГОСУДАРСТВА, СТЕПЕНИ ОСВОЕННОСТИ И СТРУКТУРЫ ЗЕМЛЕВЛАДЕНИЯ В ДОИМПЕРСКИЙ ПЕРИОД. ВСЛЕДСТВИЕ ЭТОГО, НАИБОЛЕЕ ИЗМЕНЧИВЫМИ РОДОВЫМИ ХАРАКТЕРИСТИКАМИ, В УСЛОВИЯХ ПОДЪЕМА МИГРАЦИОННОЙ АКТИВНОСТИ ПЕРВОЙ ПОЛОВИНЫ XVIII СТОЛЕТИЯ, ОТЛИЧАЛОСЬ ЗЕМЛЕВЛАДЕНИЕ НА САМЫХ МАЛООСВОЕННЫХ ТЕРРИТОРИЯХ, ТАКИХ КАК ВОРОНЕЖСКИЙ КРАЙ. НАПРОТИВ, РАЙОНЫ СТАРОГО ЗАСЕЛЕНИЯ (МОСКОВСКИЙ И РЯЗАНСКИЙ УЕЗДЫ) ВЫДЕЛЯЛИСЬ ОТНОСИТЕЛЬНОЙ УСТоЙчИВОстью. ПРОчНОстЬ СТРУКТУРЫ СОБСТВЕННОСТИ В МОСКОВСКОМ УЕЗДЕ, КАК ВИДИМ, БЫЛА САМОЙ ВЫСОКОЙ. ТАКЖЕ ОБРАТИМ ВНИМАНИЕ, ЧТО ПОКАЗАТЕЛИ ПО ИНГЕРМАНЛАНДИИ НАХОДЯТСЯ НА УРОВНЕ УЕЗДОВ ЦЕНТРАЛЬНОГО ЧЕРНОЗЕМЬЯ. ИЗ ТЕХ ФАМИЛИЙ, КОТОРЫЕ ПО ІІІ РЕВИЗИИ ВЛАДЕЛИ ВОТЧИНАМИ В СЕВЕРО-ЗАПАДНОМ РЕГИОНЕ, В МАТЕРИАЛАХ ПЕРЕПИСИ И.А. ШИПОВА БЫЛИ НАЙДЕНЫ ТОЛЬКО $43 \%$ (СООТВЕТСТВЕННО, 57 \% РОДОВ ЯВЛЯЛИСЬ «НОВЫМИ»). КО ВРЕМЕНИ ІІІ РЕВИЗИИ «СТАРЫЕ» ФАМИЛИИ СОХРАНИЛИ ЗА СОБОЙ ЛИШЬ 54 \% КРЕПОСТНЫХ КРЕСТЬЯН. 
ПО НАШИМ ПОДСЧЕТАМ, ВОТЧИННЫЙ ФОНД ИНГЕРМАНЛАНДИИ В ПЕРИОД ЦАРСТВОВАНИЯ АННЫ ИОАННОВНЫ (МЕЖДУ ПЕРЕПИСЬЮ И.А. ШИПОВА И ІІ РЕВИЗИЕЙ) ИЗМЕНИЛСЯ ГОРАЗДО МЕНЬШЕ, ЧЕМ ПРИ ЕЛИЗАВЕТЕ ПЕТРОВНЕ (МЕЖДУ ІІ И III РЕВИЗИЯМИ) ${ }^{22}$. ПРАВЛЕНИЮ АННЫ СООТВЕТСТВУЮТ БОЛЕЕ ВЫСОКИЕ КОЭФФИЦИЕНТЫ КОРРЕЛЯЦИИ: ПО ВСЕМ ФАМИЛИЯМ 0,70 (ПРИ ЕЛИЗАВЕТЕ 0,46), ПО ДУМНЫМ ФАМИЛИЯМ 0,87 (ПРИ ЕЛИЗАВЕТЕ 0,56). ОБЩИЕ ПОКАЗАТЕЛИ РОДОВОЙ ПРЕЕМСТВЕННОСТИ ВОТЧИННОГО ФОНДА В РАМКАХ З0-ЛЕТНЕГО ПЕРИОДА БЫЛИ НИЗКИМИ $(r=0,20)$. НО РАЗВИТИЕ СОБСТВЕННОСТИ ТЕХ ФАМИЛИЙ, КОТОРЫЕ ИМЕЛИ СВОИХ ПРЕДСТАВИТЕЛЕЙ В ДОПЕТРОВСКОЙ ДУМЕ, ОТЛИЧАЛОСЬ БОЛЬШЕЙ СТАБИЛЬНОСТЬЮ И ПРЕДСКАЗУЕМОСТЬЮ $(\mathrm{r}=0,65)^{23}$. КАК БЫЛО ПОКАЗАНО ВЫШЕ, СТРУКТУРА ЗЕМЛЕВЛАДЕНИЯ В ЭТОМ РЕГИОНЕ СИЛЬНО ЗАВИСЕЛА ОТ СОСТАВА ПРАВЯЩЕГО СЛОЯ СТРАНЫ. ЕСЛИ СРАВНИТЬ ПЕРЕЧНИ ЛИЦ, НОСИВШИХ ЧИНЫ 1-4 КЛАССОВ ТАБЕЛИ О РАНГАХ В 1730 И 1758 ГГ. ${ }^{24}$, ТО МОЖНО ЗАМЕТИТЬ, ЧТО ЛИШЬ ЧЕТВЕРТЬ ФАМИЛИЙ ИЗ СПИСКА 1758 Г. ВСТРЕЧАЕТСЯ В ПЕРЕЧНЕ $1730 \Gamma^{25}$ СТОЛЬ НИЗКАЯ ПРЕЕМСТВЕННОСТЬ ПРАВЯЩЕГО СЛОЯ РОССИИ ВЕСЬМА ПОКАЗАТЕЛЬНА И СОГЛАСУЕТСЯ С ОБЩИМИ ТЕНДЕНЦИЯМИ В РАЗВИТИИ ЗЕМЛЕВЛАДЕНИЯ ИНГЕРМАНЛАНДИИ. ЭТОТ ВЫВОД, В ПЕРВУЮ ОЧЕРЕДЬ, ОТНОСИТСЯ К НОВИЧКАМ, КОТОРЫЕ ПРОБИЛИСЬ В СОСТАВ ЭЛИТЫ ТОЛЬКО В XVIII СТОЛЕТИИ. ПОЛОЖЕНИЕ РОДОВ, ВХОДИВШИХ В СОСТАВ ПРАВЯЩЕГО СЛОЯ XVI-XVII ВВ., БЫЛО БОЛЕЕ СТАБИЛЬНЫМ.

ТЕПЕРЬ ПРОАНАЛИЗИРУЕМ ОСНОВНЫЕ ФАКТОРЫ, КОТОРЫЕ ОКАЗЫВАЛИ ВЛИЯНИЕ НА МОБИЛИЗАЦИЮ ЗЕМЛЕВЛАДЕНИЯ В МОСКОВСКОМ УЕЗДЕ: 1) НАСЛЕДОВАНИЕ, А ТАКЖЕ СВЯЗАННЫЙ С ЭТИМ ПРОЦЕСС ДРОБЛЕНИЯ СОБСТВЕННОСТИ, 2) КУПЛЮ-ПРОДАЖУ И ЗАКЛАД ЗЕМЛИ, 3) ПОЖАЛОВАНИЕ, 4) КОНФИСКАЦИЮ, 5) ФОРМИРОВАНИЕ ВНОВЬПОСЕЛЕННЫХ ВОТЧИН. В ТАБЛИЦЕ 4 ОБОБЩЕНЫ ДАННЫЕ ПО І И ІІ РЕВИЗИЯМ ${ }^{26}$.

\section{4. Московский уезд, мобилизация собственности между I и II ревизиями}

\begin{tabular}{|c|c|c|c|}
\hline Владетьцы по I н II ревнзням & $\begin{array}{l}\text { владенині, } \\
\text { абс. (\%) }\end{array}$ & $\begin{array}{l}\text { душі м.п., } \\
\text { a6c. (\%) }\end{array}$ & душі м.П., среднее \\
\hline одна д та же фамития & $520(58,9)$ & $28881(43,9)$ & 56 \\
\hline $6 \mathrm{~m}$. t., mom wace 6raderey & $164(18,6)$ & $10428(15,9)$ & 64 \\
\hline разные фамнлия & $325(36,8)$ & $13501(20,5)$ & 42 \\
\hline оттисано & $23(2,6)$ & $18829(28,6)$ & 819 \\
\hline пожаловано & $11(1.2)$ & $3208(4,9)$ & 292 \\
\hline вновьпоселенные вотчнны & $6(0,7)$ & $135(0,2)$ & 23 \\
\hline нет данньх & $7(0,8)$ & $1581(2,4)$ & 226 \\
\hline Hroro & $883(100)$ & $65736(100)$ & 74 \\
\hline
\end{tabular}

СОГЛАСНО ПРИВЕДЕННЫМ ДАННЫМ, СПУСТЯ 25 ЛЕТ ПОСЛЕ ПЕРВОЙ РЕВИЗИИ, СРЕДИ СОБСТВЕННИКОВ МОСКОВСКОГО УЕЗДА БЛИЗИЛАСЬ К ЗАВЕРШЕНИЮ СМЕНА ПОКОЛЕНИЙ, И ЛИШЬ 18,6 \% ВОТЧИН ОСТАВАЛОСЬ ЗА СТАРЫМИ ВЛАДЕЛЬЦАМИ. ПОЧТИ ДВЕ ТРЕТИ ИМЕНИЙ (58,9 \%) СОХРАНИЛИСЬ ЗА ПРЕДСТАВИТЕЛЯМИ ТОГО ЖЕ САМОГО РОДА ${ }^{27}$. БОЛЕЕ ТРЕТИ ВОТЧИН (36,8\%) И ПЯТАЯ ЧАСТЬ КРЕСТЬЯН (20,5\%) ПЕРЕШЛИ К ЛИЦАМ, НОСИВШИМ ДРУГУЮ ФАМИЛИЮ (ВКЛЮЧАЯ ЖЕНЩИН, СМЕНИВШИХ ФАМИЛИЮ В РЕЗУЛЬТАТЕ ЗАМУЖЕСТВА). ПРИМЕЧАТЕЛЬНО, ЧТО НА ОБЩЕЙ УСТОЙЧИВОСТИ РОДОВОГО ЗЕМЛЕВЛАДЕНИЯ ЭТО СКАЗАЛОСЬ НЕЗНАЧИТЕЛЬНО (СМ. ТАБЛ. 2). ЕСЛИ ДОПОЛНИТЕЛЬНО УЧЕСТЬ РОДСТВЕННЫЕ СВЯЗИ МЕЖДУ ВЛАДЕЛЬЦАМИ С РАЗНЫМИ ФАМИЛИЯМИ, ТО ПОЛУЧИМ СЛЕДУЮЩИЕ РЕЗУЛЬТАТЫ: К РОДСТВЕННИКАМ ПЕРЕШЛО 66 \% ИМЕНИЙ И 50 \% КРЕПОСТНЫХ, А К ЛИЦАМ, КОТОРЫЕ НЕ БЫЛИ РОДСТВЕННИКАМИ - 28,7 \% ИМЕНИЙ И 
13,9 \% КРЕПОСТНЫХ. В ПЕРЕПИСНЫХ КНИГАХ ІІ РЕВИЗИИ НЕ УКАЗАНЫ ПРИЧИНЫ СМЕНЫ СОБСТВЕННИКА, ПОЭТОМУ МЫ, К СОЖАЛЕНИЮ, НЕ МОЖЕМ ОПРЕДЕЛИТЬ КАКАЯ ЧАСТЬ ИМЕНИЙ БЫЛА ПРОДАНА, А КАКАЯ ПРОСРОЧЕНА ПО ЗАКЛАДУ ${ }^{28}$. ПОДЧЕРКНЕМ, ЧТО ПОКАЗАТЕЛИ ПО ИМЕНИЯМ, ПЕРЕШЕДШИМ К ИНОРОДЦАМ, СЛЕДУЕТ СЧИТАТЬ ЗАВЫШЕННЫМИ, ТАК КАК ЧАСТЬ ВЛАДЕЛЬЦЕВ ВПОЛНЕ МОГЛА НАХОДИТЬСЯ В ДАЛЬНЕМ РОДСТВЕ. ОДНАКО НЕТОЧНОСТЬ МИНИМАЛЬНА, ПОСКОЛЬКУ ЗАКОНОДАТЕЛЬСТВО ПЕРВОЙ ПОЛОВИНЫ XVIII В. ОТДАВАЛО ПРЕДПОЧТЕНИЕ НАСЛЕДОВАНИЮ ПО ПРЯМОЙ НИСХОДЯЩЕЙ ЛИНИИ. ЭТО ПОДТВЕРЖДАЕТСЯ ДАННЫМИ ИЗ ТАБЛИЦЫ 5. БОЛЬШИНСТВО ВОТЧИН (82 \%) И КРЕПОСТНЫХ КРЕСТЬЯН (84 \%) В МОСКОВСКОМ УЕЗДЕ НАСЛЕДОВАЛИСЬ ОТ БЛИЖАЙШИХ КРОВНЫХ РОДСТВЕННИКОВ, В ПЕРВУЮ ОЧЕРЕДЬ, ОТ ОТЦА (53 \%). ПО ПРЯМОЙ ЛИНИИ БЫЛО ПЕРЕДАНО 72 \% ИМЕНИЙ И 74\% КРЕПОСТНЫХ, ПО БОКОВЫМ - 14 И 15 \%, СООТВЕТСТВЕННО. В РАМКАХ МАЛОЙ (НУКЛЕАРНОЙ) СЕМЬИ - СУПРУЖЕСКОЙ ПАРЫ С ДЕТЬМИ - РАСПРЕДЕЛЯЛИСЬ 70 \% ВОТЧИН И $71 \%$ КРЕСТЬЯН. ТАКИМ ОБРАЗОМ, НАШИ ДАННЫЕ ПОДТВЕРЖДАЮТ ВЫВОДЫ В. КИВЕЛЬСОН И М. МАРРЕЗЕ, ЧТО В СФЕРЕ НАСЛЕДОВАНИЯ НУКЛЕАРНАЯ СЕМЬЯ ПРЕОБЛАДАЛА НАД РОДОМ В ЦЕЛОМ. ОЧЕВИДНО, ЧТО В ПЕРВОЙ ПОЛОВИНЕ ХVIII СТОЛЕТИЯ ЗЕМЕЛЬНАЯ СОБСТВЕННОСТЬ ИГРАЛА НЕЗНАЧИТЕЛЬНУЮ РОЛЬ В ПОДДЕРЖАНИИ ОТНОШЕНИЙ ВНУТРИ РАСШИРЕННОЙ РОДСТВЕННОЙ ГРУППЫ (ФАМИЛЬНОГО КЛАНА) ${ }^{29}$. ЗА ПРЕДЕЛЫ НУКЛЕАРНОЙ СЕМЬИ НЕДВИЖИМОСТЬ ВЫХОДИЛА, КАК ПРАВИЛО, ТОЛЬКО У БЕЗДЕТНЫХ СУПРУГОВ ${ }^{30}$.

\section{5. Родственные связи между владельцами унаследованных имений по I и II ревизиям}

\begin{tabular}{|c|c|c|c|c|}
\hline \multirow{2}{*}{ 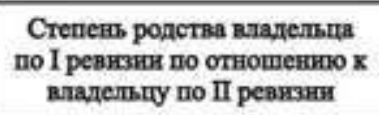 } & \multicolumn{2}{|c|}{ a6c. } & \multicolumn{2}{|c|}{ доля, \% } \\
\hline & вмадешй & ду⿴囗十. & владенкй & душ M.II. \\
\hline oren & 204 & 10944 & 52,6 & 52,9 \\
\hline MaIb & 24 & 2117 & 6.2 & 10,2 \\
\hline жена & 2 & 82 & 0,5 & 0,4 \\
\hline Mysk & 39 & 1367 & 10,1 & 6,6 \\
\hline CbIH & 1 & 55 & 0,3 & 0,3 \\
\hline паскинох & 1 & 51 & 0,3 & 0,2 \\
\hline 6par & 30 & 1755 & 7,7 & 8,5 \\
\hline cecrpa & 2 & 72 & 0.5 & 0,3 \\
\hline дxrs & 19 & 1053 & 4,9 & 5,1 \\
\hline Ters & 4 & 298 & 1,0 & 1,4 \\
\hline дед & 46 & 2015 & 11,9 & 9,7 \\
\hline $6 а 6$ ка & 3 & 284 & 0.8 & 1,4 \\
\hline деверь & 3 & 48 & 0.8 & 0,2 \\
\hline Tectib & 8 & 436 & 2,1 & 2,1 \\
\hline rema & 4 & 230 & 1,0 & 1,1 \\
\hline cвekop & 8 & 319 & 2,1 & 1,5 \\
\hline другая степень родства & 7 & 803 & 1,8 & 3,9 \\
\hline Hroro & 388 & 20706 & 100 & 100 \\
\hline
\end{tabular}

ПОДАВЛЯЮЩАЯ ЧАСТЬ НЕДВИЖИМОСТИ В ИЗУЧАЕМОЕ ВРЕМЯ ПРОДОЛЖАЛА ПЕРЕДАВАТЬСЯ ПО МУЖСКОЙ ЛИНИИ. МЕЖДУ І И ІІ РЕВИЗИЯМИ ЛИШЬ $11 \%$ ИМЕНИЙ И $18 \%$ КРЕСТЬЯН БЫЛИ УНАСЛЕДОВАНЫ ОТ ЖЕНЩИН. НО ДОЛЯ СОБСТВЕННОСТИ, ПРИНАДЛЕЖАВШАЯ ЛИЦАМ ЖЕНСКОГО ПОЛА, БЫСТРО УВЕЛИЧИВАЛАСЬ. ТАК, ПО ПЕРВОЙ РЕВИЗИИ В МОСКОВСКОМ УЕЗДЕ ЗА ЖЕНЩИНАМИ ЧИСЛИЛОСЬ $9 \%$ ВОТЧИН (8\% КРЕПОСТНЫХ), ПО ВТОРОЙ - 20 \% (16\%), ПО ТРЕТЬЕЙ - 30 \% (23\%), СООТВЕТСТВЕННО ${ }^{31}$. ИНТЕРЕСНО, ЧТО ПО ОЦЕНКЕ РЯДА ИССЛЕДОВАТЕЛЕЙ, К СЕРЕДИНЕ XVIII СТОЛЕТИЯ 
РОССИЙСКИЕ ЖЕНЩИНЫ-ДВОРЯНКИ ОБЛАДАЛИ БОЛЕЕ ПРОЧНЫМИ ПРАВАМИ В СФЕРЕ ВЛАДЕНИЯ И РАСПОРЯЖЕНИЯ НЕДВИЖИМОСТЬЮ, ЧЕМ В БОЛЬШИНСТВЕ СТРАН ЗАПАДНОЙ ЕВРОПЫ И СЕВЕРНОЙ АМЕРИКИ ${ }^{32}$. ТЕПЕРЬ РАССМОТРИМ ПРЕДПОЧТЕНИЯ ЗАВЕЩАТЕЛЕЙ В ЗАВИСИМОСТИ ОТ ИХ ПОЛА (ТАБЛИЦА 6). ТАКЖЕ ВОСПОЛЬЗУЕМСЯ ВОЗМОЖНОСТЬЮ СРАВНИТЬ ПОЛУЧЕННЫЕ РЕЗУЛЬТАТЫ С ПОДСЧЕТАМИ М.Л. МАРРЕЗЕ, КОТОРАЯ ПРОАНАЛИЗИРОВАЛА 133 ЗАВЕЩАНИЯ ЗА 1703-1867 ГГ. ${ }^{33}$

\section{6. Предпочтения завещателей вотчин по данным I и II ревизий (в зависимости от пола)}

\begin{tabular}{|c|c|c|c|c|c|}
\hline \multirow{4}{*}{\multicolumn{2}{|c|}{ Bлателец по II ревнзия }} & \multicolumn{4}{|c|}{ пол впадетьда вотины по I реиизия } \\
\hline & & \multirow{2}{*}{\multicolumn{2}{|c|}{$\begin{array}{c}\text { муххчинв } \\
\text { долк собетвенности, \% }\end{array}$}} & \multirow{2}{*}{\multicolumn{2}{|c|}{$\begin{array}{c}\text { женшинна } \\
\text { доля собетвенности, \% }\end{array}$}} \\
\hline & & & & & \\
\hline & & \multirow{2}{*}{$\frac{\text { мпаденвй }}{69.9}$} & \multirow{2}{*}{$\frac{\text { душ м..п. }}{76,1}$} & \multirow{2}{*}{$\frac{\text { владений }}{78,6}$} & \multirow{2}{*}{$\frac{\text { душі м.п. }}{81,0}$} \\
\hline$m$ & мужсчина & & & & \\
\hline nas & жсенизина & 30,4 & 24,9 & 21,4 & 19,0 \\
\hline \multicolumn{2}{|c|}{ сыा } & 46,3 & 51,2 & 42,9 & 40,4 \\
\hline \multicolumn{2}{|c|}{ доमь } & 12,2 & 13,5 & 16,7 & 18,5 \\
\hline \multicolumn{2}{|c|}{ тругой сушруг } & 11,1 & 7,9 & 4,8 & 2.2 \\
\hline \multicolumn{2}{|c|}{ Bнyк } & 10,2 & 11,1 & 7,1 & 7,5 \\
\hline \multicolumn{2}{|c|}{ внучка } & 3,1 & 0,9 & 0,0 & 0,0 \\
\hline \multicolumn{2}{|c|}{ sars } & 0,3 & 0,3 & 0,0 & 0,0 \\
\hline \multicolumn{2}{|c|}{ отषस } & 0,3 & 0,3 & 0,0 & 0,0 \\
\hline \multicolumn{2}{|c|}{ Opar } & 8,0 & 9,7 & 2,4 & 1,5 \\
\hline \multicolumn{2}{|c|}{ cectpa } & 0,6 & 0,5 & 4,8 & 1,9 \\
\hline \multicolumn{2}{|c|}{ племянник } & 4,5 & 2,9 & 9,5 & 9.3 \\
\hline \multicolumn{2}{|c|}{ племянница } & 1,1 & 3,8 & 2,4 & 0,1 \\
\hline \multicolumn{2}{|c|}{ невестка } & 0,9 & 0,3 & 0,0 & 0,0 \\
\hline \multicolumn{2}{|c|}{ зять } & 3,1 & 3,4 & 9,5 & 6,1 \\
\hline \multicolumn{2}{|c|}{ choxa } & 2,3 & 1,8 & 0,0 & 0,0 \\
\hline \multicolumn{2}{|c|}{ другая степень родства } & 1,1 & 0,7 & 7,1 & 18,3 \\
\hline \multicolumn{2}{|c|}{ Итого } & 100 & 100 & 100 & 100 \\
\hline
\end{tabular}

В ПЕРВУЮ ОЧЕРЕДЬ, СЛЕДУЕТ СОГЛАСИТЬСЯ С ГЛАВНЫМ ВЫВОДОМ М.Л. МАРРЕЗЕ, ЧТО МОДЕЛИ ПОВЕДЕНИЯ ЗАВЕЩАТЕЛЕЙ ВНЕ ЗАВИСИМОСТИ ОТ ПОЛА ОБНАРУЖИВАЮТ ГОРАЗДО БОЛЬШЕ СХОДСТВА, ЧЕМ РАЗЛИЧИЙ. ЕСЛИ В ЕВРОПЕ СЛОЖИЛАСЬ ОСОБАЯ ЖЕНСКАЯ ПРАКТИКА ПЕРЕДАЧИ СОБСТВЕННОСТИ ПО НАСЛЕДСТВУ, ТО В РОССИИ ХVIII-ХІХ ВВ. ЭТОГО НЕ ПРОИЗОШЛО. ПРАВОВЫЕ РАМКИ ВЫНУЖДАЛИ ДВОРЯНОК КОПИРОВАТЬ МУЖСКУЮ МОДЕЛЬ ПОВЕДЕНИЯ ПРИ НАСЛЕДОВАНИИ НЕДВИЖИМОСТИ ${ }^{34}$.

В ОСТАЛЬНОМ НАШИ ПОДСЧЕТЫ ПО ПЕРВОЙ ПОЛОВИНЕ XVIII СТОЛЕТИЯ И ДАННЫЕ М.Л. МАРРЕЗЕ ПО ЗАВЕЩАНИЯМ 1703-1867 ГГ. РИСУЮТ РАЗНЫЕ ТИПЫ ПОВЕДЕНИЯ СОБСТВЕННИКОВ. ТАК, ПО НАБЛЮДЕНИЯМ М.Л. МАРРЕЗЕ, ЖЕНЩИНЫ СТАНОВИЛИСЬ НАСЛЕДНИКАМИ НЕДВИЖИМОСТИ ТАКЖЕ ЧАСТО, КАК И МУЖЧИНЫ. НАПРОТИВ, СВЕДЕНИЯ I И ІІ РЕВИЗИЙ ПОКАЗЫВАЮТ, ЧТО ОКОЛО ТРЕХ ЧЕТВЕРТЕЙ СОБСТВЕННОСТИ В ЭТОТ ПЕРИОД БЫЛИ УНАСЛЕДОВАНЫ МУЖЧИНАМИ. КРОМЕ ТОГО, ВОТЧИНЫ, ПЕРЕШЕДШИЕ К ЛИЦАМ ЖЕНСКОГО ПОЛА, БЫЛИ МЕЛЬЧЕ ${ }^{35}$. ИНТЕРЕСНО, ЧТО ЖЕНЩИНЫ ПРЕДПОЧИТАЛИ ЗАВЕЩАТЬ СОБСТВЕННОСТЬ ПО МУЖСКОЙ ЛИНИИ ДАЖЕ ЧАЩЕ, ЧЕМ САМИ МУЖЧИНЫ. СТОЛЬ ЖЕ ЯВНЫЕ ДИСПРОПОРЦИИ ЗАМЕТНЫ ПРИ ПЕРЕДАЧЕ ВОТЧИН В ПРЕДЕЛАХ НУКЛЕАРНОЙ СЕМЬИ. ПО ДАННЫМ І И ІІ РЕВИЗИЙ ЗДЕСЬ ДОМИНИРОВАЛО НАСЛЕДОВАНИЕ 
ПО МУЖСКОЙ ЛИНИИ (СЫНОВЬЯМИ), А НА ДОЛЮ ДОЧЕРЕЙ ПРИХОДИЛОСЬ ЛИШЬ 12-17\% ВОТЧИН И 14-19\% КРЕПОСТНЫХ. СХОДНАЯ ТЕНДЕНЦИЯ ПРОСЛЕЖИВАЕТСЯ И ПРИ ПЕРЕДАЧЕ ВОТЧИН ВНУКАМ. ОДНАКО, ЕСЛИ ОБРАТИТЬСЯ К ДАННЫМ, СОБРАННЫМ М.Л. МАРРЕЗЕ, ТО ПОЛОЖЕНИЕ ЖЕНЩИН ПРЕДСТАВЛЯЕТСЯ БОЛЕЕ ПРОЧНЫМ, А ДОЧЕРИ УПОМИНАЮТСЯ СРЕДИ НАСЛЕДНИКОВ НЕДВИЖИМОСТИ В $31 \%$ МУЖСКИХ И В $49 \%$ ЖЕНСКИХ ЗАВЕЩАНИЙ ${ }^{36}$. ПРОВЕДЕННЫЙ АНАЛИЗ, В ЦЕЛОМ, ПОЗВОЛЯЕТ УТВЕРЖДАТЬ, ЧТО В ПЕРВОЙ ПОЛОВИНЕ XVIII СТОЛЕТИЯ ЗАВЕЩАТЕЛИ ОБОИХ ПОЛОВ ОРИЕНТИРОВАЛИСЬ НА ПЕРЕДАЧУ СОБСТВЕННОСТИ БЛИЖАЙШИМ НАСЛЕДНИКАМ, НО В ОСНОВНОМ ПО МУЖСКОЙ ЛИНИИ. ПО ВСЕЙ ВИДИМОСТИ, МОДЕЛЬ ПОВЕДЕНИЯ, ОПИСАННАЯ В КНИГЕ М.Л. МАРРЕЗЕ, С БОЛЕЕ ШИРОКИМИ ИМУЩЕСТВЕННЫМИ ПРАВАМИ ЖЕНЩИНЫ, КОГДА ДЛЯ ЗАВЕЩАТЕЛЕЙ «БЫЛ ВАЖЕН НЕ СТОЛЬКО ПОЛ НАСЛЕДНИКОВ, СКОЛЬКО СТЕПЕНЬ РОДСТВА С НИМИ» СКЛАДЫВАЕТСЯ НАМНОГО ПОЗДНЕЕ. ЭТО СТАНОВИТСЯ ОЧЕВИДНЫМ И ПРИ АНАЛИЗЕ ПЕРЕЧНЯ ЗАВЕЩАНИЙ, КОТОРЫЕ АВТОР ИСПОЛЬЗОВАЛА В СВОЕЙ РАБОТЕ. ПОДАВЛЯЮЩЕЕ БОЛЬШИНСТВО ИЗ НИХ ОТНОСИТСЯ КО ВТОРОЙ ПОЛОВИНЕ XVIII В. И К XIX СТОЛЕТИЮ ${ }^{38}$. ВАЖНЫМ ПРОЦЕССОМ, НАПРЯМУЮ СВЯЗАННЫМ С НАСЛЕДОВАНИЕМ СОБСТВЕННОСТИ, ЯВЛЯЛОСЬ ДРОБЛЕНИЕ ДВОРЯНСКИХ ИМЕНИЙ. ОЧЕВИДНО, ЧТО ОБОЗНАЧЕННАЯ ПРОБЛЕМА ИМЕЕТ НЕ ТОЛЬКО ЭКОНОМИЧЕСКУЮ, НО И ПОЛИТИЧЕСКУЮ СОСТАВЛЯЮЩУЮ. В ЧАСТНОСТИ, ПО МНЕНИЮ РЯДА ИССЛЕДОВАТЕЛЕЙ, ПРАКТИКА «ДРОБНОГО НАСЛЕДОВАНИЯ», СФОРМИРОВАВШАЯСЯ В РОССИИ С НЕЗАПАМЯТНЫХ ВРЕМЕН, ПОДРЫВАЛА САМОСТОЯТЕЛЬНОСТЬ ЗЕМЛЕВЛАДЕЛЬЦЕВ И СТАВИЛА СЛУЖИЛЫЙ КЛАСС В ЗАВИСИМОСТЬ ОТ БЛАГОСКЛОННОСТИ ГОСУДАРСТВА. СЛОЖИВШАЯСЯ СИТУАЦИЯ ДЕЛАЛА НЕВОЗМОЖНОЙ ЛЮБУЮ ОППОЗИЦИЮ ВЕРХОВНОЙ ВЛАСТИ СО СТОРОНЫ ДВОРЯНСТВА ${ }^{39}$.

ИСТОЧНИКИ, КОТОРЫЕ ИМЕЮТСЯ В НАШЕМ РАСПОРЯЖЕНИИ, НЕ ПОЗВОЛЯЮТ АНАЛИЗИРОВАТЬ ЭВОЛЮЦИЮ СОБСТВЕННОСТИ В ДЛИТЕЛЬНОЙ ИСТОРИЧЕСКОЙ ПЕРСПЕКТИВЕ. НО ОБРАБОТКА МАТЕРИАЛОВ I И ІІ РЕВИЗИЙ ДАЕТ ВЕСЬМА ИНТЕРЕСНЫЕ РЕЗУЛЬТАТЫ. ТАК, ЗА 25 ЛЕТ, ПРОШЕДШИХ МЕЖДУ ПЕРЕПИСЯМИ, ТРИ ЧЕТВЕРТИ ВОТЧИН МОСКОВСКОГО УЕЗДА (78 \%) НЕ ПОДВЕРГЛИСЬ ДРОБЛЕНИЮ НА БОЛЕЕ МЕЛКИЕ ЧАСТИ ${ }^{40}$. ПОСКОЛЬКУ КО ВРЕМЕНИ ІІ РЕВИЗИИ ЛИШЬ 19 \% ИМЕНИЙ ОСТАЛИСЬ В РУКАХ ПРЕЖНИХ ВЛАДЕЛЬЦЕВ (СМ. ТАБЛ. 4), ЭТОТ ПОКАЗАТЕЛЬ МОЖНО РАСЦЕНИВАТЬ КАК ОЧЕНЬ ВЫСОКИЙ. ТОЛЬКО 18 \% ВОТЧИН БЫЛИ РАЗДЕЛЕНЫ, 4 \% - ОБЪЕДИНЕНЫ (В ТОМ ЧИСЛЕ, С ПОСЛЕДУЮЩИМ РАЗДЕЛОМ - $1 \%)^{41}$. СОВМЕСТНЫЕ ВЛАДЕНИЯ ДВУХ И БОЛЕЕ ЛИЦ БЫЛИ НЕХАРАКТЕРНЫ ДЛЯ МОСКОВСКОГО УЕЗДА: ПО ПЕРВОЙ РЕВИЗИИ - 4 \% ВОТЧИН (В НИХ 6 \% ДУШ М.П.), ПО ВТОРОЙ - $7 \%$ (8\%), ПО ТРЕТЬЕЙ - $9 \%(7 \%)^{42}$. ПО ВСЕЙ ВИДИМОСТИ, ДВОРЯНЕ ПРЕДПОЧИТАЛИ НЕ ДЕЛИТЬ УЖЕ СЛОЖИВШИЕСЯ ВЛАДЕЛЬЧЕСКИЕ КОМПЛЕКСЫ, А ПРИ НАСЛЕДОВАНИИ ИЛИ ПОКУПКЕ БОЛЬШИНСТВО ВОТЧИН ПЕРЕХОДИЛО ИЗ РУК В РУКИ ЦЕЛИКОМ ${ }^{43}$. ЭТО СТАНОВИЛОСЬ ВОЗМОЖНЫМ, ПОСКОЛЬКУ ПОЧТИ ВСЕ СОБСТВЕННИКИ ПОДМОСКОВНЫХ ИМЕНИЙ (ПО ДАННЫМ НА 1700 Г. $\quad$ - $98 \% \%^{44}$ ) ОДНОВРЕМЕННО ЯВЛЯЛИСЬ ВЛАДЕЛЬЦАМИ ЗЕМЕЛЬ В ДРУГИХ УЕЗДАХ СТРАНЫ, ЗА СЧЕТ КОТОРЫХ И ОБЕСПЕЧИВАЛИ ДРОБЛЕНИЕ НАСЛЕДСТВА.

ПОПЫТАЕМСЯ ОЦЕНИТЬ ИНТЕНСИВНОСТЬ ДРОБЛЕНИЯ В ПОСЛЕДУЮЩЕЕ ВРЕМЯ. СКАЗКИ ТРЕТЬЕЙ ПОДУШНОЙ ПЕРЕПИСИ ПО МОСКОВСКОМУ УЕЗДУ СОХРАНИЛИСЬ НЕ ПОЛНОСТЬЮ (34091 ИЗ 81777 ДУШ М.П., $42 \%{ }^{45}$ ), А ТЕРРИТОРИИ, ОХВАЧЕННЫЕ ДОШЕДШИМИ ДО НАС МАТЕРИАЛАМИ ВТОРОЙ И ТРЕТЬЕЙ РЕВИЗИЙ, НЕ ВПОЛНЕ СОВПАДАЮТ. ОДНАКО НАМ УДАЛОСЬ ОБНАРУЖИТЬ 294 ВОТЧИНЫ, КОТОРЫЕ ВСТРЕЧАЮТСЯ В МАТЕРИАЛАХ ОБЕИХ 
РЕВИЗИЙ. ИЗ ЭТОЙ ДОСТАТОЧНО ПРЕДСТАВИТЕЛЬНОЙ ВЫБОРКИ ЗА 20 ЛЕТ ПОДВЕРГЛИСЬ РАЗДЕЛУ ЛИШЬ $6 \%$ ИМЕНИЙ. СЛЕДОВАТЕЛЬНО, ПОСЛЕ ОТМЕНЫ ПЕТРОВСКИХ ПУНКТОВ ДРОБЛЕНИЕ ПОДМОСКОВНЫХ ВОТЧИН СТАЛО ЕЩЕ БОЛЕЕ РЕДКИМ ЯВЛЕНИЕМ. ЭТУ ЖЕ ТЕНДЕНЦИЮ (СНИЖЕНИЕ МОБИЛИЗАЦИИ) МОЖНО ПРОСЛЕДИТЬ ПО ДАННЫМ О КУПЛЕПРОДАЖЕ ЗЕМЛИ (СМ. ТАБЛИЦУ 8).

ПРОВЕДЕННЫЕ ПОДСЧЕТЫ ПОЗВОЛЯЮТ СДЕЛАТЬ РЯД ВАЖНЫХ ВЫВОДОВ. КАК ВИДИМ, УКАЗ О ЕДИНОНАСЛЕДИИ УСИЛИЛ ДРОБЛЕНИЕ СОБСТВЕННОСТИ. ИЗ-ЗА НЕХВАТКИ СРЕДСТВ НА ПОКУПКУ НЕДВИЖИМОСТИ МЛАДШИМ СЫНОВЬЯМ, ЛИШЕННЫМ ПО ПЕТРОВСКОМУ УКАЗУ ОТЦОВСКИХ ВОТЧИН, СТОЛИЧНЫМ ДВОРЯНАМ ПРИХОДИЛОСЬ ПРОДАВАТЬ ЧАСТЬ СВОИХ ВЛАДЕНИЙ. НО ЭТОТ ПРОЦЕСС НЕ ИМЕЛ КАКИХ-ЛИБО КАТАСТРОФИЧЕСКИХ ПОСЛЕДСТВИЙ - ДОЛЯ ИМЕНИЙ, ПОДВЕРГШИХСЯ РАЗДЕЛУ В ПЕРИОД ДЕЙСТВИЯ ПУНКТОВ 1714 Г., БЫЛА ЛИШЬ НА 12 \% ВЫШЕ, ЧЕМ ПОСЛЕ ИХ ОТМЕНЫ. ЕЩЕ ОДИН ВЫВОД КАСАЕТСЯ ОСОБЕННОСТЕЙ РАЗВИТИЯ ЗЕМЛЕВЛАДЕНИЯ В ПОДМОСКОВЬЕ. ДЛЯ ДАННОГО РЕГИОНА БЫЛИ ХАРАКТЕРНЫ ВЫСОКАЯ СТАБИЛЬНОСТЬ РОДОВОГО ЗЕМЕЛЬНОГО ФОНДА (В ОСНОВНОМ, У ПРЕДСТАВИТЕЛЕЙ «СТАРОЙ» ЭЛИТЫ XVI-XVII ВВ.) И ОЧЕНЬ НИЗКИЕ ПОКАЗАТЕЛИ ДРОБЛЕНИЯ СОБСТВЕННОСТИ. ЭТО ПОЗВОЛЯЕТ РАССМАТРИВАТЬ ПРОБЛЕМУ ЗАВИСИМОСТИ РУССКОГО ДВОРЯНСТВА ОТ САМОДЕРЖАВИЯ С НЕСКОЛЬКО ИНЫХ ПОЗИЦИЙ, НЕЖЕЛИ ЭТО ТРАДИЦИОННО ДЕЛАЛОСЬ В ИСТОРИОГРАФИИ. ОЧЕВИДНО, ЧТО УТРАТА ЭКОНОМИЧЕСКОЙ ЖИЗНЕСПОСОБНОСТИ И ИЗМЕЛЬЧАНИЕ ВОТЧИН НЕ ЯВЛЯЛИСЬ АКТУАЛЬНОЙ УГРОЗОЙ ДЛЯ ВЕРХНЕГО СЛОЯ МОСКОВСКИХ ЧИНОВ, А НАКОПЛЕННЫЕ ЗЕМЕЛЬНЫЕ БОГАТСТВА И ТРАДИЦИОННАЯ ПРИЧАСТНОСТЬ К ВЛАСТИ СТАВИЛИ ЭТУ СОЦИАЛЬНУЮ ГРУППУ В БОЛЕЕ ВЫГОДНОЕ ПОЛОЖЕНИЕ ПО СРАВНЕНИЮ С ОСТАЛЬНОЙ МАССОЙ ДВОРЯНСТВА ${ }^{46}$. ОЦЕНИТЬ ИНТЕНСИВНОСТЬ РАЗДЕЛОВ ВОТЧИН ТАКЖЕ МОЖНО ПО СТРУКТУРЕ ДВОРЯНСКОГО ДУШЕВЛАДЕНИЯ. РАССМОТРИМ ПЕРИОД МЕЖДУ І И ІІІ РЕВИЗИЯМИ. ПРИ РАСЧЕТАХ ВСЯ СОВОКУПНОСТЬ КРЕПОСТНЫХ, ЧИСЛИВШАЯСЯ ЗА ТЕМ ИЛИ ИНЫМ СОБСТВЕННИКОМ В УЕЗДЕ, УЧИТЫВАЛАСЬ КАК ОДНО ВЛАДЕНИЕ ${ }^{47}$.

\section{7. Структура дворянской собственности в Московском уезде по I и III ревизиям, \%}

\begin{tabular}{|c|c|c|c|c|}
\hline \multirow{2}{*}{ Paзsер втаненини (дуm м.п.) } & \multicolumn{2}{|c|}{ младений } & \multicolumn{2}{|c|}{ душ м.п. } \\
\hline & I pes. & III pes. & I pes. & III рев. \\
\hline круштые (6onee 100) & 15,1 & 18,2 & 71,7 & 62.3 \\
\hline сретние (21-100) & 48,2 & 52,4 & 24,1 & 33,9 \\
\hline меткие $(1-20)$ & 36,7 & 29,4 & 4,2 & 3,8 \\
\hline
\end{tabular}

КАК СЛЕДУЕТ ИЗ ДАННЫХ, ПРЕДСТАВЛЕННЫХ В ТАБЛИЦЕ, ЗА 40 С ЛИШНИМ ЛЕТ ДОЛЯ КРУПНЫХ И СРЕДНИХ ВЛАДЕНИЙ В ПОДМОСКОВЬЕ ВЫРОСЛА, А МЕЛКИХ - СНИЗИЛАСЬ. УДЕЛЬНЫЙ ВЕС КРЕСТЬЯН, ПРОЖИВАВШИХ В КРУПНЫХ ИМЕНИЯХ, СОКРАТИЛСЯ ПРИМЕРНО НА 9 \%. В ОСНОВНОМ, ЭТО ПРОИЗОШЛО ИЗ-ЗА КОНФИСКАЦИИ ВОТЧИН КН. А.Д. МЕНШИКОВА И КН. А.Г. ДОЛГОРУКОВА (15947 ДУШ М.П. ${ }^{48}$, БОЛЕЕ 20 \% ВСЕХ ПОМЕЩИЧЬИХ КРЕСТЬЯН УЕЗДА ПО І РЕВИЗИИ). НАСЕЛЕННОСТЬ МЕЛКИХ ВОТЧИН НЕЗНАЧИТЕЛЬНО УМЕНЬШИЛАСЬ, А ПОЛОЖЕНИЕ ВЛАДЕНИЙ СРЕДНЕГО РАЗМЕРА СТАЛО БОЛЕЕ ПРОЧНЫМ (ДОЛЯ КРЕПОСТНЫХ ВЫРОСЛА ПОЧТИ НА $10 \%$ ). ТАКИМ ОБРАЗОМ, МОЖНО ПРИЙТИ К ВЫВОДУ, ЧТО ДРОБЛЕНИЕ ВОТЧИН (ВО ВСЯКОМ СЛУЧАЕ, В ТЕЧЕНИЕ ПЕРИОДА В 25-40 ЛЕТ) НЕ ОКАЗЫВАЛО СУЩЕСТВЕННОГО ВЛИЯНИЯ НА СТРУКТУРУ СОБСТВЕННОСТИ В МОСКОВСКОМ УЕЗДЕ. ОЧЕВИДНО, ЧТО ЗЕМЛЕВЛАДЕНИЕ ВОКРУГ СТАРОЙ СТОЛИЦЫ ИМЕЛО 
СВОИ ОСОБЕННОСТИ И ПОЛУЧЕННЫЕ РЕЗУЛЬТАТЫ НЕ СЛЕДУЕТ РАСПРОСТРАНЯТЬ НА ДРУГИЕ РЕГИОНЫ СТРАНЫ. ТЕМ НЕ МЕНЕЕ, К ТЕЗИСУ О ПОСТОЯННОМ ДРОБЛЕНИИ И ИЗМЕЛЬЧАНИИ ДВОРЯНСКОЙ СОБСТВЕННОСТИ КАК ДОМИНИРУЮЩЕЙ ТЕНДЕНЦИИ, ПО ВСЕЙ ВИДИМОСТИ, НАДО ОТНОСИТЬСЯ С ОСТОРОЖНОСТЬЮ. ПО ПОДСЧЕТАМ Б.Н. МИРОНОВА, УРОВЕНЬ ИМУЩЕСТВЕННОГО НЕРАВЕНСТВА СРЕДИ ПОМЕЩИКОВ ЕВРОПЕЙСКОЙ РОССИИ В 1678-1858 ГГ. (ОН ОЦЕНИВАЛСЯ ПО РАЗМЕРАМ ДУШЕВЛАДЕНИЯ) ОСТАВАЛСЯ ВЫСОКИМ, НО НЕ ИМЕЛ КАКОЙ-ЛИБО ЧЕТКО ВЫРАЖЕННОЙ ТЕНДЕНЦИИ К РОСТУ ИЛИ СНИЖЕНИЮ ${ }^{49}$. ТАКЖЕ СЛЕДУЕТ УЧИТЫВАТЬ, ЧТО «РЕСУРСЫ РАБОЧЕЙ СИЛЫ МЕДЛЕННЕЕ МЕЛЬЧАЛИ И БЫСТРЕЕ НАРАЩИВАЛИСЬ, ЧЕМ ЗЕМЕЛЬНЫЕ», А ТЕМПЫ ЭТИХ ПРОЦЕССОВ ВАРЬИРОВАЛИСЬ ОТ УЕЗДА К УЕЗДУ ${ }^{50}$.

ПЕРЕЙДЕМ К СЛЕДУЮЩЕМУ ФАКТОРУ, КОТОРЫЙ ВЛИЯЛ НА МОБИЛИЗАЦИЮ СОБСТВЕННОСТИ В ПОДМОСКОВЬЕ. РАНЕЕ УЖЕ ОТМЕЧАЛОСЬ, ЧТО ВСЛЕДСТВИЕ КУПЛИПРОДАЖИ ИЛИ ЗАКЛАДА К ПРЕДСТАВИТЕЛЯМ ДРУГОГО РОДА МЕЖДУ І И II РЕВИЗИЯМИ ПЕРЕШЛО 28,7 \% ВОТЧИН И 13,9 \% КРЕПОСТНЫХ КРЕСТЬЯН. ТЕПЕРЬ ПРОАНАЛИЗИРУЕМ ОБЩИЕ СВЕДЕНИЯ О КУПЛЕ-ПРОДАЖЕ ЗЕМЛИ В МОСКОВСКОМ УЕЗДЕ В ПЕРВОЙ ПОЛОВИНЕ XVIII СТОЛЕТИЯ (ТАБЛИЦА $8^{51}$ ).

\section{8. Купля-продажа земли в Московском уезде, 1714-1750 гг.}

\begin{tabular}{|c|c|c|c|c|c|c|}
\hline \multirow{2}{*}{ Период } & \multicolumn{2}{|c|}{ сделок } & \multicolumn{2}{|c|}{ 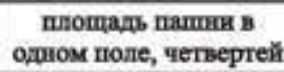 } & \multicolumn{2}{|c|}{ депа, рублей } \\
\hline & scero & $\begin{array}{l}\text { средвеe, } \\
\text { за год }\end{array}$ & Bcero & $\begin{array}{l}\text { среднее, } \\
\text { за год }\end{array}$ & scero & $\begin{array}{l}\text { cpermee, } \\
\text { за rog }\end{array}$ \\
\hline $1714-1724 \mathrm{rr}$ & 184 & 16,7 & 11946 & 1086 & 94750 & 8614 \\
\hline $1725-1729 \pi$ & 90 & 18,0 & 7588 & 1518 & 70186 & 14037 \\
\hline $1730-1740 \mathrm{rr}$ & 132 & 12,0 & 12307 & 1119 & 120218 & 10929 \\
\hline $1741-1750 \mathrm{rr}$. & 90 & 9,0 & 7013 & 701 & 97598 & 9760 \\
\hline irroro & 496 & 13,4 & 38854 & 1050 & 382752 & 10345 \\
\hline
\end{tabular}

ОЧЕВИДНО, ЧТО ИНТЕНСИВНОСТЬ СДЕЛОК С ЗЕМЛЕЙ В МОСКОВСКОМ УЕЗДЕ БЫЛА НЕВЫСОКОЙ. В КРЕПОСТНЫХ КНИГАХ ЗА 37 ЛЕТ БЫЛО ЗАФИКСИРОВАНО ТОЛЬКО 496 КУПЧИХ (ВКЛЮЧАЯ ТЕ, ГДЕ ЗЕМЛЯ ПРОДАВАЛАСЬ С КРЕСТЬЯНАМИ, МЕЛЬНИЦАМИ И «СТРОЕНИЕМ»). В 1714-1729 ГГ. НАБЛЮДАЛАСЬ ПОЛОЖИТЕЛЬНАЯ ДИНАМИКА (16,7-18,0 СДЕЛОК В ГОД). ВПОСЛЕДСТВИИ, ПРИ АННЕ ИОАННОВНЕ $(12,0)$ И ЕЛИЗАВЕТЕ ПЕТРОВНЕ $(9,0)$, ПРОЦЕСС ПОШЕЛ НА СПАД. ПОСЛЕ 1734 Г. ЕЖЕГОДНОЕ ЧИСЛО СДЕЛОК С ЗЕМЛЕЙ НИ РАЗУ НЕ ПРЕВЫШАЛО УРОВЕНЬ 1714 Г., А К 1747-1750 ГГ. СОСТАВЛЯЛО 23,5-41,2 \% ОТ ПОКАЗАТЕЛЕЙ $1714 \Gamma^{52}$ ЭТИ ДАННЫЕ УБЕДИТЕЛЬНО ДОКАЗЫВАЮТ, ЧТО ПЕТРОВСКИЕ ПУНКТЫ 1714 Г. НЕ ОСТАВАЛИСЬ НА БУМАГЕ И В ТОЙ ЧАСТИ, КОТОРАЯ КАСАЛАСЬ НАСЛЕДОВАНИЯ СОБСТВЕННОСТИ, ДЕЙСТВИТЕЛЬНО СОБЛЮДАЛИСЬ ${ }^{53}$. ОДНАКО ПОПЫТКА ГОСУДАРЯ СДЕРЖАТЬ КУПЛЮ-ПРОДАЖУ ИМЕНИЙ С ПОМОЩЬЮ ВЫСОКИХ ПОШЛИН ПО СДЕЛКАМ С ЗЕМЛЕЙ (10 КОПЕЕК С РУБЛЯ ${ }^{54}$ ), СО ВСЕЙ ОЧЕВИДНОСТЬЮ, ПРОВАЛИЛАСЬ. ВВЕДЕНИЕ ПРИНЦИПА ЕДИНОНАСЛЕДИЯ И ПОСЛЕДУЮЩЕЕ РАЗРЕШЕНИЕ БЕЗЗЕМЕЛЬНЫМ ДВОРЯНАМ-«КАДЕТАМ» ПОКУПАТЬ НЕДВИЖИМОСТЬ УСИЛИЛИ МОБИЛИЗАЦИЮ. СХОДНАЯ ЗАКОНОМЕРНОСТЬ ПРОСЛЕЖИВАЕТСЯ ПО СРЕДНИМ ПОКАЗАТЕЛЯМ ПЛОЩАДИ ПРОДАННОЙ ПАШНИ И ЦЕНЫ ВОТЧИН: РОСТ В ПЕРИОД ДЕЙСТВИЯ ПУНКТОВ 1714 Г. СМЕНЯЕТСЯ ПАДЕНИЕМ ПОСЛЕ ОТМЕНЫ УКАЗА. ТАКЖЕ МОЖНО ЗАМЕТИТЬ, ЧТО ПИКОМ КУПЛИПРОДАЖИ СОБСТВЕННОСТИ БЫЛ ПЯТИЛЕТНИЙ ПЕРИОД ПОСЛЕ СМЕРТИ ПЕТРА ВЕЛИКОГО. СРЕДНИЕ ПОКАЗАТЕЛИ 1725-1729 ГГ. (ПО ЧИСЛУ СДЕЛОК И ПАШНЕ) В ДВА РАЗА 
ПРЕВЫШАЮТ АНАЛОГИЧНЫЕ ЦИФРЫ ПО 1741-1750 ГГ. АКТИВНАЯ МОБИЛИЗАЦИЯ ЗЕМЛИ ПРИ ЕКАТЕРИНЕ І И ПЕТРЕ II ОБЪЯСНЯЕТСЯ ИЗМЕНЕНИЯМИ В ЗАКОНОДАТЕЛЬСТВЕ. ТАК, ПО УКАЗУ 14 АПРЕЛЯ 1714 Г. ПОКУПКА НЕДВИЖИМОСТИ ДВОРЯНАМИ-«КАДЕТАМИ» БЫЛА РАЗРЕШЕНА ТОЛЬКО ПО ИСТЕЧЕНИИ «УРОЧНЫХ ЛЕТ» СЛУЖБЫ (7 ЛЕТ ВОИНСКОЙ, 10 ЛЕТ ГРАЖДАНСКОЙ ИЛИ 15 ЛЕТ В «КУПЕЧЕСКОМ ЗВАНИИ») ${ }^{55}$. ПОСЛЕ СМЕРТИ ПЕТРА ВЕЛИКОГО НАЧАЛАСЬ РЕВИЗИЯ УКАЗА О ЕДИНОНАСЛЕДИИ. В СООТВЕТСТВИИ С ПУНКТАМИ 28 МАЯ 1725 Г. РАЗРЕШЕНИЕ НА ПОКУПКУ ДАВАЛОСЬ СРАЗУ ПОСЛЕ ПОСТУПЛЕНИЯ НА СЛУЖБУ. УКАЗ ТАКЖЕ ПОЗВОЛЯЛ ПРОДАЖУ «ОТЕЧЕСКОГО» НАСЛЕДСТВЕННОГО ИМЕНИЯ МЕЖДУ БРАТЬЯМИ В ТОМ СЛУЧАЕ, ЕСЛИ ОНО БЫЛО СПРАВЛЕНО ЗА НИМИ «ВООБЩЕ» (ОБЩЕ) ИЛИ РАЗДЕЛЕНО ПО ЖЕРЕБЬЯМ ДО УКАЗА О ЕДИНОНАСЛЕДИИ ${ }^{56}$.

У НАС ЕСТЬ ВОЗМОЖНОСТЬ СРАВНИТЬ МОСКОВСКИЙ УЕЗД С БОЛЕЕ ЮЖНЫМИ РЕГИОНАМИ СТРАНЫ (ТАБЛИЦА 957). СОСТАВ ЗЕМЛЕВЛАДЕЛЬЦЕВ ЗДЕСЬ ЗНАЧИТЕЛЬНО ОТЛИЧАЛСЯ ОТ СТОЛИЧНОГО УЕЗДА, ПОЭТОМУ ПРИ ПОДСЧЕТАХ УЧИТЫВАЛИСЬ СДЕЛКИ КАК С УЧАСТИЕМ ДВОРЯН, ТАК И ОДНОДВОРЦЕВ.

9. Купля-продажа и заклад земли в южных уездах России в первой половине XVIII века (за один год, по периодам) $)^{*, *}$

\begin{tabular}{|c|c|c|c|c|c|c|c|c|c|c|c|c|}
\hline \multirow[b]{2}{*}{ Уезл ** } & \multicolumn{3}{|c|}{$\begin{array}{l}\text { Haqano } \\
1700-\mathrm{x} \text { rr. }\end{array}$} & \multicolumn{3}{|c|}{$\begin{array}{l}\text { вонец } 1710-x- \\
\text { начало } 1720-x \text { rr. }\end{array}$} & \multicolumn{3}{|c|}{$\begin{array}{l}\text { середина } \\
1740-\mathrm{x} \text { rr. }\end{array}$} & \multicolumn{3}{|c|}{$\begin{array}{c}\text { начало } \\
1760-\mathrm{x} \text { r. }\end{array}$} \\
\hline & $\begin{array}{l}\text { 总 } \\
\text { 总 }\end{array}$ & 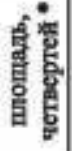 & 啳突 & $\begin{array}{l}\text { 을 } \\
\frac{5}{5} \\
\frac{5}{5}\end{array}$ & 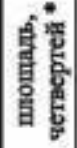 & 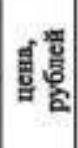 & 붕 & 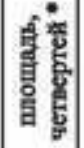 & 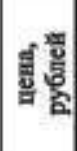 & 흘 & 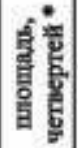 & 형영 \\
\hline Белгород & 22 & 599 & 206 & - & - & - & 35 & 1305 & 5640 & 32 & 657 & 2146 \\
\hline Брянск & - & - & - & 28 & 413 & 1453 & 18 & 108 & 1344 & 1 & 15 & 0 \\
\hline Курек & 39 & 779 & 354 & 201 & 4637 & 1576 & 120 & \begin{tabular}{|l|}
2557 \\
\end{tabular} & 1986 & 147 & 1968 & 1708 \\
\hline Лнвны & - & - & - & - & - & - & 129 & \begin{tabular}{|l|}
2929 \\
\end{tabular} & 1336 & 176 & 2322 & 961 \\
\hline Мценск & 10 & 252 & 106 & 28 & 588 & 363 & 11 & 129 & 247 & 7 & 169 & 94 \\
\hline Prasck & - & - & - & 25 & 274 & 147 & 59 & 1215 & 1633 & 36 & 418 & 1508 \\
\hline CI Ockat & 8 & 102 & 2 & 131 & 2664 & 382 & 51 & 1098 & 301 & 49 & 1034 & 669 \\
\hline Тамбов & 28 & 360 & 172 & 61 & 1112 & 611 & 44 & 1126 & 1108 & 47 & 888 & 355 \\
\hline Шаmк & 12 & 339 & 225 & 48 & 509 & 475 & 132 & $\mid 1242$ & 2065 & 34 & 449 & 3790 \\
\hline
\end{tabular}

КАК ИЗВЕСТНО, ЦЕНТРАЛЬНОЕ ЧЕРНОЗЕМЬЕ ПЕРВОЙ ПОЛОВИНЫ XVIII В. ЯВЛЯЛОСЬ ЗАСЕЛЯЕМЫМ РЕГИОНОМ, ГДЕ ПРОИСХОДИЛ АКТИВНЫЙ РОСТ ДВОРЯНСКОГО ЗЕМЛЕВЛАДЕНИЯ ${ }^{58}$. ПОЭТОМУ НЕ ВСЕГДА МОЖНО ОПРЕДЕЛИТЬ, КАКОЙ ИЗ ФАКТОРОВ ВЛИЯЛ НА ДИНАМИКУ КУПЛИ-ПРОДАЖИ СОБСТВЕННОСТИ - ОСВОЕНИЕ ТЕРРИТОРИИ ИЛИ ЗАКОНОТВОРЧЕСКАЯ ДЕЯТЕЛЬНОСТЬ ПРАВИТЕЛЬСТВА. ТЕМ НЕ МЕНЕЕ, СРАВНЕНИЕ ПОКАЗАТЕЛЕЙ ПО НАЧАЛУ ХVIII В. И РУБЕЖУ 1710-1720-Х ГГ. СВИДЕТЕЛЬСТВУЕТ, ЧТО СЛИЯНИЕ ВОТЧИНЫ И ПОМЕСТЬЯ СУЩЕСТВЕННО РАСШИРИЛО СВОБОДУ РАСПОРЯЖЕНИЯ ЗЕМЛЕЙ И УСИЛИЛО ЕЕ МОБИЛИЗАЦИЮ. СВЕДЕНИЯМИ ПО МОСКОВСКОМУ УЕЗДУ ДО 1714 Г. МЫ НЕ РАСПОЛАГАЕМ. НО ПОСЛЕ ПРИНЯТИЯ УКАЗА О ЕДИНОНАСЛЕДИИ СДЕЛКИ С НЕДВИЖИМОСТЬЮ В ЮЖНЫХ УЕЗДАХ СТРАНЫ СОВЕРШАЛИСЬ ГОРАЗДО ЧАЩЕ, ЧЕМ В ПОДМОСКОВЬЕ (В СТАРООСКОЛЬСКОМ И КУРСКОМ УЕЗДАХ - В 7,8-12 РАЗ, В БРЯНСКОМ, МЦЕНСКОМ, РЯЖСКОМ, ТАМБОВСКОМ И ШАЦКОМ - В 1,5-3,6 РАЗА). В ОТДЕЛЬНЫХ ЧЕРНОЗЕМНЫХ УЕЗДАХ ЗА 3-4 ГОДА ЗАКЛЮЧАЛОСЬ СТОЛЬКО ЖЕ СДЕЛОК, СКОЛЬКО В МОСКОВСКОМ УЕЗДЕ ЗА ВЕСЬ 40-ЛЕТНИЙ ПЕРИОД. ПО ПЛОЩАДИ ПРОДАННОЙ ПАШНИ МОСКОВСКИЙ УЕЗД ОПЕРЕЖАЛ БРЯНСКИЙ, МЦЕНСКИЙ, РЯЖСКИЙ И ШАЦКИЙ УЕЗДЫ, БЫЛ 
НА ОДНОМ УРОВНЕ С ТАМБОВСКИМ, НО ОТСТАВАЛ ОТ СТАРООСКОЛЬСКОГО И КУРСКОГО (В 2,5-4,3 РАЗА). К СЕРЕДИНЕ 1740-Х ГГ. РАЗРЫВ ПО ЧИСЛУ СДЕЛОК МЕЖДУ МОСКОВСКИМ И ЮЖНЫМИ УЕЗДАМИ СТАЛ ЕЩЕ БОЛЬШЕ. В КУРСКОМ, ЛИВЕНСКОМ И ШАЦКОМ УЕЗДАХ КУПЛЯ-ПРОДАЖА И ЗАКЛАД ЗЕМЛИ ПРОИСХОДИЛИ В $13,3-14,7$ РАЗА ЧАЩЕ. С ОСТАЛЬНЫМИ УЕЗДАМИ ЦЕНТРАЛЬНОГО ЧЕРНОЗЕМЬЯ РАЗНИЦА СОСТАВЛЯЛА 1,2-6,6 РАЗА. ПО ОБЩЕЙ ПЛОЩАДИ ПРОДАВАЕМЫХ ПАХОТНЫХ УГОДИЙ СТОЛИЧНЫЙ УЕЗД В $1740-$ Х ГГ. УЖЕ ОТСТАВАЛ ОТ 7 ИЗ 9 ЮЖНЫХ УЕЗДОВ (КРОМЕ БРЯНСКОГО И МЦЕНСКОГО), ПРИЧЕМ ОТ КУРСКОГО И ЛИВЕНСКОГО В 3,6-4,2 РАЗА. ТЕМ НЕ МЕНЕЕ, СДЕЛКИ С ЗЕМЛЕЙ В МОСКОВСКОМ УЕЗДЕ БЫЛИ СУЩЕСТВЕННО КРУПНЕЕ, ЧЕМ НА ЮГЕ СТРАНЫ. В СТОЛИЧНОМ УЕЗДЕ В СРЕДНЕМ НА ОДНУ СДЕЛКУ ПРИХОДИЛОСЬ 78 ЧЕТВЕРТЕЙ ПАШНИ (ПО ДАННЫМ, 1714-1750 ГГ. $\left.{ }^{59}\right)$, А В ЦЕНТРАЛЬНОМ ЧЕРНОЗЕМЬЕ - 18 ЧЕТВЕРТЕЙ. ЕЩЕ ОДНИМ ПОКАЗАТЕЛЕМ, ПО КОТОРОМУ ПОДМОСКОВЬЕ ОПЕРЕЖАЛО ЧЕРНОЗЕМНЫЕ УЕЗДЫ, БЫЛА ЦЕНА ВОТЧИН. ЭТО ОБЪЯСНИМО, ПОСКОЛЬКУ НА ЮГЕ СТРАНЫ ЗЕМЛЯ ОБЫЧНО ПРОДАВАЛАСЬ БЕЗ КРЕПОСТНЫХ И «СТРОЕНИЯ» (ИХ ЦЕНА БЫЛА ВЫШЕ СТОИМОСТИ ЗЕМЛИ $\left.{ }^{60}\right)$. НАПРОТИВ, В СТОЛИЧНОМ УЕЗДЕ ЭТОТ ВИД СДЕЛОК ВСТРЕЧАЛСЯ РЕДКО. ДЕФИЦИТ ЗЕМЛИ В СТАРОЗАСЕЛЕННОМ МОСКОВСКОМ УЕЗДЕ ТАКЖЕ СПОСОБСТВОВАЛ РОСТУ ЦЕН. СРЕДНЯЯ СТОИМОСТЬ ЧЕТВЕРТИ ПАХОТНОЙ ЗЕМЛИ (С КРЕПОСТНЫМИ И «СТРОЕНИЕМ») В СТОЛИЧНОМ РЕГИОНЕ В 1714-1750 ГГ. ДОСТИГАЛА 10 РУБЛЕЙ ${ }^{61}$. ДЛЯ СРАВНЕНИЯ, В КУРСКОМ УЕЗДЕ ЧЕТВЕРТЬ ПАШНИ «С УГОДЬЯМИ», НО БЕЗ КРЕПОСТНЫХ КРЕСТЬЯН, «МЕЛЬНИЧНЫХ ЖЕРЕБЬЕВ» И «КАМЕННОГО СТРОЕНИЯ», В ПЕРВОЙ ПОЛОВИНЕ XVIII В. ОЦЕНИВАЛАСЬ В 28-69 КОПЕЕК.

РАНЕЕ УЖЕ ОТМЕЧАЛОСЬ, ЧТО ДИНАМИКА МОБИЛИЗАЦИИ ЗЕМЛИ В ЦЕНТРАЛЬНОМ ЧЕРНОЗЕМЬЕ ЗАВИСЕЛА ОТ МНОГИХ ФАКТОРОВ. ТАБЛИЦА 9 ПОЗВОЛЯЕТ ВЫЯВИТЬ ОПРЕДЕЛЕННУЮ ЗАКОНОМЕРНОСТЬ. БОЛЕЕ НИЗКИЕ ТЕМПЫ КУПЛИ-ПРОДАЖИ СОБСТВЕННОСТИ СВОЙСТВЕННЫ ЗАПАДНЫМ БРЯНСКОМУ И МЦЕНСКОМУ УЕЗДАМ И, В ОПРЕДЕЛЕННОЙ МЕРЕ, ШАЦКОМУ И РЯЖСКОМУ, КОТОРЫЕ РАСПОЛАГАЛИСЬ НА СЕВЕРОВОСТОКЕ РЕГИОНА. ВСЕ ПЕРЕЧИСЛЕННЫЕ УЕЗДЫ НАХОДИЛИСЬ СЕВЕРНЕЕ ЛИНИИ «ЗАКАЗНЫХ ГОРОДОВ» $1681 \Gamma^{62}$, КОТОРЫЕ В КОНЦЕ XVII СТОЛЕТИЯ ЯВЛЯЛИСЬ ЮЖНОЙ ГРАНИЦЕЙ РАСПРОСТРАНЕНИЯ ДВОРЯНСКОГО ЗЕМЛЕВЛАДЕНИЯ ${ }^{63}$. ТАКИМ ОБРАЗОМ, ПОУЕЗДНЫЕ РАЗЛИЧИЯ В ТЕМПАХ МОБИЛИЗАЦИИ СОБСТВЕННОСТИ ВО МНОГОМ ОБЪЯСНЯЮТСЯ ОБЩЕЙ НАПРАВЛЕННОСТЬЮ «КОЛОНИЗАЦИИ» ЦЕНТРАЛЬНОГО ЧЕРНОЗЕМЬЯ: С СЕВЕРА НА ЮГ И С ЗАПАДА НА ВОСТОК. ПРИЧИНЫ НИЗКОЙ ИНТЕНСИВНОСТИ КУПЛИ-ПРОДАЖИ ЗЕМЛИ В СТАРООСВОЕННОМ ИСТОРИЧЕСКОМ ЦЕНТРЕ СТРАНЫ (МОСКОВСКОМ УЕЗДЕ) С ЭТОЙ ТОЧКИ ЗРЕНИЯ ВПОЛНЕ ОЧЕВИДНЫ.

В ЗАКЛЮЧЕНИЕ РАССМОТРИМ ФАКТОРЫ МОБИЛИЗАЦИИ, КОТОРЫЕ БЫЛИ СВЯЗАНЫ С ВМЕШАТЕЛЬСТВОМ ВЕРХОВНОЙ ВЛАСТИ - ПОЖАЛОВАНИЕ И КОНФИСКАЦИЮ. КАК ПРАВИЛО ОНИ КАСАЛИСЬ ВЛАДЕНИЙ ПРАВЯЩЕЙ ЭЛИТЫ СТРАНЫ И ЗАТРАГИВАЛИ НЕЗНАЧИТЕЛЬНОЕ ЧИСЛО ВОТЧИН (1,2\% И 2,6\%, СООТВЕТСТВЕННО). В ТО ЖЕ САМОЕ ВРЕМЯ, ИХ ВОЗДЕЙСТВИЕ НА БЛАГОСОСТОЯНИЕ ОТДЕЛЬНЫХ ФАМИЛИЙ БЫЛО ОЧЕНЬ СУЩЕСТВЕННЫМ, А МАСШТАБЫ ОТПИСКИ ИМЕНИЙ В КАЗНУ ПОЧТИ В ШЕСТЬ РАЗ ПРЕВОСХОДИЛИ РАЗМЕРЫ ПОЖАЛОВАНИЙ. ТАК, В КОНФИСКОВАННЫХ ВОТЧИНАХ ПРОЖИВАЛО 18829 ДУШ М.П. (28,6 \% ПОМЕЩИЧЬИХ КРЕСТЬЯН), А В ПОЖАЛОВАННЫХ 3208 ДУШ М.П. (4,9 \%). НАИБОЛЕЕ ЗНАЧИТЕЛЬНЫЕ ВЛАДЕНИЯ БЫЛИ ОТПИСАНЫ У КН. А.Г. ДОЛГОРУКОВА (ХАТУНСКАЯ ВОЛОСТЬ ${ }^{64}$ ), КН. А.Д. МЕНШИКОВА (ГУСЛИЦКАЯ, ГВОЗДИНСКАЯ, ДОМОДЕДОВСКАЯ, ЕРМОЛИНСКАЯ, МЯЧКОВСКАЯ ВОЛОСТИ), ГР. П.И. МУСИНА-ПУШКИНА (РАМЕНСКАЯ ВОЛОСТЬ ${ }^{65}$ ) И ГР. М.Г. ГОЛОВКИНА (РОСТОВСКАЯ 
ВОЛОСТЬ $\left.{ }^{66}\right)$. СРЕДИ КРУПНЫХ ПОЖАЛОВАНИЙ ИЗ ДВОРЦОВЫХ ВЛАДЕНИЙ СЛЕДУЕТ НАЗВАТЬ ВОТЧИНЫ ГР. П.И. ЯГУЖИНСКОГО (СЕЛО ПАВЛОВСКОЕ С ДЕРЕВНЯМИ ${ }^{67}$; КО ВРЕМЕНИ ВТОРОЙ РЕВИЗИИ УНАСЛЕДОВАНЫ СЫНОМ СЕРГЕЕМ) И ГР. С.А. САЛТЫКОВА (СЕЛО СИНЬКОВО С ДЕРЕВНЯМИ ${ }^{6}$; УНАСЛЕДОВАНЫ СЫНОВЬЯМИ ПЕТРОМ И ВЛАДИМИРОМ). ПОСКОЛЬКУ СТРУКТУРА СЕЛЬСКОГО РАССЕЛЕНИЯ В МОСКОВСКОМ УЕЗДЕ СЛОЖИЛАСЬ ДОСТАТОЧНО ДАВНО, ТО ВПОЛНЕ ПРЕДСКАЗУЕМО, ЧТО ДОЛЯ ВНОВЬПОСЕЛЕННЫХ ВОТЧИН ОКАЗАЛАСЬ НЕЗНАЧИТЕЛЬНОЙ (0,7\% ВЛАДЕНИЙ И 0,2\% ДУШ М.П.). КАКИХ-ЛИБО ЗАМЕТНЫХ ИЗМЕНЕНИЙ В РАССЕЛЕНИИ ПОМЕЩИЧЬИХ КРЕСТЬЯН ПО ТЕРРИТОРИИ УЕЗДА НЕ БЫЛО. ПРИ СРАВНЕНИИ ДВУХ РЯДОВ ДАННЫХ (ЧИСЛО ДУШ М.П. В КАЖДОМ ВЛАДЕНИИ ПО I И II РЕВИЗИИ $\left.{ }^{69}\right)$ МЫ ВИДИМ ЗАВИСИМОСТЬ ОЧЕНЬ БЛИЗКУЮ К ЛИНЕЙНОЙ $(r=0,96)$. СРАВНЕНИЕ ОСНОВНЫХ СПОСОБОВ МОБИЛИЗАЦИИ ИМЕНИЙ И СТРУКТУРЫ ВЛАДЕНИЙ (В ЗАВИСИМОСТИ ОТ ИХ РАЗМЕРА) ПОЗВОЛЯЕТ ГОВОРИТЬ О ПЯТИ МОДЕЛЯХ МОБИЛИЗАЦИИ СОБСТВЕННОСТИ. ПЕРВЫЕ ДВЕ МОДЕЛИ - НАСЛЕДОВАНИЕ РОДСТВЕННИКОМ (В Т. Ч. НОСИВШИМ ДРУГУЮ ФАМИЛИЮ) И ПЕРЕХОД К ИНОРОДЦУ (В РЕЗУЛЬТАТЕ КУПЛИ ПРОДАЖИ ИЛИ ЗАКЛАДА) - БЫЛИ ДОСТАТОЧНО БЛИЗКИ ПО СТРУКТУРНЫМ ХАРАКТЕРИСТИКАМ. ЗДЕСЬ, КАК ПРАВИЛО, ВСТРЕЧАЛИСЬ МЕЛКИЕ (1-20 ДУШ М.П.) И СРЕДНИЕ (21-100 ДУШ М.П.) ИМЕНИЯ: СРЕДИ РОДСТВЕННИКОВ - $41 \%$ И $45 \%$, СРЕДИ ИНОРОДЦЕВ - 45 \% И $49 \%$, СООТВЕТСТВЕННО. ОДНАКО БЫЛО И ОТЛИЧИЕ: КРУПНЫЕ ВЛАДЕНИЯ (БОЛЕЕ 100 ДУШ М.П.) ПЕРЕХОДИЛИ К ИНОРОДЦАМ РЕЖЕ (6 \% ПРОТИВ 14 \%). ТРЕТЬЯ И ЧЕТВЕРТАЯ МОДЕЛИ МОБИЛИЗАЦИИ - ОТПИСКА И ПОЖАЛОВАНИЕ РАЗИТЕЛЬНО ОТЛИЧАЛИСЬ КАК ОТ ВЫШЕУКАЗАННЫХ МОДЕЛЕЙ, ТАК И ДРУГ ОТ ДРУГА. КОНФИСКАЦИИ В ОСНОВНОМ ПОДВЕРГАЛИСЬ СРЕДНИЕ (39\%) И КРУПНЫЕ (43\%) ВОТЧИНЫ. ЖАЛОВАЛИСЬ ПО ПРЕИМУЩЕСТВУ КРУПНЫЕ ИМЕНИЯ (82\%). СРЕДИ ВНОВЬПОСЕЛЕННЫХ ВОТЧИН (ПЯТАЯ МОДЕЛЬ) КРУПНЫХ ВЛАДЕНИЙ НЕ ВСТРЕЧАЛОСЬ ВОВСЕ, МЕЛКИХ НАСЧИТЫВАЛОСЬ 33 \%, СРЕДНИХ - 67 \%. НАЛИЧИЕ СУЩЕСТВЕННЫХ СТРУКТУРНЫХ РАЗЛИЧИЙ МЕЖДУ УКАЗАННЫМИ МОДЕЛЯМИ ТАКЖЕ ПОДТВЕРЖДАЕТСЯ СТАТИСТИЧЕСКИ С ПОМОЩЬЮ МЕТОДА АНАЛИЗА СООТВЕТСТВИЙ (correspondence analysis) ${ }^{70}$

ПОДВЕДЕМ ОСНОВНЫЕ ИТОГИ. ОЧЕВИДНО, ЧТО СОВОКУПНОЕ ВОЗДЕЙСТВИЕ ФАКТОРОВ, СНИЖАВШИХ СТАБИЛЬНОСТЬ ДВОРЯНСКОГО ЗЕМЛЕВЛАДЕНИЯ (КУПЛЯ-ПРОДАЖА, ЗАКЛАД, КОНФИСКАЦИЯ, ПОЖАЛОВАНИЕ), БЫЛО ОЧЕНЬ СУЩЕСТВЕННЫМ. ЗА 25 ЛЕТ СОБСТВЕННИКОВ СМЕНИЛА ТРЕТЬЯ ЧАСТЬ ВОТЧИН МОСКОВСКОГО УЕЗДА (32,5\%) И ПОЛОВИНА КРЕСТЬЯН $(47,4 \%)$. ОДНАКО СЛЕДУЕТ ПРИЗНАТЬ, ЧТО РАЗВИТИЕ СОБСТВЕННОСТИ ВОКРУГ СТАРОЙ СТОЛИЦЫ НЕ ВПОЛНЕ СООТВЕТСТВУЕТ РАСПРОСТРАНЕННОМУ В ЛИТЕРАТУРЕ МНЕНИЮ О ЧАСТОМ ДРОБЛЕНИИ, ИЗМЕЛЬЧАНИИ И ПОСТОЯННОЙ КУПЛЕ-ПРОДАЖЕ НАСЕЛЕННЫХ ИМЕНИЙ. НАПРОТИВ, ПОДМОСКОВНОМУ ЗЕМЛЕВЛАДЕНИЮ УДАЛОСЬ СОХРАНИТЬ ОЧЕНЬ ВЫСОКИЙ УРОВЕНЬ УСТОЙЧИВОСТИ И ПРЕДСКАЗУЕМОСТИ РАЗВИТИЯ $(r=0,83)$. ЭТОМУ СПОСОБСТВОВАЛ ЦЕЛЫЙ РЯД ПРИЧИН. ТАК, КУПЛЯ-ПРОДАЖА И ЗАКЛАД МОГЛИ ПРИВЕСТИ К ЗНАЧИТЕЛЬНОМУ ПЕРЕРАСПРЕДЕЛЕНИЮ ЗЕМЕЛЬНОГО ФОНДА ТОЛЬКО В ДОЛГОСРОЧНОЙ ПЕРСПЕКТИВЕ. В РАМКАХ ОДНОГО ПОКОЛЕНИЯ ТАКИХ ПОСЛЕДСТВИЙ НЕ НАБЛЮДАЛОСЬ (ПО ЭТИМ ПРИЧИНАМ ИЗ РУК В РУКИ ПЕРЕШЛО ЛИШЬ 13,9\% КРЕПОСТНЫХ). РИСК ДРОБЛЕНИЯ ВЛАДЕЛЬЧЕСКИХ КОМПЛЕКСОВ ПРИ НАСЛЕДОВАНИИ БЫЛ НИЗКИМ ИЗ-ЗА НАЛИЧИЯ ЗНАЧИТЕЛЬНЫХ ЗЕМЕЛЬНЫХ РЕСУРСОВ, ПРИНАДЛЕЖАВШИХ МОСКОВСКОМУ ДВОРЯНСТВУ (В ТОМ ЧИСЛЕ, ЗА ПРЕДЕЛАМИ СТОЛИЧНОГО УЕЗДА). ПОЖАЛОВАНИЕ И КОНФИСКАЦИЯ НОСИЛИ ЧРЕЗВЫЧАЙНЫЙ, ИЗБИРАТЕЛЬНЫЙ ХАРАКТЕР И $\mathrm{HE} \mathrm{ВЛИЯЛИ} \mathrm{НА}$ 
ИМУЩЕСТВЕННУЮ СОСТОЯТЕЛЬНОСТЬ ОСНОВНОЙ МАССЫ ДВОРЯНСКИХ ФАМИЛИЙ. ОДНИМ ИЗ ВАЖНЕЙШИХ ФАКТОРОВ УСТОЙЧИВОСТИ РОДОВОГО ЗЕМЕЛЬНОГО ФОНДА БЫЛ СОЦИАЛЬНЫЙ СОСТАВ ВЛАДЕЛЬЦЕВ - ПОТОМКОВ МОСКОВСКИХ ДВОРЯН И ДУМНЫХ ЧИНОВ. ТРАДИЦИОННАЯ БЛИЗОСТЬ ЭТОГО СЛОЯ К ВЛАСТИ И ПРЕЕМСТВЕННОСТЬ КАДРОВОЙ ПОЛИТИКИ ГОСУДАРЕЙ XVII-ПЕРВОЙ ПОЛОВИНЫ XVIII ВВ. ПРИ ФОРМИРОВАНИИ ПРАВЯЩЕЙ ЭЛИТЫ СТРАНЫ БЛАГОПРИЯТНО СКАЗЫВАЛИСЬ НА РАЗВИТИИ СОБСТВЕННОСТИ.

ИНЕРЦИОННЫЙ ТИП ЭВОЛЮЦИИ ПОДМОСКОВЬЯ РЕЗКО КОНТРАСТИРОВАЛ С ДИНАМИЧНЫМ РАЗВИТИЕМ САНКТ-ПЕТЕРБУРГСКОГО РЕГИОНА. ВЗАИМОСВЯЗЬ ВЛАСТИ И СОБСТВЕННОСТИ ЗДЕСЬ ПРОЯВЛЯЛАСЬ ОСОБЕННО ЯРКО, А СТРУКТУРА ЗЕМЛЕВЛАДЕНИЯ НА ЭТОЙ ТЕРРИТОРИИ ОТРАЖАЛА ОСНОВНЫЕ ПЕРЕМЕНЫ В СОСТАВЕ ПРАВЯЩЕГО СЛОЯ ПЕРВОЙ ПОЛОВИНЫ XVIII СТОЛЕТИЯ. НАПРОТИВ, МОСКОВСКИЙ УЕЗД ДАЖЕ К СЕРЕДИНЕ ВЕКА ПРОДОЛЖАЛ ОСТАВАТЬСЯ ЦЕНТРОМ ЗЕМЛЕВЛАДЕНИЯ ТРАДИЦИОННОЙ ЭЛИТЫ ДОПЕТРОВСКОЙ ЭПОХИ. ВОТЧИННЫЙ ФОНД ДУМНЫХ ФАМИЛИЙ ОТЛИЧАЛСЯ ВЫСОКИМ УРОВНЕМ СТАБИЛЬНОСТИ, А ПРЕДСТАВИТЕЛИ ЭТОГО СЛОЯ НЕИЗМЕННО ПОЛЬЗОВАЛИСЬ ПРИОРИТЕТОМ ПРИ НАЗНАЧЕНИИ НА ВЫСШИЕ ГОСУДАРСТВЕННЫЕ ПОСТЫ.

\section{ANNEXES}

\section{. Алфавитные списки помещиков Московского уезда и Ингерманландии}

В ПРИЛОЖЕНИИ ПРИВОДЯТСЯ АЛФАВИТНЫЕ СПИСКИ ПОМЕЩИКОВ МОСКОВСКОГО УЕЗДА И ИНГЕРМАНЛАНДИИ (САНКТ-ПЕТЕРБУРГСКИЙ, ШЛИССЕЛЬБУРГСКИЙ, КОПОРСКИЙ, ЯМБУРГСКИЙ УЕЗДЫ) С УКАЗАНИЕМ ПРИНАДЛЕЖАВШЕГО ИМ ЧИСЛА КРЕПОСТНЫХ ${ }^{71}$. ПО МОСКОВСКОМУ УЕЗДУ ИСТОЧНИКАМИ ПОСЛУЖИЛИ ВЕДОМОСТИ РЕКРУТСКОГО НАБОРА 1737-1738 ГГ., СОСТАВЛЕННЫЕ ПО МАТЕРИАЛАМ І РЕВИЗИИ, ПЕРЕПИСНЫЕ КНИГИ ІІ РЕВИЗИИ И СКАЗКИ ІІІ РЕВИЗИИ. ПО УЕЗДАМ ИНГЕРМАНЛАНДИИ ИСПОЛЬЗОВАНЫ МАТЕРИАЛЫ ПЕРЕПИСИ ГВАРДИИ МАЙОРА И.А. ШИПОВА 1732-1733 ГГ., ПЕРЕПИСНЫЕ КНИГИ ІІ РЕВИЗИИ И «ПРОКУРОРСКИЕ ВЕДОМОСТИ» III РЕВИЗИИ, СОСТАВЛЕННЫЕ ПО ЗАПРОСУ ГЕНЕРАЛ-ПРОКУРОРА КН. А.А. ВЯЗЕМСКОГО. ПРИ ПОДСЧЕТАХ УЧТЕНЫ ТОЛЬКО ТЕ КРЕСТЬЯНЕ, КОТОРЫЕ ПРОЖИВАЛИ НА «УЕЗДНЫХ ЗЕМЛЯХ» (БЕЗ ДВОРОВЫХ ЛЮДЕЙ, ЧИСЛИВШИХСЯ ПО ГОРОДАМ).

ВЛАДЕЛЬЦЫ ВОТЧИН И КОЛИЧЕСТВО КРЕПОСТНЫХ ПО ВЕДОМОСТИ 1737-1738 ГГ. УКАЗАНЫ НА ВРЕМЯ І РЕВИЗИИ. «ПРИБЫЛЫЕ» ПОСЛЕ ПЕРЕПИСИ ДУШИ М.П., ОСТАВШИЕСЯ «ЗА РАСПОЛОЖЕНИЕМ ПОЛКОВ», ПРИ ПОДСЧЕТАХ НЕ УЧИТЫВАЛИСЬ. ИЗ-ЗА ОСОБЕННОСТЕЙ ИСТОЧНИКА ЧИНЫ ВЛАДЕЛЬЦЕВ ИМЕНИЙ МОГУТ БЫТЬ УКАЗАНЫ КАК НА ВРЕМЯ I РЕВИЗИИ, ТАК И НА МОМЕНТ СОСТАВЛЕНИЯ ВЕДОМОСТИ. 
ОСНОВНОЙ ФОРМАТ ЗАПИСИ В ПУБЛИКУЕМЫХ ПЕРЕЧНЯХ СЛЕДУЮЩИЙ: ФИО, ЧИН ЧИСЛО ДУШ М.П. НАПРИМЕР: ШЕРЕМЕТЕВ АЛЕКСЕЙ ФЕДОРОВИЧ, ГЕНЕРАЛ-МАЙОР, ГЕНЕРАЛ-ПРОВИАНТМЕЙСТЕР, КАВАЛЕР - 82. В ИНГЕРМАНЛАНДИИ ЧИСЛО ДУШ М.П. ДАНО РАЗДЕЛЬНО ПО КАЖДОМУ ИЗ УЕЗДОВ (ИХ НАЗВАНИЯ СОКРАЩЕНЫ). НАПРИМЕР: ПАШКОВ ЕГОР ИВАНОВИЧ, БРИГАДИР, КАПИТАН ЛЕЙБ-ГВАРДИИ ПРЕОБРАЖЕНСКОГО ПОЛКА, ВОРОНЕЖСКИЙ ВИЦЕ-ГУБЕРНАТОР, КОП. - 43, ШЛ. - 91.

ЧАСТЬ ЗАПИСЕЙ СОДЕРЖИТ ДОПОЛНИТЕЛЬНЫЕ СВЕДЕНИЯ, КОТОРЫЕ УКАЗЫВАЮТСЯ В СКОБКАХ: ФИО И ЧИНЫ БЛИЖАЙШИХ РОДСТВЕННИКОВ ВЛАДЕЛЬЦА, ФАМИЛИЮ ВЛАДЕЛИЦЫ ДО ЗАМУЖЕСТВА И Т.Д. ПОВТОРЫ ФАМИЛИЙ В ОДНОЙ И ТОЙ ЖЕ ЗАПИСИ ОБЫЧНО СОКРАЩЕНЫ ДО ИНИЦИАЛА. НАПРИМЕР: ХУДЯКОВА (УРОЖД. ЖЕЛТУХИНА) АННА ГРИГОРЬЕВНА (Х. АВРАМ ИВАНОВИЧ - МУЖ, БЫВШИЙ НАДСМОТРЩИК МОСКОВСКОЙ КРЕПОСТНОЙ КОНТОРЫ; Ж. ГРИГОРИЙ ЯКОВЛЕВИЧ - ОТЕЦ, БРИГАДИР) - 17

В ТОМ СЛУЧАЕ ЕСЛИ СЛОВО В ИСТОЧНИКЕ ЧИТАЕТСЯ НЕУВЕРЕННО, ОНО ПОМЕЧЕНО ЗНАКОМ ВОПРОСА (?). ПРОПУСКИ ТЕКСТА ОТМЕЧАЮТСЯ ЗНАКОМ ВОПРОСА В УГЛОВЫХ СКОБКАХ $<$ ? $>$.

В СПИСКАХ ПРИНЯТЫ СЛЕДУЮЩИЕ СОКРАЩЕНИЯ: БАР. - БАРОН (БАРОНЕССА), ГР. - ГРАФ (ГРАФИНЯ), КН. - КНЯЗЬ (КНЯГИНЯ), КЖ. - КНЯЖНА, ГУБ. - ГУБЕРНИЯ, ЕИВ - ЕГО (ЕЕ) ИМПЕРАТОРСКОЕ ВЕЛИЧЕСТВО, УРОЖД. - УРОЖДЕННАЯ, СПБ. - САНКТ-ПЕТЕРБУРГСКИЙ, ШЛ. - ШЛИССЕЛЬБУРГСКИЙ, КОП. - КОПОРСКИЙ, ЯМБ. - ЯМБУРГСКИЙ УЕЗДЫ.

\section{Московский уезд, I ревизия}

АВГУСТОВ САВВА ВАСИЛЬЕВИЧ, СЛУЖИТЕЛЬ ДОМА КН. А.Д. МЕНШИКОВА - 10

АКИНФИЕВ (АКИНФОВ) НИКИТА ИВАНОВИЧ, ОКОЛЬНИЧИЙ - 75

АКИНФИЕВ НИКОЛАЙ ПЕТРОВИЧ - 61

АКИНФИЕВА ИРИНА ИВАНОВНА, ВДОВА - 101

АЛАДЬИН МИХАИЛ ФЕДОРОВИЧ, КАПРАЛ ЛЕЙБ-ГВАРДИИ ПРЕОБРАЖЕНСКОГО ПОЛКА - 64

АЛЕКСЕЕВ ИВАН АНТОНОВИЧ, ПОРУЧИК - 9

АЛЕКСЕЕВ МАТВЕЙ ДМИТРИЕВИЧ, МАЙОР - 62

АЛМАЗОВ ИВАН ДМИТРИЕВИЧ, СТОЛЬНИК - 38

АЛМАЗОВ ИВАН СЕМЕНОВИЧ, КАПИТАН - 71

АЛСУФЬЕВ МАТВЕЙ ДМИТРИЕВИЧ, ОБЕР-ГОФМЕЙСТЕР, «МАРШАЛОК» - 381

АНДРЕЕВСКИЙ АЛЕКСЕЙ ИВАНОВИЧ, ПОДЬЯЧИЙ АДМИРАЛТЕЙСКОЙ КАНЦЕЛЯРИИ - 14

АНИКИЕВ ФИЛИМОН, «СПБ ЖИТЕЛЬ» - 5

АНИЧКОВ МИХАИЛ СТЕПАНОВИЧ, ПОДПОЛКОВНИК - 86

АНИЧКОВЫ ИВАН, СТОЛЬНИК И ИВАН ИВАНОВИЧИ - 8

АПРАКСИН АНДРЕЙ МАТВЕЕВИЧ, ГР. - 442

АПРАКСИН ПЕТР МАТВЕЕВИЧ, ГР., ПРЕЗИДЕНТ, БОЯРИН - 521 
АПРАКСИН ФЕДОР МАТВЕЕВИЧ, ГР., ГЕНЕРАЛ-АДМИРАЛ, ДЕЙСТВИТЕЛЬНЫЙ ТАЙНЫЙ СОВЕТНИК, КАВАЛЕР - 445

АПУХТИН ВАСИЛИЙ АНДРЕЕВИЧ - 44

АПУХТИН ПЕТР ИВАНОВИЧ - 39

АПУХТИН СТЕПАН ТИМОФЕЕВИЧ, ПОДПОЛКОВНИК - 26

АСТАФЬЕВ ВАСИЛИЙ ИВАНОВИЧ, ФЕНДРИК ЛЕЙБ-ГВАРДИИ ПРЕОБРАЖЕНСКОГО ПОЛКА - 14 АСТАФЬЕВ ЯКОВ, КОМИССАР - 1

БАБИЧЕВ ИВАН ВАСИЛЬЕВИЧ, КН., КАПИТАН - 13

БАЛК-ПОЛЕВ (ПОЛЕВ) ПЕТР ФЕДОРОВИЧ, ЛЕЙБ-ГВАРДИИ ПРЕОБРАЖЕНСКОГО ПОЛКА ЛЕЙТЕНАНТ - 142

БАРБИН НИКИФОР ЗИНОВЬЕВИЧ, КАНЦЕЛЯРИСТ - 4

БАРТЕНЕВ АРТАМОН ФЕДОРОВИЧ, ПОРУЧИК - 10

БАРТЕHEB CEMEH - 15

БАРЯТИНСКАЯ ПРАСКОВЬЯ ИВАНОВНА, КН., ВДОВА (Б. СЕМЕН, КН. - МУЖ) - 92

БАРЯТИНСКИЙ ДАНИЛА ИВАНОВИЧ, КН. - 8

БАРЯТИНСКИЙ ИВАН ФЕДОРОВИЧ, КН., ГЕНЕРАЛ-МАЙОР, ЗАТЕМ ГЕНЕРАЛ-ЛЕЙТЕНАНТ, КАВАЛЕР - 464

БАСКАКОВ ОСИП ПЕТРОВИЧ, СТРЕМЯННОЙ КОНЮХ - 5

БАУТИН МИХАИЛ - 10

БАХМЕТЕВ АЛЕКСАНДР СТЕПАНОВИЧ - 13

БАХМЕТЕВ ИВАН ЮРЬЕВИЧ - 42

БАШМАКОВА НАТАЛЬЯ ПЕТРОВНА, ВДОВА - 15

БЕЗОБРАЗОВ ИВАН АЛЕКСЕЕВИЧ - 25

БЕКЛЕМИШЕВ ГРИГОРИЙ ИСАЕВИЧ, ПОРУЧИК - 27

БЕКЛЕМИШЕВ ПЕТР ИВАНОВИЧ - 64

БЕКЛЕМИШЕВА ПРАСКОВЬЯ АЛЕКСАНДРОВНА, ВДОВА (Б. АЛЕКСАНДР - МУЖ) - 39

БЕЛЕВЦОВ ФЕДОР ФЕДОРОВИЧ, СТРЯПЧИЙ МОСКОВСКОЙ ПОТЕШНОЙ КОНЮШНИ - 1

БЕЛОШЕНСКИЙ АЛЕКСАНДР МИХАЙЛОВИЧ - 17

БЕЛЯЕВ МАКАР СТЕПАНОВИЧ, СЕКРЕТАРЬ - 77

БЕРЕЗНИКОВЫ ФЕДОР И ИВАН ИВАНОВИЧИ - 11

БЕСТУЖЕВА АКУЛИНА СЕРГЕЕВНА, ВДОВА (Б. СЕМЕН - МУЖ) - 34

БЕСТУЖЕВ-РЮМИН АЛЕКСЕЙ ИВАНОВИЧ - 39

БЕСТУЖЕВ-РЮМИН ПЕТР МИХАЙЛОВИЧ, ГЕНЕРАЛ - 48

БЕСТУЖЕВ-РЮМИН СТЕПАН ПЕТРОВИЧ - 11 
БИБИКОВ АЛЕКСЕЙ ЮРЬЕВИЧ - 10

БИДЕЕВ БОРИС МИХАЙЛОВИЧ, ДРАГУН С БРАТЬЯМИ - 33

БИДЕЕВ ПЕТР МИХАЙЛОВИЧ - 7

БИРЕВ БОРИС РОМАНОВИЧ, СОЛДАТ ЛЕФОРТОВСКОГО ПОЛКА - 43

БЛИЗНЯКОВА АКСИНЬЯ ИГНАТЬЕВНА, ВДОВА - 10

БОБОРЫКИН ИВАН ТИМОФЕЕВИЧ, ПРАПОРЩИК, ЗАТЕМ ПОРУЧИК - 23

БОБОРЫКИН ЛУКЬЯН ВАСИЛЬЕВИЧ, СЕРЖАНТ - 20

БОГДАНОВ МИХАИЛ САМСОНОВИЧ, ПОДПОЛКОВНИК - 39

БОГДАНОВ ФЕДОР АНТОНОВИЧ, ДЬЯК - 29

БОЛТИН ИВАН ИВАНОВИЧ, КАПИТАН - 36

БОЛТИН СТЕПАН МИХАЙЛОВИЧ, ВАХМИСТР - 33

БОРКОВ АНДРЕЙ ФЕДОРОВИЧ - 6

БОРКОВ ИВАН НИКИФОРОВИЧ - 5

БОРКОВА ВАСИЛИСА НИКИТИЧНА, ВДОВА - 21

БоУР РОДион Родионович - 92

БРЕДИХИН АЛЕКСАНДР ФЕДОРОВИЧ, КАПИТАН - 11

БРЕДИХИН СЕМЕН ФЕДОРОВИЧ, СТОЛЬНИК - 57

БУЕВ АНДРЕЙ СТЕПАНОВИЧ - 65

БУЕВ ЯКОВ СТЕПАНОВИЧ, КАПИТАН - 15

БУНАКОВ ГАЛАКТИОН ИЛЬИЧ, СТОЛЬНИК - 1

БУНАКОВ ИВАН ИВАНОВИЧ, СЕКРЕТАРЬ - 4

БУНАКОВА АКСИНЬЯ ПАРФЕНЬЕВНА, ВДОВА - 48

БУРЦЕВА МАРЬЯ, ВДОВА - 15

БУТРЮМОВА МАРФА, ВДОВА - 32

БУТУРЛИН АЛЕКСАНДР БОРИСОВИЧ, ГЕНЕРАЛ, КАВАЛЕР - 17

БУТУРЛИН ДМИТРИЙ ИВАНОВИЧ, НЕДОРОСЛЬ - 15

БУТУРЛИН ИВАН ИВАНОВИЧ, ГЕНЕРАЛ, БЫВШИЙ - 19

БУТУРЛИН ИВАН ФЕДОРОВИЧ - 39

БУТУРЛИН НИКОЛАЙ ИВАНОВИЧ, МАЙОР - 66

БУТУРЛИН ПЕТР ИВАНОВИЧ, БЛИЖНИЙ БОЯРИН - 33

БУТУРЛИН ФЕДОР ЕМЕЛЬЯНОВИЧ, СТОЛЬНИК - 92

ВАДБОЛЬСКИЙ ИВАН АЛЕКСЕЕВИЧ, КН. - 5

ВАДБОЛЬСКИЙ НИКИТА МАТВЕЕВИЧ, КН. - 24 
ВАДБОЛЬСКИЙ ПЕТР МАТВЕЕВИЧ, КН. - 33

ВАДБОЛЬСКИЙ СЕМЕН ИВАНОВИЧ, КН. - 4

ВАДБОЛЬСКИЙ ТИМОФЕЙ ЛУКЬЯНОВИЧ, КН. - 13

ВАСИЛЬЕВ РОМАН ПЕТРОВИЧ, КОМИССАР - 4

ВАСИЛЬЧИКОВ ВАСИЛИЙ СЕМЕНОВИЧ - 10

ВЕЛИКОГАГИН НИКОЛАЙ ИВАНОВИЧ, КН. - 77

ВЕЛЬЯМИНОВ ИОНА БОРИСОВИЧ, СТОЛЬНИК - 1

ВЕЛЬЯМИНОВА АЛЕКСАНДРА ПЕТРОВНА, ДЕВИЦА - 2

ВЕЛЬЯМИНОВ-ЗЕРНОВ ИВАН ИВАНОВИЧ, СТОЛЬНИК, СТАТСКИЙ СОВЕТНИК - 47

ВЕЛЬЯМИНОВ-ЗЕРНОВ ИВАН ЛЬВОВИЧ, МАЙОР - 20

ВЕЛЬЯМИНОВ-ЗЕРНОВ РОДИОН МИХАЙЛОВИЧ, ПРАПОРЩИК - 21

ВЕЛЬЯМИНОВ-ЗЕРНОВ ФЕДОР ЛЕОНТЬЕВИЧ, ПОДПОЛКОВНИК - 34

ВЕЛЬЯШЕВ ИВАН ВАСИЛЬЕВИЧ, КАПИТАН - 5

ВЕРДЕРЕВСКИЙ АЛЕКСЕЙ ПЕТРОВИЧ - 3

ВЕРДЕРЕВСКИЙ ИВАН МИХАЙЛОВИЧ - 3

ВЕШНЯКОВ АНДРЕЙ МИХАЙЛОВИЧ, СТОЛЬНИК - 80

ВЕШНЯКОВА ПРАСКОВЬЯ БОРИСОВНА, ВДОВА - 23

ВЛАДЫКИН ИВАН ВАСИЛЬЕВИЧ, ПОРУЧИК - 12

ВОЕЙКОВ АФАНАСИЙ СЕМЕНОВИЧ, СТОЛЬНИК - 17

ВОЕЙКОВ ИВАН ЛУКИЧ, БРИГАДИР - 22

ВОЕЙКОВ МАТВЕЙ ФЕДОРОВИЧ - 4

ВОЕЙКОВ ПЕТР ЛУКИЧ, БРИГАДИР, РИЖСКИЙ ВИЦЕ-ГУБЕРНАТОР - 20

ВОЕЙКОВА ФЕКЛА ВАСИЛЬЕВНА, ДЕВИЦА - 43

ВОЛКОВ АРТЕМИЙ АЛЕКСЕЕВИЧ, ДЬЯК КАЗАНСКОГО ДВОРЦА, БЫВШИЙ - 5

волКОВ ДМИТРИЙ, пОДПОЛКОВНИК И В. ИВАН, ПОРУчИК - 5

ВОЛКОВ НИКОН ИВАНОВИЧ, «СЛУЖИТЕЛЬ» ДОМА ЕИВ - 81

волКОВА АВДОТЬЯ, ВДОВА - 1

ВОЛКОНСКАЯ ДАРЬЯ ИВАНОВНА, КН., ВДОВА - 26

ВОЛКОНСКАЯ ИРИНА МИХАЙЛОВНА, КН., ВДОВА (В. СЕМЕН, КН. - МУЖ) - 42

ВОЛКОНСКИЙ АВРАМ МИХАЙЛОВИЧ, КН. - 50

ВОЛКОНСКИЙ АЛЕКСАНДР ГРИГОРЬЕВИЧ, КН., КАПИТАН - 97

ВОЛКОНСКИЙ АЛЕКСАНДР ДМИТРИЕВИЧ, КН. - 28

ВОЛКОНСКИЙ АЛЕКСАНДР ИВАНОВИЧ, КН., ГЕНЕРАЛ-МАЙОР - 7 
ВОЛКОНСКИЙ АНДРЕЙ ГРИГОРЬЕВИЧ, КН., ПОРУЧИК - 233

ВОЛКОНСКИЙ АНДРЕЙ ИВАНОВИЧ, КН., СТОЛЬНИК - 25

ВОЛКОНСКИЙ ВАСИЛИЙ ГРИГОРЬЕВИЧ, КН., КАПИТАН-ПОРУЧИК ЛЕЙБ-ГВАРДИИ

СЕМЕНОВСКОГО ПОЛКА - 74

ВОЛКОНСКИЙ МИХАИЛ ДМИТРИЕВИЧ, КН., ПРАПОРЩИК ДРАГУНСКОГО НОВГОРОДСКОГО

пОЛКА - 43

ВОЛКОНСКИЙ МИХАИЛ МИХАЙЛОВИЧ, КН. - 54

ВОЛКОНСКИЙ НИКОЛАЙ АНДРЕЕВИЧ, КН. - 41

ВОЛКОНСКИЙ ПЕТР БОРИСОВИЧ, КН. - 22

ВОЛКОНСКИЙ ПЕТР ВЛАДИМИРОВИЧ, КН. - 27

ВОЛКОНСКИЙ СЕМЕН ГАВРИЛОВИЧ, КН. - 8

ВОЛКОНСКИЙ ФЕДОР МИХАЙЛОВИЧ, КН. - 14

ВОЛЫНСКАЯ АННА, ВДОВА (В. МИХАИЛ - МУЖ) - 64

ВОЛЫНСКИЙ АРТЕМИЙ ПЕТРОВИЧ, ГЕНЕРАЛ-МАЙОР - 24

ВОЛЫНСКИЙ ВАСИЛИЙ ИВАНОВИЧ, ГАРДЕМАРИН, ЗАТЕМ ПОРУЧИК МОРСКОГО ФЛОТА 599

ВОЛЫНСКИЙ ИВАН МИХАЙЛОВИЧ, БРИГАДИР - 38

вОЛЫНСКИЙ МИХАИЛ МИХАЙЛОВИЧ, ПОДПОЛКОВНИК - 17

ВОРОНЕЦКИЙ ИВАН ВАСИЛЬЕВИЧ, ПОЛКОВНИК - 15

ВОРОНИН ИВАН, ДВОРЦОВЫЙ СТРЯПЧИЙ - 7

вОРОНИН РОДИОН ИВАНОВИЧ - 10

ВОРОНЦОВ ПЕТР ДМИТРИЕВИЧ - 25

ВОРОНЦОВ-ВЕЛЬЯМИНОВ МИТРОФАН ИВАНОВИЧ - 7

ВРАССКИЙ АЛЕКСЕЙ МИХАЙЛОВИЧ - 18

ВЫРУБОВ МАТВЕЙ ДМИТРИЕВИЧ, ПОДПОЛКОВНИК - 9

ВЫШЕСЛАВЦОВ СТЕПАН БОГДАНОВИЧ - 25

ВЯЗЕМСКИЙ АЛЕКСЕЙ ФЕДОРОВИЧ, КН. - 18

ВЯЗЕМСКИЙ АНДРЕЙ ФЕДОРОВИЧ, КН. - 22

ВЯЗЕМСКИЙ НИКИФОР КОНДРАТЬЕВИЧ - 43

ГАГАРИН ВАСИЛИЙ ИВАНОВИЧ, КН. - 32

ГАГАРИН СЕМЕН ИВАНОВИЧ, КН. - 80

ГАГАРИН ЮРИЙ ИВАНОВИЧ, КН. - 22

ГАМЕНТОВ ИВАН МИХАЙЛОВИЧ - 43

ГЕРАСИМОВ АФАНАСИЙ ВАСИЛЬЕВИЧ, ДЬЯК - 16 
ГЛЕБОВ АЛЕКСЕЙ ИВАНОВИЧ - 9

ГЛЕБОВ ВАСИЛИЙ МИХАЙЛОВИЧ - 57

ГЛЕБОВ ИВАН ФЕДОРОВИЧ, «ШКОЛЬНИК» - 6

ГЛЕБОВ ЛЕОНТИЙ МИХАЙЛОВИЧ, СТОЛЬНИК - 76

ГЛЕБОВ ФЕДОР МИХАЙЛОВИЧ, СТОЛЬНИК - 80

ГОЛЕНИЩЕВ-КУТУЗОВ ДРЕМОНТ ГРИГОРЬЕВИЧ, КАПИТАН ЛЕЙБ-ГВАРДИИ

ПРЕОБРАЖЕНСКОГО ПОЛКА - 28

ГОЛЕНИЩЕВ-КУТУЗОВ ИВАН МИХАЙЛОВИЧ - 15

ГОЛЕНИЩЕВ-КУТУЗОВ МИХАИЛ ФЕДОРОВИЧ - 15

ГОЛИЦЫН АЛЕКСЕЙ ДМИТРИЕВИЧ, КН. - 257

ГОЛИЦЫН ВАСИЛИЙ ПЕТРОВИЧ, КН., ЛЕЙТЕНАНТ - 166

ГОЛИЦЫН ДМИТРИЙ МИХАЙЛОВИЧ, КН., ДЕЙСТВИТЕЛЬНЫЙ ТАЙНЫЙ СОВЕТНИК,

СЕНАТОР, КАВАЛЕР - 539

ГОЛИЦЫН ИВАН АЛЕКСЕЕВИЧ, КН., БОЯРИН - 522

ГОЛИЦЫН ИВАН АНДРЕЕВИЧ, КН. - 526

ГОЛИЦЫН МИХАИЛ БОЛЬШИЙ МИХАЙЛОВИЧ, КН., ГЕНЕРАЛ-ФЕЛЬДМАРШАЛ, КАВАЛЕР 141

ГОЛИЦЫН МИХАИЛ ВАСИЛЬЕВИЧ, КН. - 353

ГОЛИЦЫН МИХАИЛ МЕНЬШИЙ МИХАЙЛОВИЧ, КН., ПОДПОРУЧИК МОРСКОГО ФЛОТА - 140 ГОЛИЦЫН НИКОЛАЙ ПЕТРОВИЧ, КН. - 300

ГОЛИЦЫН ПЕТР АЛЕКСЕЕВИЧ, КН., КИЕВСКИЙ ГУБЕРНАТОР - 76

ГОЛИЦЫН ПЕТР МИХАЙЛОВИЧ, КН., ГЕНЕРАЛ-МАЙОР, ПОДПОЛКОВНИК ЛЕЙБ-ГВАРДИИ СЕМЕНОВСКОГО ПОЛКА - 95

ГОЛИЦЫН СЕРГЕЙ АЛЕКСЕЕВИЧ, КН. - 85

ГОЛИЦЫН СЕРГЕЙ БОРИСОВИЧ, КН. - 404

ГОЛИЦЫН ФЕДОР АЛЕКСЕЕВИЧ, КН., СТОЛЬНИК - 329

ГОЛИЦЫНА АННА ИВАНОВНА, КН., ВДОВА (Г. АЛЕКСЕЙ БОРИСОВИЧ, КН. - МУЖ) - 807

ГОЛИЦЫНА ТАТЬЯНА СТЕПАНОВНА, КН., ВДОВА (Г. МИХАИЛ ВАСИЛЬЕВИЧ, КН. - МУЖ) - 44

ГОЛИЦЫНА ФЕДОСЬЯ ВЛАДИМИРОВНА, КН., ВДОВА (Г. ПЕТР МИХАЙЛОВИЧ, КН. - МУЖ) - 6

ГОЛОВИН АЛЕКСАНДР ФЕДОРОВИЧ, ГР., «МОРСКОГО ФЛОТА» - 367

ГОЛОВИН ВАСИЛИЙ ВАСИЛЬЕВИЧ - 12

ГОЛОВИН ВАСИЛИЙ ПЕТРОВИЧ, СТОЛЬНИК - 30

ГОЛОВИН ИВАН ИВАНОВИЧ, ГЕНЕРАЛ-АДЪЮТАНТ - 51

ГОЛОВИН ИВАН МИХАЙЛОВИЧ, ГЕНЕРАЛ-МАЙОР - 56 
ГОЛОВИН МАТВЕЙ АЛЕКСЕЕВИЧ, СТОЛЬНИК - 257

ГОЛОВИН НИКОЛАЙ ФЕДОРОВИЧ, ГР. - 338

ГОЛОВИН ПЕТР ИВАНОВИЧ, ГАРДЕМАРИН МОРСКОГО ФЛОТА - 42

ГОЛОВИН СЕРГЕЙ АРТАМОНОВИЧ - 319

ГОЛОВИН СЕРГЕЙ ИВАНОВИЧ - 113

ГОЛОВИН ФЕДОР ИВАНОВИЧ, ГАРДЕМАРИН - 47

ГОЛОВИНА АННА ИВАНОВНА, ВДОВА - 26

ГОЛОВКИН АФАНАСИЙ НИКИТИЧ, ЛЕЙБ-ГВАРДИИ КАПИТАН, ПОЛКОВНИК - 75

ГОЛОВКИН ГАВРИЛА ИВАНОВИЧ, ГР., ГОСУДАРСТВЕННЫЙ КАНЦЛЕР, КАВАЛЕР, ПРЕЗИДЕНТ КОЛЛЕГИИ ИНОСТРАННЫХ ДЕЛ - 216

ГОЛОВКИН ИВАН ГАВРИЛОВИЧ, ГР., ПОЛКОВНИК - 46

ГОЛОВКИН МИХАИЛ ГАВРИЛОВИЧ, ГР. - 133

ГОЛОВЛЕНКОВ ВАСИЛИЙ ФЕДОРОВИЧ, СТОЛЬНИК - 51

ГОЛОСОВ АЛЕКСЕЙ (Г. МАРЬЯ МИХАЙЛОВНА - ЖЕНА) - 15

ГОЛОХВАСТОВ ИВАН МАРТЫНОВИЧ - 13

ГОРДОН ФЕДОР ПЕТРОВИЧ, ПОЛКОВНИК - 21

ГОРЧАКОВ НИКИТА МАТВЕЕВИЧ, ЛЕЙБ-ГВАРДИИ ПРЕОБРАЖЕНСКОГО ПОЛКА КАПРАЛ - 1

ГОРЧАКОВЫ ИВАН И РОМАН ФЕДОРОВИЧИ, КН. - 140

ГРЕКОВ ИВАН МИХАЙЛОВИЧ, ДЬЯК - 14

ГРИБАНОВ ГАВРИЛА ФЕДОРОВИЧ - 2

ГРИГОРОВ ВАСИЛИЙ ИВАНОВИЧ, СИНОДАЛЬНЫЙ ДВОРЯНИН - 9

ГРИНЕВСКИЙ МАТВЕЙ ВАСИЛЬЕВИЧ, ПОДЬЯЧИЙ ПРИКАЗА БОЛЬШОЙ КАЗНЫ - 13

ГРУШЕЦКИЙ ВАСИЛИЙ МИХАЙЛОВИЧ - 45

ГРУШЕЦКИЙ СЕРГЕЙ ИВАНОВИЧ - 21

ГРЯЗНОВЫ ВАСИЛИЙ И ИВАН МИХАЙЛОВИЧИ, ГАРДЕМАРИНЫ МОРСКОГО ФЛОТА - 17

ГУЛЯЕВ МИХАИЛ ГРИГОРЬЕВИЧ, ДЬЯК - 31

ДАНИЛОВ ИВАН ДЕНИСОВИЧ - 2

ДАШКОВ АЛЕКСАНДР АЛЕКСЕЕВИЧ - 81

ДАШКОВ АЛЕКСЕЙ ИВАНОВИЧ, СУДЬЯ НАДВОРНОГО СУДА, ЧРЕЗВЫЧАЙНЫЙ ПОСЛАННИК, ТАЙНЫЙ СОВЕТНИК - 104

ДАШКОВ ИВАН (ЯКОВ?) ПЕТРОВИЧ, КН., АДЪЮТАНТ ЛЕЙБ-ГВАРДИИ ПРЕОБРАЖЕНСКОГО ПОЛКА - 63

ДАШКОВ ИВАН АНДРЕЕВИЧ - 11

ДАШКОВ ЯКОВ ИВАНОВИЧ - 126 
ДЕРЕВНИН ГАВРИЛА ФЕДОРОВИЧ, ДУМНЫЙ ДЬЯК - 89

ДИВОВ АЛЕКСЕЙ ФИЛИППОВИЧ, СОЛДАТ ЛЕЙБ-ГВАРДИИ ПРЕОБРАЖЕНСКОГО ПОЛКА - 44

ДМИТРИЕВ ВАСИЛИЙ БОРИСОВИЧ, ВАХМИСТР - 15

ДМИТРИЕВ-МАМОНОВ ВАСИЛИЙ АФАНАСЬЕВИЧ, ПОРУЧИК МОРСКОГО ФЛОТА - 43

ДМИТРИЕВ-МАМОНОВ ИВАН ИЛЬИЧ, ГЕНЕРАЛ-МАЙОР, ЛЕЙБ-ГВАРДИИ МАЙОР, КАВАЛЕР 283

ДМИТРИЕВЫ-МАМОНОВЫ АЛЕКСЕЙ, ПОДПОРУЧИК И АРТАМОН, ПОРУЧИК ВАСИЛЬЕВИЧИ 54

ДОКУДОВСКИЙ АЛЕКСАНДР ФЕДОРОВИЧ, СОВЕТНИК - 16

ДОЛГОРУКОВ АЛЕКСАНДР ЛУКИЧ, КН., ПОЛКОВНИК - 76

ДОЛГОРУКОВ АЛЕКСЕЙ ВАСИЛЬЕВИЧ, КН., ПРАПОРЩИК ЛЕЙБ-ГВАРДИИ ПРЕОБРАЖЕНСКОГО ПОЛКА - 84

ДОЛГОРУКОВ АЛЕКСЕЙ ГРИГОРЬЕВИЧ, КН. - 258

ДОЛГОРУКОВ АЛЕКСЕЙ МИХАЙЛОВИЧ, КН., ГАРДЕМАРИН МОРСКОГО ФЛОТА - 61

ДОЛГОРУКОВ АЛЕКСЕЙ, КН. - 180

ДОЛГОРУКОВ ВАСИЛИЙ ЛУКИЧ, КН. - 79

ДОЛГОРУКОВ ВАСИЛИЙ МИХАЙЛОВИЧ, КН., СТОЛЬНИК - 142

ДОЛГОРУКОВ ВЛАДИМИР ВЛАДИМИРОВИЧ, КН., ПОРУЧИК МОРСКОГО ФЛОТА - 45

ДОЛГОРУКОВ ВЛАДИМИР ПЕТРОВИЧ, КН. - 39

ДОЛГОРУКОВ ГРИГОРИЙ ФЕДОРОВИЧ, КН., ДЕЙСТВИТЕЛЬНЫЙ ТАЙНЫЙ СОВЕТНИК, КАВАЛЕР - 6547

ДОЛГОРУКОВ ИВАН ИВАНОВИЧ, КН. - 5

ДОЛГОРУКОВ МИХАИЛ ВЛАДИМИРОВИЧ, КН. - 188

ДОЛГОРУКОВ СЕРГЕЙ ВЛАДИМИРОВИЧ, КН. - 21

ДОЛГОРУКОВ СЕРГЕЙ ГРИГОРЬЕВИЧ, КН. - 187

ДОЛГОРУКОВ СЕРГЕЙ МИХАЙЛОВИЧ, КН. - 69

ДОЛГОРУКОВ СЕРГЕЙ ПЕТРОВИЧ, КН. - 208

ДОЛГОРУКОВЫ ИВАН И ЮРИЙ ЮРЬЕВИЧИ, КН. - 141

ДОМНИНЫ ВЛАДИМИР И СЕРГЕЙ ЛЮБИМОВИЧИ - 70

ДОМОЖИРОВ ВАСИЛИЙ ЛОГИНОВИЧ, КАПИТАН - 14

ДОМОжиРОВ ДМИТРИй БОРИСОВИч - 11

ДОХТУРОВ АФАНАСИЙ ЯКОВЛЕВИЧ - 18

ДОХТУРОВ ПЕТР ИВАНОВИЧ, ЛЕЙБ-ГВАРДИИ ПРЕОБРАЖЕНСКОГО ПОЛКА СОЛДАТ - 5

ДУБЕНСКИЙ ДАНИЛА МИТРОФАНОВИЧ, МАЙОР - 5 
ДУМАШЕВ ВАСИЛИЙ КУЗЬМИЧ - 43

ДУМАШЕВЫ АЛЕКСАНДР И ПЕТР ЯКОВЛЕВИЧИ - 20

ДУРНОВО ИВАН ИВАНОВИЧ - 9

ДУРНОВО ПЕТР ПОТАПОВИЧ, КАПИТАН - 2

ДУРОВ <?> АЛЕКСАНДРОВИЧ, МАЙОР - 28

ДУРОВ АЛЕКСАНДР ИВАНОВИЧ, МАЙОР - 10

ДЯБРИНСКИЙ БОРИС НИкИТИЧ, КН. - 55

ЕВЛАШЕВ АЛЕКСЕЙ ПЕТРОВИЧ - 22

ЕГУПОВ-ЧЕРКАССКИЙ ГРИГОРИЙ ИВАНОВИЧ, КН., ЛЕЙБ-ГВАРДИИ СЕМЕНОВСКОГО ПОЛКА УНТЕР-ЛЕЙТЕНАНТ - 107

ЕЛИЗАРОВ АФАНАСИЙ МИХАЙЛОВИЧ, ПОРУЧИК - 54

ЕРМОЛАЕВ ПЕТР ЛЬВОВИЧ, КАПИТАН - 118

ЕРОПКИН ВАСИЛИЙ МИХАЙЛОВИЧ, СТОЛЬНИК - 13

ЕРОПКИН МИХАИЛ ИВАНОВИЧ - 6

ЕРОПКИН ПЕТР МИХАЙЛОВИЧ - 13

ЕРШОВ ВАСИЛИЙ СЕМЕНОВИЧ - 97

ЕСЕНЕВ ИВАН СТЕПАНОВИЧ - 15

ЕСЕНЕВ МИХАИЛ СТЕПАНОВИЧ - 7

ЖЕЛЯБУЖСКИЙ МИХАИЛ ВАСИЛЬЕВИЧ, СУДЬЯ НАДВОРНОГО СУДА - 20

ЖЕРЕБЦОВ ГАВРИЛА ИВАНОВИЧ, СТОЛЬНИК - 1

ЖИДОВИНОВ НИКОЛАЙ ИВАНОВИЧ - 48

ЖИРОВОГО-ЗАСЕКИН НИКИТА МИХАЙЛОВИЧ, КН. - 26

ЖУКОВ ЛАВРЕНТИЙ АЛЕКСАНДРОВИЧ, ЖИЛЕЦ - 3

ЖУКОВ СЕМЕН ЕЛИЗАРОВИЧ - 8

ЗАБОРОВСКИЙ АЛЕКСЕЙ ЕРЕМЕЕВИЧ, КАПИТАН - 16

ЗАГРЯЖСКИЙ АРТЕМИЙ ГРИГОРЬЕВИЧ, ПОДПОЛКОВНИК - 24

ЗАГРЯЖСКИЙ ВАСИЛИЙ МАКСИМОВИЧ, ЛЕЙБ-ГВАРДИИ СЕМЕНОВСКОГО ПОЛКА ПОРУЧИК 47

ЗАЙЦЕВ КЛИМОНТ ЛЕОНТЬЕВИЧ, ПОДЬЯЧИЙ СЧЕТНОЙ КАНЦЕЛЯРИИ - 7

ЗАМЯТНИН ЕГОР МАТВЕЕВИЧ, МАЛОЛЕТНИЙ - 35

ЗАМЯТНИН МИХАИЛ ИВАНОВИЧ - 16

ЗАСЕЦКИЙ ИВАН ИВАНОВИЧ, МАЙОР - 77

ЗАСЕЦКИЙ МАТВЕЙ ИВАНОВИЧ, СТОЛЬНИК - 74

ЗАСЕЦКИЙ ПЕТР ИВАНОВИЧ - 63 
ЗАСЕЦКИЙ ФЕДОР ИВАНОВИЧ - 7

ЗИНОВЬЕВ ВАСИЛИЙ ВАСИЛЬЕВИЧ - 4

ЗИНОВЬЕВ ГРИГОРИЙ ПЕТРОВИЧ, ЛАНДРАТ - 34

ЗИНОВЬЕВ СТЕПАН ПЕТРОВИЧ - 40

ЗИНОВЬЕВА АВДОТЬЯ ВАСИЛЬЕВНА, ВДОВА (КАПИТАН - МУЖ) - 56

ЗИНОВЬЕВА АННА НИКИТИЧНА, ВДОВА (З. ФЕДОР АФАНАСЬЕВИЧ - МУЖ) - 36

ЗОТОВ ВАСИЛИЙ НИКИТИЧ, БРИГАДИР, ЗАТЕМ ГЕНЕРАЛ-МАЙОР - 98

ЗОТОВ КОНОН НИКИТИЧ, КАПИТАН МОРСКОГО ФЛОТА - 2

ЗУБОВ ИВАН БОРИСОВИЧ, КАПИТАН - 10

ЗУБОВ НИКОЛАЙ ВАСИЛЬЕВИЧ - 18

ЗЫБИН АЛЕКСАНДР ЕФИМОВИЧ, ГАРДЕМАРИН - 71

ЗЫБИН АЛЕКСЕЙ КИРИЛЛОВИЧ, ПОЛКОВНИК АДМИРАЛТЕЙСТВА - 13

ЗЫБИН ВАСИЛИЙ МАКСИМОВИЧ - 7

ЗЫБИН ЕФИМ ПАНКРАТЬЕВИЧ, ВОЕННЫЙ СОВЕТНИК - 22

ЗЫБИН ПЕТР КИРИЛЛОВИЧ, СТОЛЬНИК - 7

ЗЮЗИН МИХАИЛ АЛЕКСАНДРОВИЧ, ПОРУЧИК - 74

ИВАНОВ АНДРЕЙ ПАВЛОВИЧ - 69

ИВАНОВ ИВАН ОСИПОВИЧ, ПОДЬЯЧИЙ - 8

ИВАНОВ НИКОЛАЙ АВТАМОНОВИЧ - 987

ИГНАТЬЕВА СТЕПАНИДА ДМИТРИЕВНА, ВДОВА - 22

ИГНАТЬЕВЫ ВАСИЛИЙ ИВАНОВИЧ И ПЕТР ЛУКИЧ - 9

ИЕВЛЕВ АНДРЕЙ ИВАНОВИЧ, ПОДЬЯЧИЙ - 2

ИЕВЛЕВ ПРОХОР ИВАНОВИЧ - 31

ИЗМАЙЛОВ ВАСИЛИЙ АНДРЕЕВИЧ - 101

ИЗМАЙЛОВ ИВАН ПЕТРОВИЧ, ГЕНЕРАЛ-МАЙОР - 48

ИЗМАЙЛОВ МИХАИЛ ПЕТРОВИЧ - 53

ИЗМАЙЛОВА АВДОТЬЯ ВАСИЛЬЕВНА, ВДОВА (И. ПЕТР ИВАНОВИЧ - МУЖ) - 32

ИМЕРЕТИНСКАЯ ДАРЬЯ АРЧИЛОВНА, ЦАРЕВНА - 730

ИСАКОВ ФЕДОР, ДРАГУН - 9

ИСЛЕНЬЕВ ВАСИЛИЙ ДАНИЛОВИЧ, СОВЕТНИК - 151

КАЗАКОВ ВАСИЛИЙ АНТОНОВИЧ - 6

КАМЫНИН ВАСИЛИЙ ПЕТРОВИЧ - 52

КАМЫНИН ДМИТРИЙ АРТЕМЬЕВИЧ - 34 
КАНТЕМИР ДМИТРИЙ КОНСТАНТИНОВИЧ, КН., ВОЛОШСКИЙ ГОСПОДАРЬ - 364

КАРАМЫШЕВ ФЕДОР ИВАНОВИЧ, СТОЛЬНИК - 96

КАРПОВ СЕМЕН ПРОКОФЬЕВИЧ, СТОЛЬНИК - 68

КАСИМОВСКИЙ ИВАН ВАСИЛЬЕВИЧ, ЦАРЕВИЧ - 88

КАФТЫРЕВ СЕМЕН СТЕПАНОВИЧ - 3

КАХОВСКИЙ? <?> ДМИТРИЕВИЧ, КАПИТАН - 15

КВАШНИН-САМАРИН ПЕТР АНДРЕЕВИЧ, КАЗНАЧЕЙ - 28

КИРЕЕВСКИЙ НИКИТА ЯКОВЛЕВИЧ, ПРАПОРЩИК - 14

КИРЕЕВСКИЙ СЕМЕН АФАНАСЬЕВИЧ, СЕРЖАНТ - 26

КИСЕЛЕВ БОГДАН ТРОФИМОВИЧ, МАЙОР - 12

КИСЛЕНСКАЯ НАТАЛЬЯ АНДРЕЕВНА, ВДОВА (К. ГАВРИЛА - МУЖ) - 31

КИШКИН МИХАИЛ ТИМОФЕЕВИЧ, МАЙОР - 19

КЛЕМЕНТЬЕВ АНДРЕЙ ПЕТРОВИЧ - 18

КЛЕШНИН ФЕДОР, СТОЛЬНИК - 55

КОБЫЛЯКОВ ПЕТР АНУФРИЕВИЧ, КОПИИСТ ЮСТИЦ-КОЛЛЕГИИ - 13

КОЖИН ИВАН ВАСИЛЬЕВИЧ, СТОЛЬНИК - 40

КОЗЛОВ НИКИТА АФАНАСЬЕВИЧ, ПОДПОЛКОВНИК, ЗАТЕМ ПОЛКОВНИК - 108

КОЗЛОВСКАЯ НАСТАСЬЯ, КН., ВДОВА (К. СТЕПАН, КН. - МУЖ) - 23

КОЗЛОВСКИЙ ИВАН БОРИСОВИЧ, КН., ПРАПОРЩИК - 14

КОЗЛОВСКИЙ МИХАИЛ МАРКОВИЧ, КН., ПОРУЧИК - 18

КОЗЛОВСКИЙ СЕМЕН БОРИСОВИЧ, КН., АДЪЮТАНТ - 20

КОЗЛОВСКИЙ СЕМЕН МИХАЙЛОВИЧ, КН. - 47

КОЗЛОВСКИЙ ФЕДОР СЕМЕНОВИЧ, КН. - 30

КОЗЯЕВ ГРИГОРИЙ ИВАНОВИЧ, СОЛДАТ ЛЕЙБ-ГВАРДИИ ПРЕОБРАЖЕНСКОГО ПОЛКА - 19

КОЗЯЕВ СТЕПАН ЛЬВОВИЧ - 14

коковинский никитА Осипович - 42

КОКОВИНСКИЙ НИКИТА ФЕДОРОВИЧ - 43

КОКОШКИН ИВАН ЛЕОНТЬЕВИЧ - 28

КОЛОГРИВОВ АЛЕКСЕЙ БОРИСОВИЧ, КАПРАЛ - 26

КОЛОГРИВОВ АЛЕКСЕЙ МИРОНОВИЧ, ПРАПОРЩИК - 15

КОЛОГРИВОВ ИВАН МИРОНОВИЧ, СТОЛЬНИК - 11

КОЛОГРИВОВ ЮРИЙ ИВАНОВИЧ - 25

КОЛОКОЛЬЦЕВ ИВАН ТИМОФЕЕВИЧ, КАНЦЕЛЯРИСТ МОСКОВСКОГО НАДВОРНОГО СУДА - 28 
КОЛТОВСКИЙ АЛЕКСАНДР СЕМЕНОВИЧ - 11

КОЛТОВСКИЙ ГРИГОРИЙ АЛЕКСЕЕВИЧ - 7

КОЛТОВСКИЙ ПЕТР ВАСИЛЬЕВИЧ, МАЙОР - 24

КОЛЫЧОВ АЛЕКСАНДР ИВАНОВИЧ - 37

КОЛЫЧОВ ДАНИЛА ИВАНОВИЧ, КАПИТАН - 7

КОЛЫЧОВ ИВАН ИВАНОВИЧ, КАПИТАН - 8

КОЛЫЧОВ МАТВЕЙ ВАСИЛЬЕВИЧ - 26

КОЛЫЧОВ СТЕПАН АНДРЕЕВИЧ, БЛИЖНИЙ СТОЛЬНИК - 362

КОЛЫЧОВА МАРФА АФАНАСЬЕВНА, ВДОВА - 11

КОЛЬЦОВ-МОСАЛЬСКИЙ ДМИТРИЙ АНДРЕЕВИЧ, КН. - 16

КОЛЬЦОВ-МОСАЛЬСКИЙ ИВАН АНДРЕЕВИЧ, КН., КАПИТАН БУТЫРСКОГО ПОЛКА - 8

КОЛЬЦОВ-МОСАЛЬСКИЙ ИВАН ПЕТРОВИЧ, КН. - 5

КОЛЬЦОВ-МОСАЛЬСКИЙ ФЕДОР МИХАЙЛОВИЧ, КН., СТОЛЬНИК - 21

КОЛЬЦОВ-МОСАЛЬСКИЙ ЯКОВ ЯКОВЛЕВИЧ, КН., ОБЕР-КРИГС-КОМИССАР - 9

КОНОВНИЦЫНА АННА ЛАРИОНОВНА, ВДОВА - 15

КОРОБЬИН МАТВЕЙ СТЕПАНОВИЧ, КАПИТАН МОРСКОГО ФЛОТА - 18

КОРОБЬИНА МАВРА ЛЬВОВНА, ВДОВА (К. МИХАИЛ - МУЖ) - 67

КОРОВИН СТЕПАН ЯКОВЛЕВИЧ, СТОЛЬНИК - 31

КОРОВЬЕВ ВАСИЛИЙ КОНСТАНТИНОВИЧ - 10

КОРОТНЕВ ВАСИЛИЙ МАКСИМОВИЧ - 5

КРАВКОВ ВАСИЛИЙ ФЕДОРОВИЧ, ПОРУЧИК - 22

КРЕТОВ КЛИМ СТЕПАНОВИЧ, СЕКРЕТАРЬ - 43

КРЕЧЕТНИКОВ СЕМЕН ЯКОВЛЕВИЧ - 8

КРЕЧЕТНИКОВ ФЕДОР ЯКОВЛЕВИЧ, СТОЛЬНИК - 20

КРУГЛИКОВЫ АЛЕКСАНДР, ПОРУЧИК И ПЕТР, ПОДПОЛКОВНИК ЛЬВОВИЧИ - 15

КУДАЕВ ГРИГОРИЙ ЕВСТРАТОВИЧ - 11

КУДАЕВ ИЛЬЯ ЕВСТРАТОВИЧ - 11

КУЗЬМИН ФЕДОР ИВАНОВИЧ, СТОЛЬНИК - 43

КУЗЬМИН ФЕДОР, СТОЛЬНИК - 5

КУЗЬМИН-КАРАВАЕВ АФАНАСИЙ АНДРЕЕВИЧ - 17

КУЗЬМИН-КАРАВАЕВ ДМИТРИЙ СТЕПАНОВИЧ - 84

КУЗЬМИН-КАРАВАЕВ СТЕПАН ИВАНОВИЧ, СТОЛЬНИК - 63

КУРАКИН БОРИС ИВАНОВИЧ, КН., ГЕНЕРАЛ-МАЙОР, ПОДПОЛКОВНИК ЛЕЙБ-ГВАРДИИ ПРЕОБРАЖЕНСКОГО ПОЛКА, ДЕЙСТВИТЕЛЬНЫЙ ТАЙНЫЙ СОВЕТНИК, КАВАЛЕР - 1081 
КУРАКИНА МАВРА ДМИТРИЕВНА, КН., ВДОВА - 120

КУРБАТОВ АЛЕКСЕЙ АЛЕКСАНДРОВИЧ, ВИЦЕ-ГУБЕРНАТОР, БЫВШИЙ - 771

КУТУЗОВ ИВАН ПЕТРОВИЧ - 8

КУТУЗОВ НИкОЛАЙ НИКИТИЧ - 25

ЛАБЗИН ИВАН ЯКОВЛЕВИЧ, КАПИТАН - 6

ЛАБЗИН ПЕТР ЯКОВЛЕВИЧ - 13

ЛАГОВЧИН ФЕДОР ВАСИЛЬЕВИЧ - 36

ЛАЧИНОВ ПЕТР ИВАНОВИЧ, БРИГАДИР - 76

ЛЕБЕДЕВ ФЕДОР, СЕКРЕТАРЬ - 16

ЛЕВШИН АЛЕКСЕЙ ДЕНИСОВИЧ - 37

ЛЕОНТЬЕВ ВАСИЛИЙ ФЕДОРОВИЧ, ПОДПОЛКОВНИК - 131

ЛЕОНТЬЕВ ИВАН ПЕТРОВИЧ, БРИГАДИР - 56

ЛЕОНТЬЕВ МИХАИЛ ИВАНОВИЧ, ГЕНЕРАЛ, КАВАЛЕР - 31

ЛЕОНТЬЕВА АВДОТЬЯ ГРИГОРЬЕВНА, ВДОВА - 5

ЛИТВИНОВ ИВАН АЛЕКСЕЕВИЧ - 15

ЛИХАРЕВ АЛЕКСАНДР, ПОРУЧИК - 21

ЛИХАРЕВ АЛЕКСЕЙ КИРИЛЛОВИЧ, КАПИТАН - 17

ЛИХАЧЕВ ИВАН ИВАНОВИЧ, ПОЛКОВОЙ КВАРТИРМЕЙСТЕР - 44

ЛОБАНОВ-РОСТОВСКИЙ ИВАН ЯКОВЛЕВИЧ, КН., МОРСКОГО ФЛОТА КАПИТАН-ЛЕЙТЕНАНТ И

Л.-Р. ФЕДОР МИХАЙЛОВИЧ, КН. - 68

ЛОБАНОВ-РОСТОВСКИЙ МИХАИЛ ЯКОВЛЕВИЧ, КН., ПОРУЧИК И УРУСОВ НИКИТА, КН., ПОДПОЛКОВНИК - 48 (СПОРНОЕ ВЛАДЕНИЕ)

ЛОБАНОВ-РОСТОВСКИЙ ЯКОВ ИВАНОВИЧ, КН., СТОЛЬНИК - 139

ЛОДЫГИН МИХАИЛ ФЕДОРОВИЧ - 22

ЛОДЫГИН СЕМЕН АНДРЕЕВИЧ - 21

ЛОДЫЖЕНСКАЯ ЕЛЕНА НИКИТИЧНА, ВДОВА - 77

ЛОДЫЖЕНСКИЕ АНДРЕЙ ЮРЬЕВИЧ И ВАСИЛИЙ ДМИТРИЕВИЧ, КАПИТАН МОРСКОГО ФЛОТА $-47$

ЛОДЫЖЕНСКИЙ ВАСИЛИЙ ИВАНОВИЧ, КАПИТАН - 11

ЛОПУХИН АВРАМ ФЕДОРОВИЧ - 73

ЛОПУХИН ИВАН ПЕТРОВИЧ - 25

ЛОПУХИН СТЕПАН ВАСИЛЬЕВИЧ, ПОРУЧИК МОРСКОГО ФЛОТА - 162

ЛОПУХИНА МАРФА АРТЕМЬЕВНА, ВДОВА И ЕЕ СЫН ПЛЕМЯННИКОВ ПЕТР ГРИГОРЬЕВИЧ, КАПИТАН - 72 
ЛУТКОВСКИЙ ИЛЬЯ ЕРОФЕЕВИЧ, ПОЛКОВНИК - 17

ЛЬВОВ АЛЕКСЕЙ ИВАНОВИЧ, ФЛИГЕЛЬ-АДЪЮТАНТ - 66

ЛЬВОВ ИВАН БОРИСОВИЧ, КН. - 18

ЛЬВОВ МИХАИЛ БОРИСОВИЧ, КН., СТОЛЬНИК - 42

ЛЬВОВ СЕРГЕЙ ЯКОВЛЕВИЧ, КН. - 47

ЛЬВОВА АННА АРТАМОНОВНА, КН., ВДОВА - 23

ЛЬВОВА ЕЛЕНА БОРИСОВНА, КН., ДЕВИЦА - 53

ЛЯПИН АРТЕМОН ПЕРФИЛЬЕВИЧ - 11

ЛЯПУНОВ ТИМОФЕЙ АЛЕКСАНДРОВИЧ - 5

ЛЯПУНОВ ФЕДОР АРТЕМЬЕВИЧ - 9

МАКАРОВ АЛЕКСЕЙ ВАСИЛЬЕВИЧ, ТАЙНЫЙ СОВЕТНИК - 19

МАКУЛОВ ВАСИЛИЙ, КН. - 23

МАМАЕВ ИВАН МИХАЙЛОВИЧ, КАПИТАН - 21

МАНСУРОВ ГЕРАСИМ АЛЕКСЕЕВИЧ, АСЕССОР - 131

МАНСУРОВ ДМИТРИЙ ВАСИЛЬЕВИЧ, ПОРУЧИК - 31

МАНСУРОВ МАКСИМ АНДРЕЕВИЧ, ПРАПОРЩИК - 215

МАНСУРОВ ЯКОВ НИКИТИЧ, КАПРАЛ - 39

МАНСУРОВА ТАТЬЯНА ИВАНОВНА, ВДОВА - 39

МАНУКОВ СЕМЕН ВОРФОЛОМЕЕВИЧ, ПОДЬЯЧИЙ - 34

МАРКОВ АЛЕКСЕЙ ДМИТРИЕВИЧ, ЛЕЙБ-ГВАРДИИ ПРЕОБРАЖЕНСКОГО ПОЛКА СОЛДАТ - 12

МАРКОВ ВАСИЛИЙ АРТЕМЬЕВИЧ, СТРЕМЯННОЙ КОНЮХ - 40

МАРТЕМЬЯНОВ ФЕДОР ЛУКИЧ - 148

МАРТЫНОВ ЯКОВ ФЕДОРОВИЧ, КАПИТАН - 44

МАСКИН МИХАИЛ АНДРЕЕВИЧ - 55

МАСКИН СЕМЕН МАТВЕЕВИЧ - 28

МАСЛОВ АЛЕКСЕЙ МОКЕЕВИЧ, АДЪЮТАНТ - 33

МАСЛОВ ГРИГОРИЙ МОКЕЕВИЧ, ЖИЛЕЦ - 18

МАСЛОВ СТЕПАН МОКЕЕВИЧ, ПОДПОЛКОВНИК - 58

МАТВЕЕВ АНДРЕЙ АРТЕМОНОВИЧ, ГР., ТАЙНЫЙ СОВЕТНИК - 332

МАТЮШКИН ИВАН ПЕТРОВИЧ, СТОЛЬНИК - 61

МАТЮШКИН МИХАИЛ АФАНАСЬЕВИЧ, ГЕНЕРАЛ, КАВАЛЕР, ЛЕЙБ-ГВАРДИИ ПОДПОЛКОВНИК $-94$

МЕЛЛЕР ВАХРАМЕЙ ВАХРАМЕЕВИЧ, ИНОЗЕМЕЦ - 54

МЕНШИКОВ АЛЕКСАНДР ДАНИЛОВИЧ, КН., БЫВШИЙ - 9400 
МЕРКУЛЬЕВ АЛЕКСЕЙ, ОРУЖЕЙНЫЙ НАДЗИРАТЕЛЬ - 92

МЕЩЕРСКИЙ ВАСИЛИЙ АЛЕКСЕЕВИЧ, КН. - 43

МЕЩЕРСКИЙ ВАСИЛИЙ ИВАНОВИЧ, КН., ПОРУЧИК ТВЕРСКОГО ДРАГУНСКОГО ПОЛКА - 33

МЕЩЕРСКИЙ ЕФИМ ВАСИЛЬЕВИЧ, КН. - 20

МЕЩЕРСКИЙ ИВАН ВАСИЛЬЕВИЧ, КН., ПОДПОРУЧИК - 64

МЕЩЕРСКИЙ ИВАН ИВАНОВИЧ, КН. - 39

МИЖУЕВ КУЗЬМА, СЕКРЕТАРЬ - 48

МИЛОСЛАВСКИЙ АЛЕКСЕЙ АЛЕКСЕЕВИЧ, СТОЛЬНИК - 124

МИЛОСЛАВСКИЙ ЛЕВ АЛЕКСАНДРОВИЧ - 116

МИЛОСЛАВСКИЙ МИХАИЛ СЕРГЕЕВИЧ, МИЧМАН МОРСКОГО ФЛОТА - 334

МИЛОСЛАВСКИЙ СЕРГЕЙ ИВАНОВИЧ, СТОЛЬНИК - 126

МИЛЮКОВ ВАСИЛИЙ ИВАНОВИЧ, СТОЛЬНИК - 58

МИНИН АЛЕКСАНДР СТЕПАНОВИЧ, СОЛДАТ ЛЕЙБ-ГВАРДИИ ПРЕОБРАЖЕНСКОГО ПОЛКА 18

МИТРОФАНОВ ФЕДОР ЛАРИОНОВИЧ, ПОЛКОВНИК - 17

МИШУКОВ ЗАХАРИЙ ДАНИЛОВИЧ, КАПИТАН МОРСКОГО ФЛОТА - 70

МОЛЧАНОВ ИВАН ИВАНОВИЧ - 18

МОЛЧАНОВ ИВАН СИДОРОВИЧ, КОМИССАР - 60

МОЛЧАНОВ ФЕДОР ИВАНОВИЧ, СЕРЖАНТ - 22

МОРТКИНА АКСИНЬЯ ГАВРИЛОВНА, КН., ВДОВА - 36

МОШКОВ ПЕТР ИВАНОВИЧ - 32

МУСИН-ПУШКИН ИВАН АЛЕКСЕЕВИЧ, ГР., ТАЙНЫЙ СОВЕТНИК - 1366

МУСИН-ПУШКИН ЛЕВ САВВИЧ - 25

МУСИН-ПУШКИН ПЛАТОН ИВАНОВИЧ, ГР., ЛЕЙБ-ГВАРДИИ ПРЕОБРАЖЕНСКОГО ПОЛКА КАПИТАН-ЛЕЙТЕНАНТ - 55

МУСИН-ПУШКИН СЕМЕН АФАНАСЬЕВИЧ, СОЛДАТ ЛЕЙБ-ГВАРДИИ ПРЕОБРАЖЕНСКОГО ПоЛКА - 6

МЯСНОЙ ДАНИЛА ИВАНОВИЧ, КАПИТАН МОРСКОГО ФЛОТА - 62

МЯЧКОВ ГРИГОРИЙ ИВАНОВИЧ - 11

НАВРОЦКИЙ АРТЕМИЙ ЗАХАРОВИЧ, ДЬЯК - 38

НАГАЕВ ИВАН КОНДРАТЬЕВИЧ, ПОРУЧИК, КОМИССАР - 87

НАГАЕВА МАТРЕНА ВАСИЛЬЕВНА, ВДОВА - 5

НАРБЕКОВ СТЕПАН САВВИЧ, ДУМНЫЙ ДВОРЯНИН - 26

НАРЫШКИН АЛЕКСЕЙ ИВАНОВИЧ, СТОЛЬНИК - 355 
НАРЫШКИН ВАСИЛИЙ ВАСИЛЬЕВИЧ - 61

НАРЫШКИН ВАСИЛИЙ ВАСИЛЬЕВИЧ И ЕГО ДЯДЯ Н. СЕМЕН ГРИГОРЬЕВИЧ, ГЕНЕРАЛ-

АДЪЮТАНТ - 108

НАРЫШКИН ИВАН ИВАНОВИЧ, СТОЛЬНИК - 60

НАРЫШКИН КИРИЛЛА АЛЕКСЕЕВИЧ, БЛИЖНИЙ КРАВЧИЙ - 439

НАРЫШКИН МИХАИЛ ГРИГОРЬЕВИЧ, БЛИЖНИЙ СТОЛЬНИК - 52

НАРЫШКИНЫ АЛЕКСАНДР И ИВАН ЛЬВОВИЧИ - 2547

НАУМОВ ГРИГОРИЙ ЯКОВЛЕВИЧ, ПОДПОЛКОВНИК - 18

НАУМОВ ИВАН НИКИТИЧ, СТОЛЬНИК - 113

НАУМОВ ФЕДОР ВАСИЛЬЕВИЧ, СОВЕТНИК КАМЕР-КОЛЛЕГИИ - 44

НАУМОВА АФИМЬЯ МИХАЙЛОВНА, ВДОВА (Н. ПЕТР - МУЖ) - 29

НАУМОВА ТАТЬЯНА ВАСИЛЬЕВНА, ВДОВА - 23

НАЩОКИН ИВАН ФЕДОРОВИЧ, МОРСКОГО ФЛОТА УНТЕР-ЛЕЙТЕНАНТ - 2

НАЩОКИНЫ МИХАИЛ, ПОЛКОВНИК И НИКИТА, МАЙОР ИВАНОВИЧИ - 138

НЕБОЛЬСИН МИХЕЙ ИВАНОВИЧ, КОМИССАР - 4

НЕЛЕДИНСКИЙ-МЕЛЕЦКИЙ СТЕПАН ПЕТРОВИЧ, СТОЛЬНИК - 69

НЕЛЕДИНСКИЙ-МЕЛЕЦКИЙ ЮРИЙ СТЕПАНОВИЧ, СТОЛЬНИК - 79

НЕЛИДОВ ДМИТРИЙ ФЕДОРОВИЧ - 29

НЕПЛЮЕВ ЕГОР СЕМЕНОВИЧ, СТОЛЬНИК - 7

НЕРОНОВ БОРИС ИВАНОВИЧ, СТАТСКИЙ СОВЕТНИК - 80

НЕРОНОВ ИЛЬЯ ИВАНОВИЧ, ПОРУЧИК - 63

НЕСВИЦКАЯ МАРЬЯ ИВАНОВНА, КН., ВДОВА (Н. МИХАИЛ, КН. - МУЖ) - 50

НЕСТЕРОВ АЛЕКСАНДР АЛЕКСЕЕВИЧ - 36

НЕСТЕРОВ ВАСИЛИЙ, ДЬЯК - 53

НЕСТЕРОВ СЕРГЕЙ АЛЕКСАНДРОВИЧ, СОЛДАТ ЛЕЙБ-ГВАРДИИ ПРЕОБРАЖЕНСКОГО ПОЛКА 95

НЕСТЕРОВ ФЕДОР ЛУКИЧ, ПОДЬЯЧИЙ - 6

НИКИФОРОВ ЛУКА ПРОТАСЬЕВИЧ - 47

НИКОЛЕВ ЕГОР ИВАНОВИЧ, СТОЛЬНИК - 33

НИКОЛЕВ ПЕТР МИХАЙЛОВИЧ, «ШКОЛЬНИК» - 43

НИКОЛЕВЫ АННА, НАДЕЖДА И УСТИНЬЯ ИВАНОВНЫ, ДЕВИЦЫ - 18

НОВОСИЛЬЦОВ АЛЕКСЕЙ ЯКОВЛЕВИЧ - 21

НОРОВ ГАВРИЛА ВАСИЛЬЕВИЧ, ПОЛКОВНИК - 40

НОРОВЛЕВ ГАВРИЛА, МАЙОР - 10 
ОБЛОВА ДАРЬЯ ГРИГОРЬЕВНА, ВДОВА - 10

ОБОЛЕНСКИЙ АЛЕКСЕЙ АНДРЕЕВИЧ, КН., КАПИТАН - 13

ОБРЕСКОВ ИВАН АФАНАСЬЕВИЧ, ПРАПОРЩИК ЛЕЙБ-ГВАРДИИ ПРЕОБРАЖЕНСКОГО ПОЛКА 9

ОВИНОВ ИВАН НИКИТИЧ, ДЬЯК - 16

ОВЦЫН ГАВРИЛА МИХАЙЛОВИЧ, ЛЕЙБ-ГВАРДИИ СЕМЕНОВСКОГО ПОЛКА СОЛДАТ, ЗАТЕМ

СЕРЖАНТ - 26

ОВЦЫНА ТАТЬЯНА ИВАНОВНА, ДЕВИЦА - 4

ОГАРЕВ АНДРЕЙ ГЕОРГИЕВИЧ, СТОЛЬНИК - 12

ОДОЕВСКАЯ АВДОТЬЯ ИВАНОВНА, КН., ВДОВА (О. АЛЕКСЕЙ ЮРЬЕВИЧ, КН. - МУЖ) - 206

ОДОЕВСКАЯ ЕВДОКИЯ ИВАНОВНА, КН., ВДОВА - 169

ОДОЕВСКИЙ ВАСИЛИЙ ЮРЬЕВИЧ, КН., ПОДПОЛКОВНИК, ЗАТЕМ ПОЛКОВНИК, ЛЕЙБ-

ГВАРДИИ КАПИТАН - 241

ОДОЕВСКИЙ МИХАИЛ ЮРЬЕВИЧ, КН., БЛИЖНИЙ СТОЛЬНИК - 159

ОКОРОКОВ АЛЕКСАНДР ВАСИЛЬЕВИЧ - 27

ОЛОВЕННИКОВ ИВАН ПЕТРОВИЧ, ПОДЬЯЧИЙ СИБИРСКОЙ КАНЦЕЛЯРИИ - 90

ОЛОВЕННИКОВА ИРИНА НИКИФОРОВНА, ВДОВА (О. ПАРФЕНИЙ - МУЖ) - 29

ОСЕИН (АСЕИН) АЛЕКСЕЙ ФЕДОРОВИЧ, ПОЛКОВНИК - 86

ОЧАКОВА ФЕДОСЬЯ ТИМОФЕЕВНА, ВДОВА - 16

ПАВЛОВ НИКИТА, ДЬЯК - 21

ПАВЛОВ СТЕПАН ДМИТРИЕВИЧ, ПОДПОРУЧИК - 14

ПАВЛОВ СТЕПАН КАРПОВИЧ, КОМИССАР - 21

ПАВЛОВ СТЕПАН ФЕДОРОВИЧ, СТОЛЬНИК - 14

ПАЛЬЧИКОВ ФИЛИПП ПЕТРОВИЧ, УНТЕР-ЛЕЙТЕНАНТ ЛЕЙБ-ГВАРДИИ ПРЕОБРАЖЕНСКОГО ПОЛКА БОМБАРДИРСКОЙ РОТЫ - 115

ПАНИН АЛЕКСЕЙ ИВАНОВИЧ, ГЕНЕРАЛ-МАЙОР - 17

ПАНИН ИВАН ВАСИЛЬЕВИЧ, КАПИТАН - 10

ПАНИН МИХАИЛ ИВАНОВИЧ, НЕДОРОСЛЬ - 30

ПАРФЕНЬЕВ СЕРГЕЙ АНДРЕЯНОВИЧ, МАЙОР - 22

ПАТРИКЕЕВ ИВАН ДЕМЕНТЬЕВИЧ, СЕКРЕТАРЬ - 8

ПАТРИКЕЕВ СЕМЕН МИРОНОВИЧ - 28

ПАТРИКЕЕВ ФЕДОР ОСИПОВИЧ - 9

ПЕТЕЛИН АЛЕКСЕЙ ПЕТРОВИЧ, ПОДПРАПОРЩИК - 37

ПЕТРОВ-СОЛОВО ГРИГОРИЙ МИХАЙЛОВИЧ, СТОЛЬНИК - 32 
ПЛЕМЯННИКОВ ПЕТР ГРИГОРЬЕВИЧ, КАПИТАН - 51

ПЛЕМЯННИКОВА АКУЛИНА ГЕРАСИМОВНА, ВДОВА - 12

ПЛЕЩЕЕВ АЛЕКСЕЙ ЛЬВОВИЧ, ТАЙНЫЙ СОВЕТНИК, СИБИРСКИЙ ГУБЕРНАТОР, СЕНАТОР, ПРЕЗИДЕНТ КАМЕР-КОЛЛЕГИИ - 96

ПЛЕЩЕЕВ АНДРЕЙ ГРИГОРЬЕВИЧ, ПОЛКОВНИК - 24

ПЛЕЩЕЕВ ВАСИЛИЙ АНДРЕЕВИЧ, МОРСКОГО ФЛОТА ГАРДЕМАРИН - 17

ПЛЕЩЕЕВ ИВАН МИХАЙЛОВИЧ, ЛЕЙБ-ГВАРДИИ СЕМЕНОВСКОГО ПОЛКА СЕРЖАНТ - 16

ПЛЕЩЕЕВ ИВАН НИКИФОРОВИЧ, СТАТСКИЙ СОВЕТНИК, ЗАТЕМ ТАЙНЫЙ СОВЕТНИК, СЕНАTOP - 49

ПЛЕЩЕЕВ ФЕДОР АЛЕКСЕЕВИЧ, КАПИТАН - 44

ПЛЕЩЕЕВ ФЕДОР ГРИГОРЬЕВИЧ, КАПИТАН - 26

ПЛОХОВО АНДРЕЙ ЛЕОНТЬЕВИЧ - 28

ПЛОХОВО ГРИГОРИЙ АНДРЕЕВИЧ - 34

ПОЗНЯКОВ ИВАН ДАВЫДОВИЧ - 10

ПОЛЕНОВ МИХАИЛ МИХАЙЛОВИЧ - 22

ПОЛИБИН АЛЕКСЕЙ БОГДАНОВИЧ - 14

ПОЛИБИН АНДРЕЙ АРТЕМЬЕВИЧ - 24

ПОЛИБИН ИЛЬЯ АРТЕМЬЕВИЧ, ПОРУЧИК - 6

ПОЛИБИН ФЕДОР АРТЕМЬЕВИЧ, ПОЛКОВНИК - 38

ПОЛИВАНОВ ВЕНЕДИКТ ИВАНОВИЧ - 30

ПОЛИВАНОВ ИВАН ИЛЬИЧ - 6

ПОЛИВАНОВ МИХАИЛ КУЛИКОВИЧ - 6

ПОЛИВАНОВ НИКИТА ДАНИЛОВИЧ - 7

ПОЛТЕВ ВАСИЛИЙ ИВАНОВИЧ - 22

ПОЛТЕВ НИКИТА ДМИТРИЕВИЧ, СТОЛЬНИК - 29

ПОЛТЕВ СЕМЕН РОМАНОВИЧ, ПОРУЧИК - 68

ПОЛУЭКТОВ БОРИС ВЛАДИМИРОВИЧ, АДЪЮТАНТ - 24

ПОЛУЭКТОВ ИВАН ИВАНОВИЧ, СТОЛЬНИК - 17

ПОЛЯНСКИЙ ИВАН МАКАРОВИЧ, КОМИССАР - 18

ПОРЕЦКИЙ ДМИТРИЙ ЛАРИОНОВИЧ, ПОЛКОВНИК - 26

ПОРОШИН АНДРЕЙ ЯКОВЛЕВИЧ, КАПРАЛ КАВАЛЕРИИ АРХАНГЕЛОГОРОДСКОГО ПОЛКА - 50

ПОСПЕЛОВ ВАСИЛИЙ ПЕТРОВИЧ, КАМЕР-ЮНКЕР - 10

ПОСТНИКОВ ИВАН ИВАНОВИЧ, ЛЕЙБ-ГВАРДИИ ПРЕОБРАЖЕНСКОГО ПОЛКА КАПИТАНпоРУЧИК - 32 
ПОТЕМКИН ДМИТРИЙ ФЕДОРОВИЧ - 89

ПОТЕМКИН ИВАН СТЕПАНОВИЧ, ИНТЕНДАНТ - 118

ПРИКЛОНСКИЙ ИВАН ВАСИЛЬЕВИЧ, КАПИТАН - 16

ПРИКЛОНСКИЙ МИХАИЛ ИВАНОВИЧ, СТОЛЬНИК - 1

ПРОЗОРОВСКИЙ АЛЕКСАНДР НИКИТИЧ, КН., ЛЕЙТЕНАНТ МОРСКОГО ФЛОТА - 98

ПРОЗОРОВСКИЙ АНДРЕЙ ПЕТРОВИЧ, КН., БОЯРИН - 82

ПРОЗОРОВСКИЙ ВЛАДИМИР НИКИТИЧ, КН., ГЕНЕРАЛ-АДЪЮТАНТ - 15

ПРОЗОРОВСКИЙ ИВАН АНДРЕЕВИЧ, КН. - 15

ПРОЗОРОВСКИЙ ПЕТР ИВАНОВИЧ, КН., БОЯРИН - 111

ПРОТАСЬЕВ МИХАИЛ АЛЕКСАНДРОВИЧ, «ШКОЛЬНИК», НЕДОРОСЛЬ - 222

ПРОТОПОПОВ ИВАН АЛЕКСАНДРОВИЧ - 57

ПРОТОПОПОВ ЛЕОНТИЙ ИВАНОВИЧ - 8

ПУТЯТИН СТЕПАН ИВАНОВИЧ, КН., ВИЦЕ-ГУБЕРНАТОР - 6

ПУШКИН АЛЕКСАНДР ПЕТРОВИЧ, ЛЕЙБ-ГВАРДИИ ПРЕОБРАЖЕНСКОГО ПОЛКА СОЛДАТ - 41

ПУШКИН ИВАН КАЛИНОВИЧ, СТОЛЬНИК - 25

ПЯТИН БОРИС ИВАНОВИЧ, СТРЯПЧИЙ СЫТНОГО ДВОРЦА - 30

ПЯТОВО СЕМЕН ЕРЕМЕЕВИЧ, КАПИТАН - 16

ПЯТОВО СТЕПАН ПАРФЕНЬЕВИЧ, ОБЕР-КРИГС-КОМИССАР - 30

РАЕВСКИЙ АЛЕКСАНДР ТИТОВИЧ, ЛЕЙБ-ГВАРДИИ ПРЕОБРАЖЕНСКОГО ПОЛКА КАПИТАНПОРУЧИК - 5

РАЕВСКИЙ ИВАН АРТЕМЬЕВИЧ - 12

РАЕВСКИЙ ИВАН ТИТОВИЧ, ПОДПОЛКОВНИК - 32

РАТМАНОВ АНДРЕЯН (АНДРЕЙ) ГРИГОРЬЕВИЧ, ДЬЯК - 49

РЕПНИН АНИКИТА ИВАНОВИЧ, КН., ГЕНЕРАЛ-АНШЕФ, ГЕНЕРАЛ-ГУБЕРНАТОР, КАВАЛЕР 433

РЖЕВСКИЕ ИЛЬЯ И МАТВЕЙ ВАСИЛЬЕВИЧИ - 27

РЖЕВСКИЙ АЛЕКСАНДР ТИМОФЕЕВИЧ, ПРОКУРОР ЮСТИЦ-КОЛЛЕГИИ - 234

РЖЕВСКИЙ ИВАН АЛЕКСЕЕВИЧ, СТОЛЬНИК - 7

РИМСКИЙ-КОРСАКОВ АНДРЕЙ ЛЕОНТЬЕВИЧ, СТОЛЬНИК - 47

РОМОДАНОВСКАЯ НАСТАСЬЯ БОРИСОВНА, КН., ВДОВА - 243

РОМОДАНОВСКИЙ ИВАН ФЕДОРОВИЧ, КН., ДЕЙСТВИТЕЛЬНЫЙ ТАЙНЫЙ СОВЕТНИК, КАВАЛЕР - 1162

РТИЩЕВ АЛЕКСЕЙ МИХАЙЛОВИЧ, ЖИЛЕЦ - 10

РТИЩЕВ ВАСИЛИЙ МИХАЙЛОВИЧ, МАЙОР - 367 
РУМЯНЦЕВ АЛЕКСАНДР ИВАНОВИЧ, МАЙОР ЛЕЙБ-ГВАРДИИ ПРЕОБРАЖЕНСКОГО ПОЛКА,

ГЕНЕРАЛ-АДЪЮТАНТ, БРИГАДИР - 38

РУМЯНЦЕВ НИКИФОР, ДЬЯК - 12

САБАНИН (СОБАКИН?) ФЕДОР ГРИГОРЬЕВИЧ - 18

САБУРОВ ВАСИЛИЙ ИВАНОВИЧ, ПРОКУРОР - 37

САБУРОВЫ ИВАН, ПОДПОЛКОВНИК И ЯКОВ, МАЙОР ВАСИЛЬЕВИЧИ - 24

САВЕЛОВ АФАНАСИЙ ТИМОФЕЕВИЧ, СТАТСКИЙ СОВЕТНИК - 45

САВЕЛОВ МИХАИЛ БОГДАНОВИЧ, КАПИТАН - 59

САВЕЛОВ ПЕТР ТИМОФЕЕВИЧ, СТАТСКИЙ СОВЕТНИК - 16

$<\mathrm{p}$ class="ann

\section{NOTES}

1. А.В. РОМАНОВИЧ-СЛАВАТИНСКИЙ, ДВОРЯНСТВО В РОССИИ ОТ НАЧАЛА ХVІІІ ВЕКА ДО ОТМЕНЫ КРЕПОСТНОГО ПРАВА, СПБ., 1870, С. 166; С.В. РОЖДЕСТВЕНСКИЙ, СЛУЖИЛОЕ ЗЕМЛЕВЛАДЕНИЕ В МОСКОВСКОМ ГОСУДАРСТВЕ ХVI ВЕКА, СПБ., 1897, С. 61-78; Ю.В. ГОТЬЕ, ЗАМОСКОВНЫЙ КРАЙ В ХVII ВЕКЕ, М., 1906, С. 407-422; С.Б. ВЕСЕЛОВСКИЙ, ФЕОДАЛЬНОЕ ЗЕМЛЕВЛАДЕНИЕ В СЕВЕРО-ВОСТОЧНОЙ РУСИ, Т. 1, М.-Л., 1947, С. 50-55, 80-86, 165-202; Р. ПАЙПС, РОССИЯ ПРИ СТАРОМ РЕЖИМЕ, М., 1993, С. 233, 236-237; Д.А. ЧЕРНЕНКО, ЗЕМЛЕВЛАДЕНИЕ И ХОЗЯЙСТВЕННО-ДЕМОГРАФИЧЕСКИЕ ПРОЦЕССЫ В ЦЕНТРАЛЬНОЙ РОССИИ ХVIIXVIII ВВ.: ОПЫТ РЕГИОНАЛЬНОЙ ТИПОЛОГИИ, ВОЛОГДА, 2008, С. 152-164. ПОДРОБНЫЙ АНАЛИЗ УКАЗА О ЕДИНОНАСЛЕДИИ 1714 Г. И ЕГО ВЛИЯНИЯ НА РАЗВИТИЕ ДВОРЯНСКОЙ Совственности см.: L.A. Farrow, «Peter the Great's Law of Single Inheritance: State Imperatives and Noble Resistance», Russian Review, 55 (3), 1996, p. 430-447; idem, Between Clan and Crown: The Struggle to Define Noble Property Rights in Imperial Russia, Newark, DE, 2004, p. 52-95.

2. V. Kivelson, "The Effects of Partible Inheritance: Gentry Families and the State in Muscovy», Russian Review, 53 (2), 1994, p. 197-212; eadem, Autocracy in the Provinces: The Muscovite Gentry and Political Culture in the Seventeenth Century, Stanford, 1996, p. 101-128. РАБОТЫ В. КИВЕЛЬСОН ОСНОВАНЫ НА ИСТОЧНИКАХ ПО ВЛАДИМИРО-СУЗДАЛЬСКОМУ ДВОРЯНСТВУ XVII В. РЕЦЕНЗИЮ Р. КРАММИ НА ЭТУ МОНОГРАФИЮ СМ.: Slavic Review, 56 (4), 1997, p. 777-778. M.L. Marrese, A Woman's Kingdom: Noblewomen and the Control of Property in Russia, 1700-1861, Ithaca - London, 2002 (РУССКИЙ ПЕРЕВОД: М.Л. МАРРЕЗЕ, БАБЬЕ ЦАРСТВО: ДВОРЯНКИ И ВЛАДЕНИЕ ИМУЩЕСТВОМ В РОССИИ (1700-1861), М., 2009). М. МАРРЕЗЕ ПРОАНАЛИЗИРОВАЛА СВЕДЕНИЯ О СДЕЛКАХ С РАЗЛИЧНЫМИ ВИДАМИ ИМУЩЕСТВА ПО ВЛАДИМИРСКОМУ, КАШИНСКОМУ, ТАМБОВСКОМУ И КУРСКОМУ УЕЗДАМ ЗА ПОЛТОРА ВЕКА. ТАКЖЕ ИСПОЛЬЗОВАЛИСЬ МАТЕРИАЛЫ ЮСТИЦ-КОЛЛЕГИИ, ГДЕ ОТЛОЖИЛИСЬ ДАННЫЕ ИЗ ВСЕХ ГУБЕРНИЙ. ОБЩИЙ ОБЪЕМ ВЫБОРКИ, ПРИВЛЕЧЕННОЙ АВТОРОМ, - ОКОЛО 8 ТЫСяЧ АКТОВ.

3. В РЯДЕ СЛУЧАЕВ ДОПОЛНИТЕЛЬНО ПРИВЛЕКАЛИСЬ СВЕДЕНИЯ IІІ РЕВИЗИИ. СТАТЬЯ ОСНОВАНА НА ДАННЫХ, ПОЛУЧЕННЫХ В РЕЗУЛЬТАТЕ СПЛОШНОЙ СТАТИСТИЧЕСКОЙ ОБРАБОТКИ МАТЕРИАЛОВ I, ІІ И ІІІ РЕВИЗИЙ ПО МОСКОВСКОМУ УЕЗДУ, А ТАКЖЕ 
МАТЕРИАЛОВ ПЕРЕПИСИ ГВАРДИИ МАЙОРА И.А. ШИПОВА (1732-1733 ГГ.), II И ІІІ РЕВИЗИЙ ПО САНКТ-ПЕТЕРБУРГСКОМУ, ШЛИССЕЛЬБУРГСКОМУ, ЯМБУРГСКОМУ И КОПОРСКОМУ УЕЗДАМ. - РОССИЙСКИЙ ГОСУДАРСТВЕННЫЙ АРХИВ ДРЕВНИХ АКТОВ (ДАЛЕЕ - РГАДА), Ф. 248, КН. 1110, Л. 1865-1952; кН. 1161, л. 4-331 оБ.; оП. 109, кН. 158, л. 796-813; Ф. 350, оП. 2, КН. 1480-1482, 1823, 1835-1842, 1854-1867, 2621, 4139, 4202.

4. ПО «ОСНОВНОМУ ГОДУ» РЕВИЗИЙ. - В.М. КАБУЗАН, НАРОДОНАСЕЛЕНИЕ РОССИИ В ХVIII ПЕРВОЙ ПОЛОВИНЕ ХІХ В. (ПО МАТЕРИАЛАМ РЕВИЗИЙ), М., 1963, С. 117, 119-121; ОН ЖЕ, НАРОДЫ РОССИИ В ХVIII ВЕКА: ЧИСЛЕННОСТЬ И ЭТНИЧЕСКИЙ СОСТАВ, М., 1990, С. 11.

5. СМ.: С.Б. ВЕСЕЛОВСКИЙ, ИССЛЕДОВАНИЯ ПО ИСТОРИИ ОПРИЧНИНЫ, М., 1963, С. 78-79; А.П. ПАВЛОВ, «ЗАКОНОДАТЕЛЬСТВО И ПРАКТИКА ИСПОМЕЩЕНИЯ ЧЛЕНОВ ГОСУДАРЕВА ДВОРА ПОД МОСКВОЙ В 20-Х ГОДАХ XVII В.», СУДЕБНИК ИВАНА ІІІ: СТАНОВЛЕНИЕ САМОДЕРЖАВНОГО ГОСУДАРСТВА НА РУСИ, СПБ., 2004, С. 308-331. ПРАВЯЩАЯ ЭЛИТА МОСКОВСКОГО ГОСУДАРСТВА IX-НАЧАЛА ХVIII В.: ОЧЕРКИ ИСТОРИИ, СПБ., 2006, С. 207, 353-355.

6. С.В. ЧЕРНИКОВ, «ВЛАСТЬ И СОБСТВЕННОСТЬ В РОССИИ ЭПОХИ ПЕТРОВСКИХ РЕФОРМ: ЗЕМЕЛЬНЫЕ РАЗДАЧИ В СЕВЕРО-ЗАПАДНОМ РЕГИОНЕ ПЕРВОЙ ЧЕТВЕРТИ ХVIII В.», АКТУАЛЬНЫЕ ПРОБЛЕМЫ АГРАРНОЙ ИСТОРИИ ВОСТОЧНОЙ ЕВРОПЫ: ИСТОРИОГРАФИЯ, МЕТОДЫ ИССЛЕДОВАНИЯ И МЕТОДОЛОГИЯ, ОПЫТ И ПЕРСПЕКТИВЫ, КН. 1, ВОЛОГДА, 2009, С. 122-125; ОН ЖЕ, «МАТЕРИАЛЫ ПОДУШНЫХ ПЕРЕПИСЕЙ ИНГЕРМАНЛАНДИИ 1730-60-Х ГГ. КАК ИСТОЧНИК ПО ЗЕМЛЕВЛАДЕНИЮ ПРАВЯЩЕЙ ЭЛИТЫ РОССИИ», АКТУАЛЬНЫЕ ПРОБЛЕМЫ АГРАРНОЙ ИСТОРИИ ВОСТОЧНОЙ ЕВРОПЫ Х-ХХІ ВВ.: ИСТОЧНИКИ И МЕТОДЫ ИССЛЕДОВАНИЯ, РЯЗАНЬ, 2012, С. 159-168.

7. ПЕРВАЯ РЕВИЗИЯ В ИНГЕРМАНЛАНДИИ НЕ ПРОВОДИЛАСЬ. - В.М. КАБУЗАН, НАРОДОНАСЕЛЕНИЕ РОССИИ ..., С. 50, 57.

8. С.В. ЧЕРНИКОВ, «СОСТАВ И ОСОБЕННОСТИ СОЦИАЛЬНОГО СТАТУСА СВЕТСКОЙ ПРАВЯЩЕЙ ЭЛИТЫ РОССИИ ПЕРВОЙ ЧЕТВЕРТИ ХVIII ВЕКА: ТРАДИЦИИ И НОВАЦИИ», Cahiers du Monde russe, 51 (2-3), 2010, p. 271; ОН ЖЕ, «МАТЕРИАЛЫ ПОДУШНЫХ ПЕРЕПИСЕЙ ИНГЕРМАНЛАНДИИ ...», С. 162-164. СТРУКТУРА ЭЛИТЫ В 1730 И 1758 ГГ. ОЦЕНИВАЛАСЬ ПО СОСТАВУ ЛИЦ, НОСИВШИХ ЧИНЫ 1-4 КЛАССОВ ТАБЕЛИ О РАНГАХ (Т.Е. БЕЗ БРИГАДИРСКОГО РАНГА, ТАКЖЕ ВХОДИВШЕГО В «ГЕНЕРАЛИТЕТ»). ПО ЭТОЙ ПРИЧИНЕ, ПРИВЕДЕННЫЕ ПОКАЗАТЕЛИ ПО ДОЛЕ ПРЕДСТАВИТЕЛЕЙ ДУМНЫХ ФАМИЛИЙ В СОСТАВЕ ЭЛИТЫ ЗА ЭТИ ГОДЫ МОГУТ БЫТЬ ЗАВЫШЕНЫ.

9. ПОДРОБНЕЕ СМ.: R. Crummey, Aristocrats and Servitors: the Boyar Elite in Russia, 1613-1689, Princeton, 1983; idem, «Peter and the Boyar Aristocracy, 1689-1700», Canadian-American Slavic Studies, 8 (2), 1974, p. 274-287; B. Meehan-Waters, Autocracy and aristocracy: The Russian Service Elite of 1730, New Brunswick, NJ, 1982; ЧЕРНИКОВ, «СОСТАВ И ОСОБЕННОСТИ СОЦИАЛЬНОГО СТАТУСА ...», p. 259-280.

10. В ПЕРИОД ПРАВЛЕНИЯ СОФЬИ, ДУМНЫЕ И ВЫСШИЕ ДВОРЦОВЫЕ ЧИНЫ ПОЛУЧАЛИ КАК СТОРОННИКИ КЛАНА МИЛОСЛАВСКИХ, ТАК И НАРЫШКИНЫХ. - А.С. ЛАВРОВ, РЕГЕНТСТВО ЦАРЕВНЫ СОФЬИ АЛЕКСЕЕВНЫ. СЛУЖИЛОЕ ОБЩЕСТВО И БОРЬБА ЗА ВЛАСТЬ В ВЕРХАХ РУССКОГО ГОСУДАРСТВА В 1682-1689 ГГ., М., 1999, С. 79-100.

11. ПО ИТОГОВОЙ ВЕДОМОСТИ, СОСТАВЛЕННОЙ ПОСЛЕ ЗАВЕРШЕНИЯ II РЕВИЗИИ, В ЧЕТЫРЕХ УЕЗДАХ ИНГЕРМАНЛАНДИИ В НАЧАЛЕ 1730-Х ГГ. ЧИСЛИЛОСЬ 25913 ДУШ М.П. ПОМЕЩИЧЬИХ КРЕСТЬЯН, А ПО ІІ РЕВИЗИИ - 28670 ДУШ М.П. (РГАДА, Ф. 350, ОП. 2, КН. 4202, Л. 523-530). НАШИ ПОДСЧЕТЫ ДАЮТ БЛИЗКИЕ РЕЗУЛЬТАТЫ - 24110 И 28571 ДУША М.П., СООТВЕТСТВЕННО. 
12. СМ.: ПЕРЕПИСИ НАСЕЛЕНИЯ РОССИИ, М., 1972, ВЫП. 3, С. 7.

13. КАЖДОЕ ВЛАДЕНИЕ, УЧТЕННОЕ ПЕРЕПИСНЫМИ КНИГАМИ ІІ РЕВИЗИИ, БЫЛО НАЙДЕНО В МАТЕРИАЛАХ І РЕВИЗИИ - ВЕДОМОСТИ РЕКРУТСКОГО НАБОРА 1737-1738 ГГ. (ИЗ НЕЕ БЫЛИ ЗАИМСТВОВАНЫ СВЕДЕНИЯ О КОЛИЧЕСТВЕ ДУШ М.П. ПО І РЕВИЗИИ). СВЕДЕНИЯ О ВЛАДЕЛЬЦАХ ИМЕНИЙ НА ВРЕМЯ І РЕВИЗИИ, КОТОРЫЕ УКАЗАНЫ В ПЕРЕПИСНЫХ КНИГАХ II РЕВИЗИИ И В ВЕДОМОСТИ 1737-1738 ГГ., СОВПАДАЮТ (ИСКЛЮЧЕНИЯ ЕДИНИЧНЫ). О ДАТИРОВКЕ ДАННЫХ, СОДЕРЖАЩИХСЯ В ВЕДОМОСТЯХ РЕКРУТСКОГО НАБОРА, СМ.: С.В. ЧЕРНИКОВ, ДВОРЯНСКИЕ ИМЕНИЯ ЦЕНТРАЛЬНО-ЧЕРНОЗЕМНОГО РЕГИОНА РОССИИ В ПЕРВОЙ ПОЛОВИНЕ ХVIII ВЕКА, РЯЗАНЬ, 2003, С. 34.

14. АНАЛИЗ ВЛИЯНИЯ «ВЫБРОСОВ» (НЕТИПИЧНЫХ ДАННЫХ), КОТОРЫЕ ИСКУССТВЕННЫМ ОБРАЗОМ СМЕЩАЮТ (УВЕЛИЧИВАЮТ ИЛИ УМЕНЬШАЮТ) КОЭФФИЦИЕНТ КОРРЕЛЯЦИИ, БЫЛ ПРОВЕДЕН НА ДИАГРАММЕ РАССЕЯНИЯ В ПАКЕТЕ STАТISTICА. ПОДРОБНЕЕ ОБ ЭТОМ МЕТОДЕ СМ.: В.П. БОРОВИКОВ, STАТISTICА. ИСКУССТВО АНАЛИЗА ДАННЫХ НА КОМПЬЮТЕРЕ, СПБ., 2003, С. 222.

15. СМ. ТАКЖЕ: С.В. ЧЕРНИКОВ, «РОССИЙСКАЯ ЭЛИТА ЭПОХИ РЕФОРМ ПЕТРА ВЕЛИКОГО: СОСТАВ И СОЦИАЛЬНАЯ СТРУКТУРА», ГОСУДАРСТВО И ОБЩЕСТВО В РОССИИ ХV - НАЧАЛА ХХ ВЕКА, СПБ., 2007, С. 376.

16. В ДАННОМ СЛУЧАЕ, РЕЧЬ ИДЕТ О БОЛЕЕ ШИРОКОМ СЛОЕ ЛЮДЕЙ, ЧЕМ ПРАВЯЩАЯ ЭЛИТА СТРАНЫ. ПОДРОБНЕЕ О ЗЕМЕЛЬНЫХ РАЗДАЧАХ ИНГЕРМАНЛАНДИИ СМ.: ЧЕРНИКОВ, «ВЛАСТЬ И СОБСТВЕННОСТЬ В РОССИИ ЭПОХИ ПЕТРОВСКИХ РЕФОРМ ...», С. 121-130.

17. ПОДСЧИТАНО ПО ВЕДОМОСТЯМ РЕКРУТСКОГО НАБОРА 1737-1738 ГГ. (І РЕВИЗИЯ), «ПРОКУРОРСКИМ ВЕДОМОСТЯМ» И РЕВИЗСКИМ СКАЗКАМ ІІІ ПОДУШНОЙ ПЕРЕПИСИ: РГАДА, Ф. 248, ОП. 17, КН. 1163, Ч. 1, Л. 135-196 ОБ., 337 ОБ.-373 ОБ., 377-397 ОБ., 597-702 ОБ.; оП. 109, кН. 158, л. 212-278, 815-845; оп. 117, кН. 1464, л. 100-124; Ф. 350, оП. 2, кН. 748, 753, 952-956, 1676-1682. ВЕСЬ КОМПЛЕКС «ПРОКУРОРСКИХ ВЕДОМОСТЕЙ» ДАТИРУЕТСЯ 1766-1767 ГГ. ХАРАКТЕРИСТИКУ ЭТОГО ИСТОЧНИКА СМ.: Н. М. ШЕПУКОВА, «К ВОПРОСУ О ЧИСЛЕННОСТИ БАРЩИННЫХ И ОБРОЧНЫХ ПОМЕЩИЧЬИХ КРЕСТЬЯН ЕВРОПЕЙСКОЙ РОССИИ ВО 2-Й ПОЛОВИНЕ XVIII ВЕКА», ЕЖЕГОДНИК ПО АГРАРНОЙ ИСТОРИИ ВОСТОЧНОЙ ЕВРОПЫ ЗА 1964 Г. (ДАЛЕЕ: ЕАИВЕ), КИШИНЕВ, 1966, С. 400-408; М.Ф. ПРОХОРОВ, КРЕПОСТНОЕ КРЕСТЬЯНСТВО РОССИИ В 1750 - НАЧАЛЕ 1770-Х ГОДОВ, ДИСС. ... ДОКТОРА ИСТ. НАУК, М., 1997, С. 86-88.

18. ПОДРОБНЕЕ СМ.: С.В. ЧЕРНИКОВ, «ПОМЕЩИКИ И КРЕПОСТНОЕ КРЕСТЬЯНСТВО РЯЗАНСКОГО УЕЗДА В 20-60-Х ГГ. XVIII ВЕКА (ПО МАТЕРИАЛАМ ПЕРВОЙ И ТРЕТЬЕЙ РЕВИЗИЙ)», РЯЗАНСКАЯ СТАРИНА, 2006, № 2-3, РЯЗАНЬ, С. 31-33.

19. О ПОЛИТИКЕ «ЗАКАЗНЫХ ГОРОДОВ» СМ.: А.А. НОВОСЕЛЬСКИЙ, «РАСПРОСТРАНЕНИЕ КРЕПОСТНИЧЕСКОГО ЗЕМЛЕВЛАДЕНИЯ В ЮЖНЫХ УЕЗДАХ МОСКОВСКОГО ГОСУДАРСТВА В XVII В.», ИСТОРИЧЕСКИЕ ЗАПИСКИ, Т. 4, М., 1938, С. 21-40; В.М. ВАЖИНСКИЙ, ЗЕМЛЕВЛАДЕНИЕ И СКЛАДЫВАНИЕ ОБЩИНЫ ОДНОДВОРЦЕВ В ХVII ВЕКЕ (ПО МАТЕРИАЛАМ ЮЖНЫХ УЕЗДОВ РОССИИ), ВОРОНЕЖ, 1974, С. 78-88.

20. ОБ ОТПИСКЕ ДВОРЯНСКИХ И МОНАСТЫРСКИХ ВЛАДЕНИЙ СМ.: В.М. ВАЖИНСКИЙ, «СЕЛЬСКИЕ ПОСЕЛЕНИЯ ЛИПЕЦКОГО КРАЯ В ХVII ВЕКЕ», ЗАПИСКИ КРАЕВЕДЧЕСКОГО ОБЩЕСТВА, ВЫП. 1, ЛИПЕЦК, 1995, С. 30-31; ОН ЖЕ, «МОНАСТЫРИ В ЛИПЕЦКОМ КРАЕ ДО НАЧАЛА ХХ ВЕКА», ИСТОРИЯ-ФИЛОСОФИЯ-КУЛЬТУРА: ИСТОРИКО-ФИЛОСОФСКИЕ ЧТЕНИЯ, ЛИПЕЦК, 1994, С. 121-123; В.П. ЗАГОРОВСКИЙ, БЕЛГОРОДСКАЯ ЧЕРТА, ВОРОНЕЖ, 1969, С. 132-135. 
21. Е.В. АНИСИМОВ, ПОДАТНАЯ РЕФОРМА ПЕТРА І: ВВЕДЕНИЕ ПОДУШНОЙ ПОДАТИ В РОССИИ 1719-1728 ГГ., Л., 1982, С. 165-189.

22. ВРЕМЯ ПРОВЕДЕНИЯ ПЕРЕПИСЕЙ НЕ СОВПАДАЕТ СО СМЕНОЙ МОНАРХОВ НА РОССИЙСКОМ ПРЕСТОЛЕ, НО ХРОНОЛОГИЧЕСКИЙ СДВИГ НЕЗНАЧИТЕЛЕН (ПО ОСНОВНОМУ ГОДУ» РЕВИЗИЙ НЕ БОЛЕЕ ТРЕХ ЛЕТ).

23. ЧЕРНИКОВ, «МАТЕРИАЛЫ ПОДУШНЫХ ПЕРЕПИСЕЙ ИНГЕРМАНЛАНДИИ ...», С. 160.

24. ДЛЯ АНАЛИЗА СОСТАВА ПРАВЯЩЕГО СЛОЯ НАЧАЛА 1730 Г. ИСПОЛЬЗОВАЛСЯ СПИСОК П.Ф. КАРАБАНОВА С УТОЧНЕНИЯМИ, ВНЕСЕННЫМИ Б. МИХАН-УОТЕРС И И.В. КУРУКИНЫМ (СМ.: М.Н. ЛОНГИНОВ, «РУССКИЙ ГЕНЕРАЛИТЕТ В 1730 ГОДУ (ПО СПИСКУ П.Ф. КАРАБАНОВА)», ОСМНАДЦАТЫЙ ВЕК, КН. ІІІ, М., 1869, С. 161-177; В. Meehan-Waters, Autocracy and aristocracy: The Russian Service Elite of 1730, New Brunswick, NJ, 1982; И.В. КУРУКИН, ЭПОХА «ДВОРСКИХ БУРЬ»: ОЧЕРКИ ПОЛИТИЧЕСКОЙ ИСТОРИИ ПОСЛЕПЕТРОВСКОЙ РОССИИ, 1725-1762 ГГ., РЯЗАНЬ, 2003, С. 183-191; И.В. КУРУКИН, А.Б. ПЛОТНИКОВ, 19 ЯНВАРЯ - 25 ФЕВРАЛЯ 1730 ГОДА: СОБЫТИЯ, ЛЮДИ, ДОКУМЕНТЫ, М., 2010, С. 61-93). ДЛЯ 1758 Г. ИСПОЛЬЗОВАН «СПИСОК ПЕРВЫХ ЧЕТЫРЕХ КЛАССОВ ПРИДВОРНЫХ, ВОИНСКИХ И СТАТСКИХ ЧИНОВ» (РГАДА, Ф. 248, ОП. 113, КН. 1353, Л. 1-28 ОБ.). НА ОБЛОЖКЕ ДЕЛА УКАЗАН 1759 Г., ОДНАКО ДАТИРОВКА ПОСЛЕДНИХ ПОЖАЛОВАНИЙ, УЧТЕННЫХ В ПЕРЕЧНЕ, УКАЗЫВАЕТ НА ТО, ЧТО ОН БЫЛ СОСТАВЛЕН ВЕСНОЙ-ЛЕТОМ 1758 Г.

25. ИЗ ДУМНЫХ ФАМИЛИЙ: АПРАКСИНЫ, БУТУРЛИНЫ, ГОЛИЦЫНЫ, ГОЛОВИНЫ, ГОЛОВКИНЫ, ДОЛГОРУКОВЫ, КУРАКИНЫ, ЛЕОНТЬЕВЫ, ЛОПУХИНЫ, НАРЫШКИНЫ, ПАНИНЫ, САЛТЫКОВЫ, СУХОТИНЫ, ТРУБЕЦКИЕ, ЧЕРКАССКИЕ (И БЕКОВИЧИ-ЧЕРКАССКИЕ), ШАХОВСКИЕ, ШЕПЕЛЕВЫ, ШЕРЕМЕТЕВЫ, ЩЕРБАТОВЫ (20 РОДОВ, 54 \%). ИЗ СРЕДЫ НЕДУМНОГО ДВОРЯНСТВА: БЕСТУЖЕВЫ-РЮМИНЫ, БИБИКОВЫ, ВОЕЙКОВЫ, КОШЕЛЕВЫ, МЕЩЕРСКИЕ, ОЛСУФЬЕВЫ, РУМЯНЦОВЫ, УШАКОВЫ, ЧЕРНЫШЕВЫ, ШУВАЛОВЫ, ЮСУПОВЫ (11 РОДОВ, $30 \%$ ). ИЗ ИНОЗЕМЦЕВ: БАЛК, ГРУЗИНСКИЕ, КАМПЕНГАУЗЕНЫ, МИНИХИ, СИВЕРСЫ, ЯГУЖИНСКИЕ (6 РОДОВ, $16 \%$ ). ВСЕГО: 37 ФАМИЛИЙ.

26. ЧАСТЬ ИМЕНИЙ (4\% ПО ПЕРВОЙ РЕВИЗИИ, $7 \%$ - ПО ВТОРОЙ) НАХОДИЛАСЬ В СОВМЕСТНОМ ВЛАДЕНИИ. ПО ЭТОЙ ПРИЧИНЕ СУММЫ ПО СТОЛБЦАМ В ТАБЛИЦАХ 4-6 МОГУТ ПРЕВЫШАТЬ ИТОГОВЫЕ ЗНАЧЕНИЯ.

27. ПОСКОЛЬКУ СПУСТЯ ЧЕТВЕРТЬ ВЕКА В РУКАХ ПРЕДСТАВИТЕЛЕЙ ДВОРЯНСКОЙ ФАМИЛИИ ОСТАВАЛОСЬ ОКОЛО $60 \%$ ИХ ПРЕЖНИХ ВОТЧИН, ТО НА ОТРЕЗКЕ В 50 ЛЕТ, ПРИ УСЛОВИИ СОХРАНЕНИЯ ТОЙ ЖЕ ТЕНДЕНЦИИ, КОТОРАЯ ЗАФИКСИРОВАНА МЕЖДУ І И ІІ РЕВИЗИЯМИ, ЭТОТ ПОКАЗАТЕЛЬ СОСТАВИТ $36 \%$. ПО ПОДСЧЕТАМ Ю.В. ГОТЬЕ, В МОСКОВСКОМ УЕЗДЕ, ЧЕРЕЗ 50-60 ЛЕТ (МЕЖДУ СОСТАВЛЕНИЕМ ПИСЦОВЫХ КНИГ 1620-Х ГГ. И ПЕРЕПИСЯМИ КОНЦА ВЕКА - 1678 Г. И 1684-1686 ГГ.), У ЕДИНОРОДЦЕВ ОСТАВАЛОСЬ 37,3 \% ИМЕНИЙ (В ТОМ ЧИСЛЕ, 39,2 \% ПОМЕСТИЙ И 35,6\% ВОТЧИН), А В СОСЕДНИХ УЕЗДАХ ЗАМОСКОВНОГО КРАЯ - 31,3 \% (Ю.В. ГОТЬЕ, ЗАМОСКОВНЫЙ КРАЙ..., С. 417, 419). ТАКИМ ОБРАЗОМ, ДОЛЯ ВОТЧИН, СОХРАНЯВШИХСЯ В РОДОВОЙ СОБСТВЕННОСТИ В ПЕРВОЙ ПОЛОВИНЕ XVIII СТОЛЕТИЯ, СОПОСТАВИМА С УРОВНЕМ XVII ВЕКА.

28. ДЛЯ СРАВНЕНИЯ, ПО ДАННЫМ НА 1723 И 1745 ГГ., В КУРСКОМ УЕЗДЕ ЗАКЛАДНЫЕ ОФОРМЛЯЛИСЬ ГОРАЗДО РЕЖЕ, ЧЕМ КУПЧИЕ. В СДЕЛКАХ ПО ПАШНЕ С УГОДЬЯМИ - РЕЖЕ В 6,9-7,7 РАЗА, В СДЕЛКАХ ПО ПАШНЕ С УГОДЬЯМИ, КРЕПОСТНЫМИ И «СТРОЕНИЕМ» - В 2,5-4,5 РАЗА. - С.В. ЧЕРНИКОВ, «К ВОПРОСУ О ФОРМИРОВАНИИ РЫНКА ЗЕМЛИ В КУРСКОМ УЕЗДЕ В ПЕРВОЙ ПОЛОВИНЕ ХVIII В.», ДИНАМИКА И ТЕМПЫ АГРАРНОГО РАЗВИТИЯ РОССИИ: ИНФРАСТРУКТУРА И РЫНОК, ОРЕЛ, 2006, С. 178. 
29. Kivelson, Autocracy in the Provinces, p. 101-128; М.Л. МАРРЕЗЕ, БАБЬЕ ЦАРСТВО, С. 201. КИВЕЛЬСОН УБЕДИТЕЛЬНО ДОКАЗЫВАЕТ, ЧТО УЖЕ В ХVII СТОЛЕТИИ РАСШИРЕННАЯ РОДСТВЕННАЯ ГРУППА (КЛАН) ИГРАЛА МЕНЕЕ ВАЖНУЮ РОЛЬ В СРЕДЕ ПРОВИНЦИАЛЬНОГО ДВОРЯНСТВА НЕЖЕЛИ В КРУГУ БОЯРСКОЙ АРИСТОКРАТИИ. - Kivelson, Autocracy in the Provinces, p. 103.

30. МАРРЕЗЕ, БАББЕ ЦАРСТВО, С. 212-213, 216-217.

31. ДЛЯ СРАВНЕНИЯ, ПО ДАННЫМ НОВГОРОДСКИХ ПИСЦОВЫХ КНИГ 1582-1584 ГГ. И 1626-1627 ГГ., ЖЕНЩИНЫ СОСТАВЛЯЛИ ОТ 2,3 ДО 5,5\% ВСЕХ ЗЕМЛЕВЛАДЕЛЬЦЕВ. МАРРЕЗЕ, БАББЕ ЦАРСТВО, С. 147. О ДОЛЕ НЕДВИЖИМОСТИ, ПРИНАДЛЕЖАВШЕЙ ЖЕНЩИНАМ В ЗАПАДНОЙ ЕВРОПЕ И СЕВЕРНОЙ АМЕРИКЕ В XVIII-XIX ВВ., СМ.: ТАМ ЖЕ, С. 161.

32. ПОДРОБНЕе См.: G. Weickhardt, «Legal Rights of Women in Russia, 1100-1750», Slavic Review, 55 (1), 1996, p. 19-20. РАСШИРЕНИЕ ПРАВ ЖЕНЩИН, В ТОМ ЧИСЛЕ ЗАМУЖНИХ, ПРИ РАСПОРЯЖЕНИИ НЕДВИЖИМОСТЬЮ В ТЕЧЕНИЕ ПЕРВОЙ ПОЛОВИНЫ XVIII В. (КУПЛЯПРОДАЖА, ЗАКЛАД И Т.Д.) ТАКЖЕ ХОРОШО ПРОСЛЕЖИВАЕТСЯ НА ОСНОВЕ ДАННЫХ, ПРЕДСТАВЛЕННЫХ В РАБОТЕ М. Л. МАРРЕЗЕ. - МАРРЕЗЕ, БАББЕ ЦАРСТВО, С. 149-150, 152-155.

33. МАРРЕЗЕ, БАБЬЕ ЦАРСТВО, С. 207, 212-213, 216-217. ДАННЫЕ М.Л. МАРРЕЗЕ ОТНОСЯТСЯ КО ВСЕЙ РОССИИ, А НЕ ТОЛЬКО К МОСКОВСКОМУ УЕЗДУ, КАК В НАШЕМ СЛУЧАЕ. АВТОР АНАЛИЗИРОВАЛА ЗАВЕЩАНИЯ В СОСТАВЕ ЕДИНОГО МАССИВА, ПОЭТОМУ У НАС НЕТ ВОЗМОЖНОСТИ ПРОСЛЕДИТЬ ОСОБЕННОСТИ НАСЛЕДОВАНИЯ ПО БОЛЕЕ УЗКИМ ХРОНОЛОГИЧЕСКИМ ПЕРИОДАМ. МАТЕРИАЛЫ РЕВИЗИЙ (В ОТЛИЧИИ ОТ ЗАВЕЩАНИЙ) НЕ ПОЗВОЛЯЮТ ВЫЯВИТЬ РАЗЛИЧИЯ В ПОВЕДЕНИИ БЕЗДЕТНЫХ СУПРУГОВ И ЗАВЕЩАТЕЛЕЙ, КОТОРЫЕ ИМЕЛИ ПРЯМЫХ НАСЛЕДНИКОВ.

34. МАРРЕЗЕ, БАББЕ ЦАРСТВО, С. 201, 222-226. СЛЕДУЕТ ОБРАТИТЬ ВНИМАНИЕ НА ПРЕДПОСЛЕДНЮЮ СТРОКУ ТАБЛИЦЫ 6. ОЧЕВИДНЫ СУЩЕСТВЕННЫЕ РАЗЛИЧИЯ В ПОКАЗАТЕЛЯХ ПО ВОТЧИНАМ, ПЕРЕШЕДШИМ ОТ ЖЕНЩИН И МУЖЧИН. ОДНАКО НА ОСНОВЕ ЭТИХ ДАННЫХ НЕЛЬЗЯ ДЕЛАТЬ ВЫВОД, ЧТО ЖЕНЩИНЫ ЗАВЕЩАЛИ СОБСТВЕННОСТЬ БОЛЕЕ ШИРОКОМУ КРУГУ НАСЛЕДНИКОВ. ИЗНАЧАЛЬНО ДВЕ КРУПНЫЕ ВОТЧИНЫ ЦАРЕВНЫ ДАРЬИ АРЧИЛОВНЫ ИМЕРЕТИНСКОЙ (ПО ІІ РЕВИЗИИ - 661 ДУША М.П.) БЫЛИ ЗАВЕЩАНЫ ЕЕ ПЛЕМЯННИЦЕ СОФЬЕ (ДОЧЕРИ ПЕРВОГО ГЕНЕРАЛФЕЛЬДЦЕЙХМЕЙСТЕРА АЛЕКСАНДРА АРЧИЛОВИЧА) И ЛИШЬ КО ВРЕМЕНИ ІІ РЕВИЗИИ ПЕРЕШЛИ К МУЖУ СОФЬИ - ГЕНЕРАЛ-МАЙОРУ КН. ГЕОРГИЮ ЛЕОНТЬЕВИЧУ ДАДИАНИ. «ПРОТОКОЛЫ, ЖУРНАЛЫ И УКАЗЫ ВЕРХОВНОГО ТАЙНОГО СОВЕТА, ИЮЛЬ-ДЕКАБРЬ 1728 Г.», СБОРНИК ИМПЕРАТОРСКОГО РУССКОГО ИСТОРИЧЕСКОГО ОБЩЕСТВА, Т. 84, СПБ., 1893, С. 269-272; РГАДА, Ф. 350, ОП. 2, КН. 1840, Л. 96 ОБ.-106; КН. 1842, Л. 893-925 ОБ.

35. ПРИ ПЕРЕДАЧЕ ВОТЧИН ЖЕНЩИНАМ, ДОЛЯ ВЛАДЕНИЙ ВЫШЕ, ЧЕМ ДОЛЯ КРЕПОСТНЫХ; ПО ИМЕНИЯМ, КОТОРЫЕ УНАСЛЕДОВАЛИ МУЖЧИНЫ - ОБРАТНАЯ ЗАВИСИМОСТЬ.

36. ВМЕСТЕ С ТЕМ, ДАННЫЕ ТАБЛИЦЫ 6 ХОРОШО СОГЛАСУЮТСЯ С ВЫВОДОМ М.Л. МАРРЕЗЕ, ЧТО ЖЕНЩИНЫ ЧАЩЕ, ЧЕМ МУЖЧИНЫ, ЗАБОТИЛИСЬ О ТОМ, ЧТОБЫ ИХ ДОЧЕРИ ПОЛУЧИЛИ В НАСЛЕДСТВО ЗЕМЛЮ И КРЕПОСТНЫХ. - МАРРЕЗЕ, БАББЕ ЦАРСТВО, С. 214.

37. МАРРЕЗЕ, БАБЬЕ ЦАРСТВО, С. 208.

38. МАРРЕЗЕ, БАББЕ ЦАРСТВО, С. 228-229. 
39. ОБЗОР ОСНОВНЫХ ТОЧЕК ЗРЕНИЯ ПО ДАННОМУ ВОПРОСУ СМ.: Kivelson, «The Effects of Partible Inheritance...», p. 197-201. О ЗАВИСИМОстИ ДВОРЯНСТВА ОТ ГОСУДАРСТВЕННОЙ СЛУЖБЫ И ЖАЛОВАНИЯ СМ.: С.М. ТРОИЦКИЙ, РУССКИЙ АБСОЛЮТИЗМ И ДВОРЯНСТВО В XVIII В.: ФОРМИРОВАНИЕ БЮРОКРАТИИ, М., 1974, С. 266; И.В. ФАИЗОВА, «МАНИФЕСТ О ВОЛЬНОСТИ» И СЛУЖБА ДВОРЯНСТВА В ХVІІІ СТОЛЕТИИ, М., 1999, С. 51, 90, 93, 95, 132.

40. ДРОБЛЕНИЕМ СЧИТАЛИСЬ ТЕ СЛУЧАИ, КОГДА ВМЕСТО ОДНОЙ ВОТЧИНЫ (ПРИНАДЛЕЖАВШЕЙ ОДНОМУ ВЛАДЕЛЬЦУ ИЛИ ГРУППЕ ЛИЦ БЕЗ РАЗДЕЛА) В ТОМ ИЛИ ИНОМ НАСЕЛЕННОМ ПУНКТЕ (ЛИБО ГРУППЕ СЕЛ И ДЕРЕВЕНЬ, СОСТАВЛЯВШИХ ВОТЧИНУ) КО ВРЕМЕНИ ІІ РЕВИЗИИ ПОЯВЛЯЛОСЬ НЕСКОЛЬКО ОТДЕЛЬНЫХ ВЛАДЕНИЙ. СЛУЧАИ РАЗДЕЛА НЕНАСЕЛЕННОЙ ЗЕМЛИ (КАК ПРАВИЛО, ОНИ НЕ ФИКСИРОВАЛИСЬ МАТЕРИАЛАМИ ПЕРЕПИСЕЙ) НЕ УЧТЕНЫ. ПЕРЕВОДЫ КРЕПОСТНЫХ ИЗ ОДНОГО ИМЕНИЯ В ДРУГОЕ (ПРИ ИХ ПРОДАЖЕ ИЛИ НАСЛЕДОВАНИИ) ТАКЖЕ НЕ РАССМАТРИВАЛИСЬ КАК ФАКТ ДРОБЛЕНИЯ ВОТчИНЫ.

41. ПОДСЧИТАНО ПО СОПОСТАВИМЫМ ДАННЫМ МАТЕРИАЛОВ I И ІІ РЕВИЗИЙ.

42. ВЕРОЯТНО, ДОЛЯ СОВЛАДЕНИЙ БЛИЗКАЯ К 10 \% БЫЛА ТИПИЧНА ДЛЯ ЦЕНТРАЛЬНЫХ РЕГИОНОВ РОССИИ. - СМ.: Я.Е. ВОДАРСКИЙ, НАСЕЛЕНИЕ РОССИИ В КОНЦЕ XVII - НАЧАЛЕ XVIII ВЕКА: ЧИСЛЕННОСТЬ, СОСЛОВНО-КЛАССОВЫЙ СОСТАВ, РАЗМЕЩЕНИЕ, М., 1977, С. 73. ЧЕРНЕНКО, ЗЕМЛЕВЛАДЕНИЕ И ХОЗЯЙСТВЕННО-ДЕМОГРАФИЧЕСКИЕ ПРОЦЕССЫ, С. 82, 86.

43. ИНТЕРЕСНЫЙ ВЫВОД О «ПОВЕДЕНИИ ЗАВЕЩАТЕЛЕЙ» БЫЛ СДЕЛАН М.Л. МАРРЕЗЕ. ПО ЕЕ МНЕНИЮ, ДВОРЯНЕ ДАЖЕ ПОСЛЕ 1731 Г. ПЫТАЛИСЬ ИЗБЕЖАТЬ КРАЙНЕГО ДРОБЛЕНИЯ ИМЕНИЙ, ИСКЛЮЧАЯ ИЗ ЧИСЛА НАСЛЕДНИКОВ ОДНОГО ИЛИ НЕСКОЛЬКИХ СВОИХ ДЕТЕЙ. -МАРРЕЗЕ, БАБЬЕ ЦАРСТВО, С. 208-209.

44. Я.Е. ВОДАРСКИЙ, О.А. ШВАТЧЕНКО, СОСТ., ДВОРЯНСТВО РОССИИ И ЕГО КРЕПОСТНЫЕ КРЕСТЬЯНЕ, ХVII - ПЕРВАЯ ПОЛОВИНА ХVIII В., М., 1989, С. 93.

45. СМ.: ПЕРЕПИСИ НАСЕЛЕНИЯ РОССИИ, М., 1972, ВЫП. 3, С. 7.

46. ОБРАТИМ ВНИМАНИЕ, ЧТО В ПЕРВОЙ ПОЛОВИНЕ ХVIII В. ТАКИМ ЗНАТНЫМ ФАМИЛИЯМ КАК КН. ГОЛИЦЫНЫ И ДОЛГОРУКОВЫ, НЕСМОТРЯ НА УЧАСТИЕ В ДВОРЦОВЫХ ИНТРИГАХ И КОНФИСКАЦИЮ РЯДА КРУПНЫХ ИМЕНИЙ, УДАЛОСЬ НЕ ТОЛЬКО СОХРАНИТЬ В НЕПРИКОСНОВЕННОСТИ БОЛЬШУЮ ЧАСТЬ ВОТЧИН, НО И ЗНАЧИТЕЛЬНО РАСШИРИТЬ СВОЕ ЗЕМЛЕВЛАДЕНИЕ. - ЧЕРНИКОВ, ДВОРЯНСКИЕ ИМЕНИЯ ЦЕНТРАЛЬНО-ЧЕРНОЗЕМНОГО РЕГИОНА, с. 142, 249, 254.

47. ИМЕННО ПО ЭТОЙ ПРИЧИНЕ, НАШИ ПОДСЧЕТЫ ПО ВЕДОМОСТЯМ 1737-1738 ГГ. (I РЕВИЗИЯ) РАСХОДЯТСЯ С ДАННЫМИ Я.Е. ВОДАРСКОГО. - СМ.: ВОДАРСКИЙ, НАСЕЛЕНИЕ РОССИИ, С. 76; ВОДАРСКИЙ, ШВАТЧЕНКО, СОСТ., ДВОРЯНСТВО РОССИИ И ЕГО КРЕПОСТНЫЕ КРЕСТЬЯНЕ, С. 116-117. О КЛАССИФИКАЦИИ ИМЕНИЙ ПО ВЕЛИЧИНЕ В ЗАВИСИМОСТИ ОТ ИХ НАСЕЛЕННОСТИ СМ.: ВОДАРСКИЙ, НАСЕЛЕНИЕ РОССИИ, С. 59.

48. РГАДА, Ф. 248, КН. 1161, Л. 20 ОБ., 45 ОБ., 141 ОБ., 197, 204, 206 ОБ., 207 ОБ., 222 ОБ., 226; Ф. 350, оП. 2, Д. 1823, Л. 365, 907.

49. Б.Н. МИРОНОВ, СОЦИАЛЬНАЯ ИСТОРИЯ РОССИИ ПЕРИОДА ИМПЕРИИ (ХVIII-НАЧАЛО ХХ В.). ГЕНЕЗИС ЛИЧНОСТИ, ДЕМОКРАТИЧЕСКОЙ СЕМЬИ И ПРАВОВОГО ГОСУДАРСТВА, Т. 1, СПБ., 2003, С. 93.

50. ЧЕРНЕНКО, ЗЕМЛЕВЛАДЕНИЕ И ХОЗЯЙСТВЕННО-ДЕМОГРАФИЧЕСКИЕ ПРОЦЕССЫ, С. 154-155, 181-183, 190. 
51. ТАБЛИЦА СОСТАВЛЕНА ПО.: И.А. КАБИРОВА, НАСЛЕДОВАНИЕ И КУПЛЯ-ПРОДАЖА ЗЕМЕЛЬНЫХ ВЛАДЕНИЙ В РОССИИ ПЕРВОЙ ПОЛОВИНЫ ХVIII ВЕКА (ПО ЗАКОНОДАТЕЛЬНОНОРМАТИВНЫМ МАТЕРИАЛАМ И ЧАСТНОПРАВОВЫМ АКТАМ МОСКОВСКОГО УЕЗДА), ДИСС. ... КАНД. ИСТ. НАУК, ГЛАЗОВ, 2003, С. 91, 97, 106, 112, 120, 127.

52. КАБИРОВА, НАСЛЕДОВАНИЕ И КУПЛЯ-ПРОДАЖА ЗЕМЕЛЬНЫХ ВЛАДЕНИЙ, С. 134.

53. ТОТ ЖЕ ВЫВОД СОДЕРЖИТСЯ В РАБОТАХ М.Д. РАБИНОВИЧА И Г.В. КАЛАШНИКОВА, КОТОРЫЕ ОСНОВАНЫ НА АНАЛИЗЕ ОБШИРНОГО КОМПЛЕКСА ОФИЦЕРСКИХ СКАЗОК И СМОТРОВЫХ СПИСКОВ ПОЛКОВ РУССКОЙ АРМИИ 1720-1745 ГГ. - М.Д. РАБИНОВИЧ, «СОЦИАЛЬНОЕ ПРОИСХОЖДЕНИЕ И ИМУЩЕСТВЕННОЕ ПОЛОЖЕНИЕ ОФИЦЕРОВ РЕГУЛЯРНОЙ РУССКОЙ АРМИИ В КОНЦЕ СЕВЕРНОЙ ВОЙНЫ», РОССИЯ В ПЕРИОД РЕФОРМ ПЕТРА I, М., 1973, С. 162; Г.В. КАЛАШНИКОВ, ОФИЦЕРСКИЙ КОРПУС РУССКОЙ АРМИИ В 1725-1745 ГГ., ДИСС. ... КАНД. ИСТ. НАУК, СПБ, 1999, С. 122.

54. ПОЛНОЕ СОБРАНИЕ ЗАКОНОВ РОССИЙСКОЙ ИМПЕРИИ, СПБ., 1830 (ДАЛЕЕ: ПСЗ), Т. IV, № 2789, П. 12, С. 93.

55. ПСЗ, Т. V, № 2596.

56. пСз, т. VII, № 4722, С. 490, 494.

57. ПОДСЧИТАНО ПО ДАННЫМ КРЕПОСТНЫХ КНИГ: РГАДА, Ф. 615, КН. 891, 945, 973, 1489 , $1513,1518,1610,5271,5286,5359,5470,5844,5971,6324,6332,6354,6448,9586,9608$, 9609, 9657, 9658, 9662, 10661, 10679, 10750, 10756, 10902, 11241, 11256, 11339, 11489, 12907, 12909, 12922, 12957, 13047. УЧТЕНЫ СДЕЛКИ ПО КУПЛЕ-ПРОДАЖЕ И ЗАКЛАДУ ЗЕМЛИ. ПОСЛЕДНИЕ ВСТРЕЧАЮТСЯ СРАВНИТЕЛЬНО РЕДКО. ПО НАЧАЛУ ХVIII СТОЛЕТИЯ В ПОДСЧЕТЫ ВКЛЮЧЕНЫ СДЕЛКИ О «МЕНЕ», «ПОСТУПКЕ» (ИЛИ «СДАЧЕ») ПОМЕСТИЙ.

58. ВОДАРСКИЙ, НАСЕЛЕНИЕ РОССИИ, С. 166-179; ЧЕРНИКОВ, ДВОРЯНСКИЕ ИМЕНИЯ ЦЕНТРАЛЬНО-ЧЕРНОЗЕМНОГО РЕГИОНА.

59. КАБИРОВА, НАСЛЕДОВАНИЕ И КУПЛЯ-ПРОДАЖА ЗЕМЕЛЬНЫХ ВЛАДЕНИЙ, С. 134.

60. ПРИМЕРЫ ЦЕН НА КРЕПОСТНЫХ В ЗАВИСИМОСТИ ОТ ПОЛА И ВОЗРАСТА СМ.: Ю.А. ТИХОНОВ, ДВОРЯНСКАЯ УСАДЬБА И КРЕСТЬЯНСКИЙ ДВОР В РОССИИ XVII-XVIII ВВ.: СОСУЩЕСТВОВАНИЕ И ПРОТИВОСТОЯНИЕ, М.-СПБ., 2005, С. 218.

61. КАБИРОВА, НАСЛЕДОВАНИЕ И КУПЛЯ-ПРОДАЖА ЗЕМЕЛЬНЫХ ВЛАДЕНИЙ, С. 134.

62. ЧЕРНЬ, НОВОСИЛЬ, ОРЕЛ, ЛЕБЕДЯНЬ, ДАНКОВ, ЕЛЕЦ, КРОМЫ, КУРСК, ЕФРЕМОВ, ЛИВНЫ, БЕЛГОРОД, СТАРЫЙ ОСКОЛ, ВОРОНЕЖ, РЫЛЬСК, ПУТИВЛЬ, СЕВСК. - ПСЗ, Т. ІІ, № 884, 1074 (П. 56).

63. ЧЕРНИКОВ, ДВОРЯНСКИЕ ИМЕНИЯ ЦЕНТРАЛЬНО-ЧЕРНОЗЕМНОГО РЕГИОНА, С. 78-79.

64. ПОЖАЛОВАНА ЕГО ОТЦУ КН. Г.Ф. ДОЛГОРУКОВУ В 1708 Г. - Н. УСТРЯЛОВ, ИСТОРИЯ ЦАРСТВОВАНИЯ ПЕТРА ВЕЛИКОГО, Т. 1, СПБ., 1858, С. 398.

65. ПОЖАЛОВАНА ЕГО ОТЦУ ГР. И.А. МУСИНУ-ПУШКИНУ ПО ЧАСТЯМ В 1709-1710 ГГ. И 1722 Г. - РГАДА, Ф. 248, КН. 6416, Л. 729, 742.

66. ПРИДАНОЕ ЕГО ЖЕНЫ КЖ. Е.И. РОМОДАНОВСКОЙ; ПО І РЕВИЗИИ ИМЕНИЕ ЧИСЛИЛОСЬ ЗА КН. И.Ф. РОМОДАНОВСКИМ. - РГАДА, Ф. 350, ОП. 2, КН. 1842, Л. 334-394 ОБ.; КН. 1823, Л. 1289; Ф. 248, КН. 1161, Л. 159 ОБ. П. К. АЛЕФИРЕНКО, «КРУПНОЕ ВОТЧИННОЕ ХОЗЯЙСТВО ГРАФА М.Г. ГОЛОВКИНА В РОССИИ ПЕРВОЙ ПОЛОВИНЫ XVIII В.», ЕАИВЕ ЗА 1959 Г., М., 1961, C. 138,148 .

67. ПОЖАЛОВАНО 6 СЕНТЯБРЯ 1730 Г. - РГАДА, Ф. 248, КН. 182, Л. 323. 
68. РГАДА, Ф. 350, ОП. 2, КН. 1842, Л. 615-632 ОБ.

69. ПО СОПОСТАВИМЫМ ДАННЫМ. КОНФИСКОВАННЫЕ, ПОЖАЛОВАННЫЕ И ВНОВЬПОСЕЛЕННЫЕ ИМЕНИЯ БЫЛИ ИСКЛЮЧЕНЫ ИЗ ПОДСЧЕТОВ.

70. ПОДРОБНЕЕ О МЕТОДЕ СМ.: БОРОВИКОВ, STATISTICA, С. 561-576.

71. ИСТОЧНИКИ СМ. В ПРИМЕЧАНИИ 3 К ТЕКСТУ СТАТЬИ.

72. ПЕТР БАЛК-ПОЛЕВ ПЕРЕШЕЛ ИЗ ЛЮТЕРАНСКОГО ВЕРОИСПОВЕДАНИЯ В ПРАВОСЛАВНОЕ

7 НОЯБРЯ 1743 Г. И НАРЕЧЕН ИМЕНЕМ ПАВЛА. - П. БАРАНОВ, ОПИСЬ ВЫСОЧАЙШИМ УКАЗАМ И ПОВЕЛЕНИЯМ, ХРАНЯЩИМСЯ В С.-ПЕТЕРБУРГСКОМ СЕНАТСКОМ АРХИВЕ ЗА ХVIII ВЕК, Т. III, 1740-1762, СПБ., 1878, № 9129, С. 135.

\section{RÉSUMÉS}

The article analyzes the features of landed property transfer in the historical center of Russia, the district of Moscow, during the first half of the eighteenth century. The author comes to the conclusion that landed property did not change hands much (particularly that of the "old" elite of the sixteenth and seventeenth centuries). Estate division, purchase, and sales were relatively rare in the Moscow district. The article also addresses the question of how changes inside Russia's ruling elite affected the structure of landed property in the regions of Moscow and St. Petersburg. An annex presents an alphabetical list of the landowners of both "capital" regions together with the number of serfs according to the first, second, and third censuses. This is the first time that such a list has been compiled.

L'article analyse les particularités de la cession de la propriété terrienne dans le centre historique de la Russie, le district de Moscou, dans la première moitié du XVIII ${ }^{\mathrm{e}}$ siècle. L'auteur conclut à un niveau élevé de stabilité du fonds terrien de cette région (notamment au sein de la «vieille» élite des $\mathrm{XVI}^{\mathrm{e}}-\mathrm{XVII}^{\mathrm{e}}$ siècles). Dans le district de Moscou, les phénomènes de division, d'achat et de vente des domaines patrimoniaux étaient relativement rares. L'article examine également la question de l'influence des modifications de l'élite gouvernante de la Russie sur la structure des propriétés terriennes des régions de Moscou et de Saint-Pétersbourg. Une annexe présente pour la première fois une liste alphabétique des propriétaires des deux régions «capitales» avec mention du nombre des serfs selon les $\mathrm{I}^{\mathrm{er}}$, $\mathrm{II}^{\mathrm{e}}$ et $\mathrm{III}^{\mathrm{e}}$ recensements.

\section{AUTEUR}

\section{СЕРГЕЙ В. ЧЕРНИКОВ}

Université technique d'État de Lipetsk 